\title{
EFEITOS DE SEGUNDA ORDEM EM EDIFÍCIOS USUAIS DE CONCRETO ARMADO
}

REGINA MARIA DOS SANTOS CARMO

Dissertação apresentada à Escola de Engenharia de São Carlos, da Universidade de São Paulo, como parte dos requisitos para obtenção do Título de Mestre em Engenharia de Estruturas.

ORIENTADOR: Márcio Roberto Silva Corrêa 
Ofereço aos meus pais esta e todas as conquistas de minha vida. Dedico também aos meus seis irmãos mais esta vitória.

Amo vocês todos. 


\section{AGRADECIMENTOS}

Ao Prof. Márcio Roberto Silva Corrêa pelo trabalho de orientação, atenção, compreensão e brilhantes idéias.

Aos meus professores da Escola Politécnica da Bahia-UFBa pelo incentivo e apoio.

Aos professores, colegas e funcionários do Departamento de Estruturas da EESC-USP que de alguma forma contribuíram para a realização deste trabalho.

Aos engenheiros e funcionários da TECSOF ENGENHARIA DE ESTRUTURAS S/C LTDA pela atenção e carinho.

Aos meus verdadeiros amigos pela companhia, pela ajuda e pelo carinho nesses anos de convivência.

Enfim, a todas as pessoas que direta ou indiretamente possibilitaram a realização desta pesquisa. 


\section{SUMÁRIO}

Lista de Figuras

Lista de Tabelas

Lista de Símbolos

Lista de Abreviaturas e Siglas

Resumo

Abstract

CAPÍTULO 1 - INTRODUÇÃO

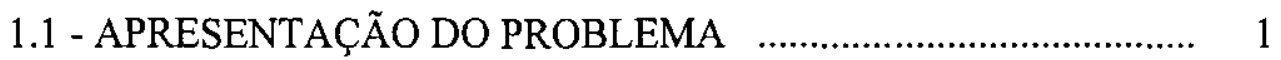

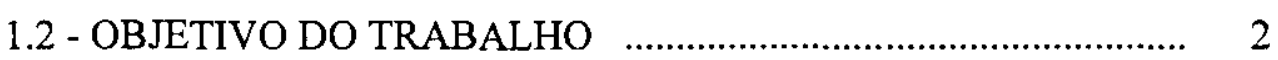

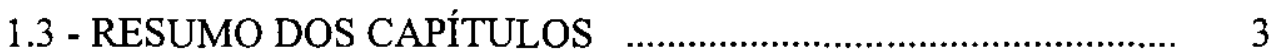

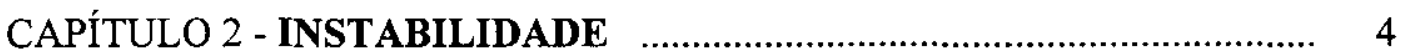

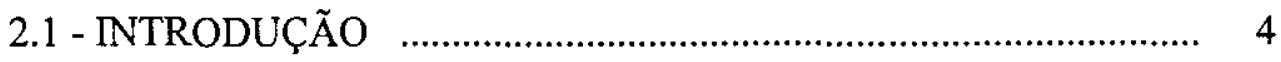

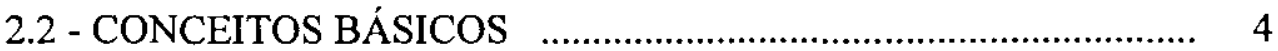

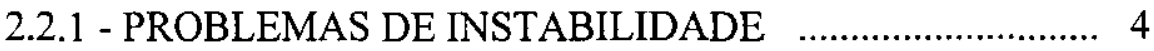

a) Problema de Instabilidade com Bifurcação do Equilíbrio ou Problema de Flambagem ................. 4

b) Problema de Segunda Ordem $\quad$..................................... 7

c) Problema de Ponto Limite

2.2.2 - CASOS ELEMENTARES - BARRA ELÁSTICA

LINEAR

a) Instabilidade com Bifurcação do Equilíbrio na Compressão Axial .............................................. 12

b) Efeito de Segunda Ordem - Flexão Composta ............ 17

2.2.3 - REGIME INELÁSTICO _........................................... 19

2.2.4 - PROBLEMAS DE INSTABILIDADE EM EDIFÍCIOS ALTOS DE CONCRETO ARMADO _......... 22 


\section{CAPÍTULO 3 - EFEITOS DE SEGUNDA ORDEM}

EM EDIFICIOS ALTOS

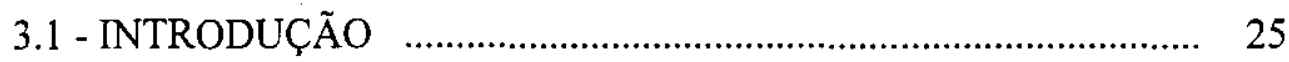

3.2 - CRITÉRIO DE IMOBILIDADE ………................................. 26

3.3 - ALGUNS CONCEITOS E SIMPLIFICAÇÕES ADOTADAS 27

a) Modelo Simplificado …………………………………...... 27

b) Análise Não-Linear ......................................................... 28

c) Efeitos Globais e Locais de Segunda Ordem ………............... 33

d) Classificação das Estruturas …………………………........... 34

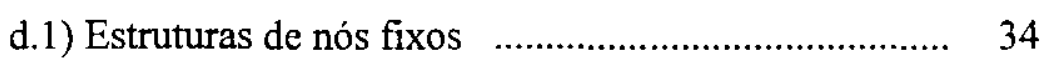

d.2) Estruturas de nós móveis ......................................... 34

e) Sub-Estruturas de Contraventamento

e Elementos Contraventados …………………………........... 34

f) Elementos isolados ........................................................

g) Ações Horizontais ............................................................. 35

3.4 - RELAÇÃO FLECHA / ALTURA (a/H) …………................ 36

3.4 .1 - EXEMPLO DE APLICAÇÃO ……............................ 40

3.5 - PARÂMETROS DE INTABILIDADE GLOBAL .......................... 42

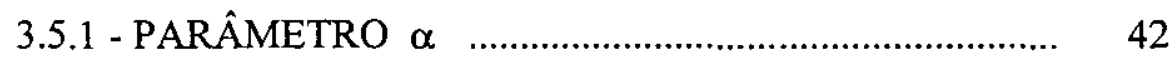

3.5.1.1 - EXEMPLO DE APLICAÇÃO ........................ 50

3.5.2 - PARÂMETRO $\gamma_{\mathbf{z}}$ ……………………………..... 52

3.5.2.1 - EXEMPLO DE APLICAÇÃO ……………… 55

3.6 - PROCEDIMENTOS USUAIS DE CONSIDERAÇÃO

DE EFEITOS DE SEGUNDA ORDEM ……………............. 56

3.6.1 - PROCESSO RIGOROSO ……………………......... 57

a) Programa com Recursos para Análise

de Segunda Ordem Utilizado no Trabalho....................... 58

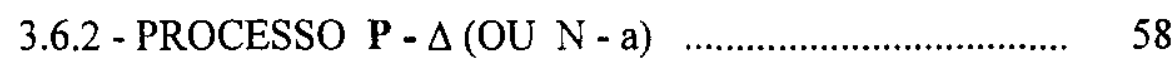

3.6.3 - PROCESSO SIMPLIFICADO ……………...................... 60

3.6.4 - EXEMPLO DE APLICAÇÃO ……………………......... 61

a) Processo Rigoroso ………………………………......... 64

b) Processo P - $\Delta$

c) Processo Simplificado ………………………………..... 66 


\section{CAPÍTULO 4 - EXEMPLOS DE APLICAÇÃO EM EDIFÍCIOS}

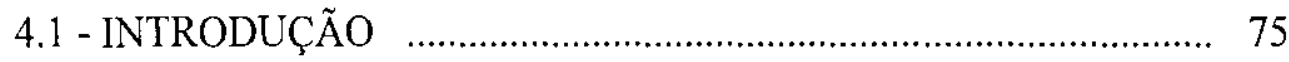

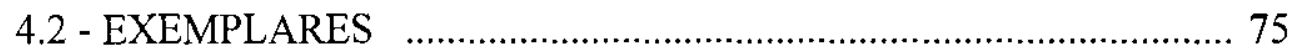

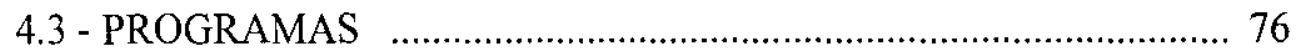

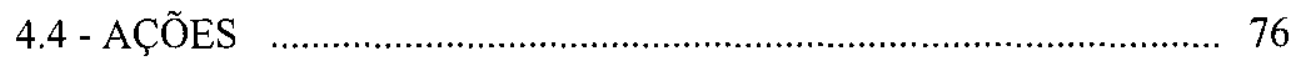

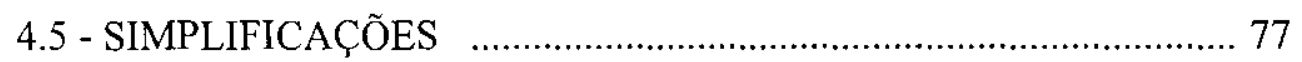

4.6 - RESULTADOS OBTIDOS …………………………………..... 77

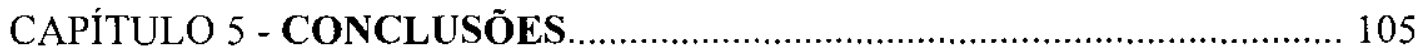

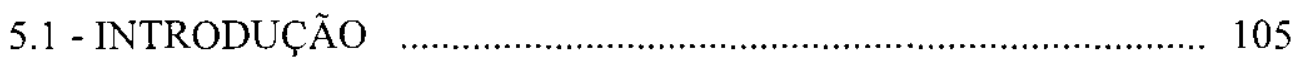

5.2 - CONSIDERAÇÕES FEITAS NA REALIZAÇÃO

DE UMA ANÁLISE DE SEGUNDA ORDEM ……………….... 106

5.3 - CORRELAÇÃO ENTRE OS PARÂMETROS

$\alpha, \gamma_{\mathbf{z}}$ E A RELAÇÃO FLECHA/ALTURA ............................. 107

5.4 -AVALIAÇÃO DO PROCESSO SIMPLIFICADO

DE ANÁLISE DE SEGUNDA ORDEM ………………….......... 109

CAPÍTULO 5 - REFERÊNCIAS BIBLIOGRÁFICAS …............................ 110

ANEXO A - FORMAS DAS ESTRUTURAS № 6, 12, 13, 20, $28 \quad$............... A-1 


\section{LISTA DE FIGURAS}

FIGURA 1 - Problema de Flambagem em Regime Elástico ............................ 5

FIGURA 2 - Problema de Flambagem em Regime Inelástico ........................ 7

FIGURA 3 - Problema de Segunda Ordem no Regime Elástico f...................... 8

FIGURA 4 - Problema de Ponto Limite …................................................ 9

FIGURA 5 - Exemplo Clássico de Problema de Ponto Limite $\quad$.......................... 10

FIGURA 6 - Barra Elástica Linear Bi-Articulada ........................................... 12

FIGURA 7 - Valores de $P_{\text {cr }}$ para Alguns Exemplos de Variantes do Caso Fundamental .............................................................. 14

FIGURA 8 - Barra Elástica Linear Submetida a Carregamento Axial Uniformemente Distribuído ........................ 15

FIGURA 9 - Curva de Flambagem (Curva de Euler) …............................... 17

FIGURA 10 - Diagrama de Ensaio de Compressão em Barra de Material Inelástico ............................................................. 20

FIGURA 11 - Curva de Flambagem (Curva de Euler) ................................. 22

FIGURA 12 - Modelo Simplificado Utilizado na Formulação de Relações Básicas .............................................................. 27

FIGURA 13 - Exemplos Utilizados na Comparação dos Diversos Valores Sugeridos de Redução da Rigidez EI para a Consideração da NLF ......................................................................... 32

FIGURA 14 - Limitações de Deslocamentos Laterais para Edifícios ................. 38

FIGURA 15 - Edifício SPAZIO UNO(forma do pav. tipo e elevação esquemática) ....................................................... 41

FIGURA 16 - Produto de Rigidez Equivalente .............................................. 44

FIGURA 17 - Modelo de Um Pavimento Utilizado na Avaliação da Influência da Distribuição das Ações Verticais Entre os Pilares da Estrutura (notação utilizada por VASCONCELOS(1985)).

FIGURA 18 - Determinação do Coeficiente $\gamma_{\mathbf{Z}}$ 
FIGURA 19 - Processo P - $\Delta$

FIGURA 20 - Incidência da Ação Horizontal nos Sentidos

Convencionados Positivo e Negativo

FIGURA 21 - Deslocamentos ao Longo da Altura do Edifício SPAZIO UNO (das 3 iterações dos processos P- $\Delta$ (a) e rigoroso (b) e dos 3 processos (c)) 74

FIGURA 22 - Áreas Efetivas $\left(\mathbf{A}_{\mathfrak{e}}\right)$ de um Edifício 78

FIGURA 23- Relações $\alpha \times \mathbf{a} / \mathbf{H}$ e $\gamma_{\mathbf{z}} \times \mathbf{a} / \mathbf{H}$ 81

FIGURA 24- Relação $\alpha \times \gamma_{\mathbf{z}}$ 82

FIGURA 25- Edificio TOP LIFE (forma do pav. tipo e elevação esquemática) 86

FIGURA 26 - Comparação entre os Resultados na Fundação 94

FIGURA 27 - Comparação entre os Resultados para Flechas no Topo 95

FIGURA 28 - Comparação entre os Resultados no Âmbito Global 96

FIGURA 29 - Comparação entre os Resultados Globais p/ a Primeira Faixa ..... 99

FIGURA 30 - Comparação entre os Resultados Globais p/ a Segunda Faixa ..... 99

FIGURA 31 - Comparação entre os Resultados Globais p/ a Terceira Faixa....... 99

FIGURA 32 - Comparação entre os Resultados Globais p/ os Pilares.............. 100

FIGURA 33 - Comparação entre os Resultados Globais p/ as Vigas................. 100

FIGURA 34 - Comparação entre os Resultados Globais p/ os Pilares-1a Faixa.... 101

FIGURA 35 - Comparação entre os Resultados Globais p/ as Vigas-1a Faixa...... 101

FIGURA 36 - Comparação entre os Resultados Globais p/ os Pilares-2a Faixa... 102 FIGURA 37 - Comparação entre os Resultados Globais p/ as Vigas-2a Faixa... 102 FIGURA 38 - Comparação entre os Resultados Globais p/ os Pilares-3a Faixa.... 103

FIGURA 39 - Comparação entre os Resultados Globais p/ as Vigas-3ạ Faixa... 103

FIGURA A-1 - Estrutura №6 
FIGURA A-4 - Estrutura $\mathrm{N}_{-}^{\circ} 20$

A-4

FIGURA A-4 - Estrutura №28

A-5 


\section{LISTA DE TABELAS}

TABELA 1 - Configurações de Equilíbrio para Barra

Axiaimente Carregada

TABELA 2 - Configurações de Equilíbrio para Barra

Excentricamente Carregada

TABELA 3 - Comparação entre Valores da Flecha no Topo para as Três variações de Redução do Produto EI 33

TABELA 4 - Valores de $\mathbf{C}$

TABELA 5 - Processo P- $\Delta$ para o Exemplo do Ed. SPAZIO UNO:

1a. Iteração - (sentidos positivos dos eixos)

TABELA 6 - Processo P- $\Delta$ para o Exemplo do Ed. SPAZIO UNO:

2a. Iteração - (sentidos positivos dos eixos) 68

TABELA 7 - Processo P- $\Delta$ para o Exemplo do Ed. SPAZIO UNO:

3a. Iteração - (sentidos positivos dos eixos)

TABELA 8 - Comparação dos Resuitados Obtidos Segundo os Três Processos e Análise de Segunda Ordem para o Exemplo do Ed. SPAZIO NO (sentidos positivos dos eixos)

TABELA 9 - Comparação dos Resultados Obtidos Segundo os Três Processos e Análise de Segunda Ordem para o Exemplo do Ed. SPAZIO UNO (sentidos negativos dos eixos)

TABELA 10 - Efeitos Primeira Ordem para a Estrutura do Ed. SPAZIO UNO Submetida Apenas a Ações Horizontais

TABELA 11 - Comparação dos Resultados para as Três variações de Redução do Produto EI

TABELA 12 - Resuitados Obtidos da Análise Segundo a Direção X 79

TABELA 13 - Resultados Obtidos da Análise Segundo a Direção Y 80

TABELA 14 - Comparação dos Resultados Obtidos Segundo os Três Processos de Análise de Segunda Ordem para o Exemplo do Ed. TOP LIFE 
TABELA 15 - Comparação dos Resultados Obtidos Segundo os Três Processos de Análise de Segunda Ordem para o Exemplo do Ed. TOP LIFE

TABELA 16 - Comparação dos Resultados Obtidos Segundo os Três Processos de Análise de Segunda Ordem para o Exemplo do Ed. SPAZIO UNO

TABELA 17 - Comparação dos Resultados Obtidos Segundo os Três Processos de Análise de Segunda Ordem para o Exemplo do Ed. STRADUS

TABELA 18 - Comparação dos Resultados Obtidos Segundo os Três Processos de Análise de Segunda Ordem para o Exemplo do Ed. CONDOMÍNIO III 90

TABELA 19 - Comparação dos Resultados Obtidos Segundo os Três Processos de Análise de Segunda Ordem para o Exemplo do Ed. RUA INDIANA

TABELA 20 - Comparação dos Resultados Obtidos Segundo os Três Processos de Análise de Segunda Ordem para o Exemplo do Ed. CARTIER TOWER

TABELA 21- Comparação dos Resultados Obtidos Segundo os Três Processos de Análise de Segunda Ordem para o Exemplo do Ed. CORINTO 93

TABELA 22- Majoradores Globais dos Efeitos de Primeira Ordem de Acordo com Três Processos de Análise de Segunda Ordem 


\section{LISTA DE SÍMBOLOS}

a - Deslocamento horizontal máximo ou flecha no topo da estrutura

b - Base da seção transversal

e - Excentricidade

$\mathbf{e}_{1}$ - Excentricidade inicial ou de primeira ordem

$\mathbf{e}_{2}$ - Excentricidade de segunda ordem

$f_{\text {cd }}$ - Resistência de cálculo do concreto a compressão

$f_{\mathbf{e}}$ - Tensão limite de proporcionalidade

h - Altura da seção transversal

i - Raio de giração da seção transversal

k - Coeficiente multiplicativo das ações horizontais para se obter os esforços finais que incluem os de segunda ordem

$\ell$ - Comprimento da barra elástica

$\ell_{\mathbf{e}}$ - Comprimento de flambagem

n - Número de pavimentos

q - Carga uniformemente distribuída

1/r - Curvatura da barra

$\boldsymbol{r}^{\prime}$ - Razão de uma progressão geométrica

$\mathbf{x}$ - Posição medida na vertical em relação à base da estrutura

$\mathbf{y}$ - Deslocamentos horizontais ou flechas da estrutura

w - Módulo de resistência à flexão da seção transversal da barra

A - Área da seção transversal da barra

$\mathrm{C}_{1}$ e $\mathbf{C}_{2}$ - Constantes de Integração

E - Módulo de deformação longitudinal

$\mathbf{E}_{\mathbf{c}}$ - Módulo de deformação longitudinal do concreto 
$\mathbf{E}_{\mathbf{r}}$ - Módulo de deformação longitudinal reduzido

$\mathbf{E}_{\mathbf{t}}$ - Módulo de deformação longitudinal tangente

EI - Módulo de deformação por flexão

(EI) $)_{\text {eq }}$ - Módulo de deformação por flexão ou produto de rigidez equivalente

F - Força axial de compressão ou resultante das ações verticais de uma estrutura

$\mathrm{F}_{\mathrm{cr}}$ - Carga crítica, carga de flambagem, ou carga de Euler

$\mathbf{F H}_{\mathbf{i}}$ - Ação horizontal fictícia aplicada ao nível do pavimento i devida ao desaprumo

$\mathbf{F}_{\text {Hid }}$ - Ação horizontal de cálculo ou ação de vento aplicada ao nível do pavimento i

$F_{\mathrm{i}}$ - Resultante das ações verticais de cada pavimento i do edifício

$\mathbf{F}_{\mathbf{k}}$ - Valor característico das ações ou valor característico da resultante das ações verticais de uma estrutura

$\left(\mathbf{F}_{t_{\mathbf{c r}}}\right.$ - Carga crítica para a teoria do módulo tangente

H - Altura total da estrutura

$\mathbf{H}_{\mathbf{i}}$ - Força horizontal adicional fictícia ("sway force") ao nível do pavimento i, devida ao efeito P- $\Delta$

I - Momento de inércia da seção transversal

$I_{c}$ - Momento de inércia da seção transversal bruta do elemento de concreto

$\mathbf{I}_{\mathbf{v}}$ - Momento de inércia da seção transversal bruta do elemento tipo viga

$\mathbf{I}_{\mathbf{p}}$ - Momento de inércia da seção transversal bruta do elemento tipo pilar

M - Momento fletor

$\Delta \mathbf{M}$ - Acréscimo de momento

$\mathbf{M}_{1 \mathrm{~d}}$ - Momento de cálculo de primeira ordem

$\mathbf{M}_{\mathbf{2 d}}$ - Momento final de cálculo que inclue o de segunda ordem

$\mathbf{N}_{\mathbf{S d}}$ - Força normal solicitante de cálculo

R - Resultante de ações

$\mathbf{P}_{\mathbf{i}}$ - Somatório das resultantes de ações verticais dos pavimentos contidos entre o topo do edifício e o nível do pavimento $\mathbf{i}$ (apenas para efeito de uso no processo $\mathbf{P}-\Delta)$

$S_{1}$ - Fator topográfico 
$\mathbf{S}_{\mathbf{3}}$ - Fator estatístico

$\mathrm{S}_{\mathrm{d}}$ - Esforço solicitante de cálculo

$\mathbf{X}, \mathbf{Y}$ - Direções de incidência do vento

$\alpha$ - Parâmetro de instabilidade global ou parâmetro alfa.

$\alpha_{c r}$ - Valor crítico do parâmetro de instabilidade

$\beta$ - Desvio de prumo

$\delta$ - Deslocamento relativo lateral entre dois pavimentos consecutivos ou vertical das extremidades de lintéis conectados a duas paredes

$\delta_{1}$ - Deslocamento horizontal de primeira ordem do ponto de aplicação da resultante das ações verticais

$\gamma$ - Fator de flexibilidade ou coeficiente de comportamento

$\gamma_{c}$ - Coeficiente de segurança para o concreto

$\gamma_{f}$ - Coeficientes de segurança

$\gamma_{f 1}, \gamma_{f 2}, \gamma_{f 3}$ - Coeficientes parciais de segurança

$\gamma_{\mathbf{s}}$ - Coeficientes de segurança para a armadura

$\gamma_{\mathbf{Z}}$ - Parâmetro global de instabilidade

$\varphi$ - Fator de redução de resistência

$\lambda$ - Índice de esbeltez

$\lambda_{\text {lim }}$ - Valor limite do índice de esbeitez

$v$ - Coeficiente de segurança contra flambagem

$\sigma$ - Tensão de compressão

$\sigma_{\text {máx }}$ - Tensão máxima de compressão

$\sigma_{\mathrm{cr}}$ - Tensão crítica máxima de compressão

$\left(\sigma_{t}\right)_{\text {cr }}$ - Tensão crítica para a teoria do módulo tangente

$\psi$ - Parâmetro de forma da estrutura

$\psi_{0}$ - Coeficiente de combinação de ações

$\Delta$ - Deslocamento horizontal relativo entre pav.(para efeito de uso no processo $P-\Delta$ ) 


\title{
LISTA DE ABREVIATURAS E SIGLAS
}

\author{
ABNT - Associação Brasileira de Normas Técnicas \\ ACI - American Concrete Institute \\ CEB - Comité Europeén du Béton \\ NB ou NBR - Norma Brasileira \\ NLF - Não-Linearidade Física \\ NLG - Não-Linearidade Geométrica
}




\section{RESUMO}

CARMO, R.M.S. Efeitos de segunda ordem em edificios usuais de concreto armado. São Carlos, 1995. 112p. Dissertação (Mestrado) - Escola de Engenharia de São Carlos, Universidade de São Paulo.

Neste trabalho são estudados os parâmetros de verificação do estado limite de deformações excessivas (a relação flecha-altura-a/H) e da estabilidade global (o parâmetro $\alpha$ e o coeficiente $\gamma_{\mathbf{z}}$ ) das estruturas de edifícios. Através da utilização de exemplos de estruturas de trinta (30) edifícios usuais de concreto armado, estabelecese uma relação entre esses parâmetros, objetivando propiciar ao projetista de estruturas condições de avaliar a eficiência e o grau de confiabilidade de cada um deles. São também discutidos e comparados alguns dos procedimentos usuais para realizar uma análise global de segunda ordem das estruturas. Nesta análise deve-se levar em conta tanto a não-linearidade física (NLF) quanto a geométrica (NLG) e, para tanto, são adotados métodos rigorosos e aproximados. Quer-se com isso, principalmente, analisar o processo simplificado como suficiente para se obter os esforços finais de segunda ordem, uma vez que se pretende incluir tal procedimento na norma brasileira NB-1, atualmente em fase de revisão.

Palavras-chave: Edifícios altos - instabilidade global; efeitos de segunda ordem 


\begin{abstract}
CARMO, R.M.S. Second order effects in usual reinforced concrete buildings. São Carlos, 1995. 112p. Dissertação (Mestrado) - Escola de Engenharia de São Carlos, Universidade de São Paulo.

In this work, a servicebility parameter (displacement-height ratio $-\mathbf{a} / \mathbf{H}$ ) is studied, as well as the global stability parameters of building structures ( $\alpha$ and $\gamma_{\mathbf{z}}$ stability coefficients). By analyzing thirty (30) actual reinforced concrete building structures, a relationship among these parameters $\left(\alpha, \gamma_{\mathbf{z}}\right.$ and $\left.\mathbf{a} / \mathbf{H}\right)$ is achieved aiming to demonstrate to the building structure designers their level of efficiency and reliability for practical purposes. Some standard procedures for global second order structure analysis are also discussed with comparison among them. In this analysis, the material and the geometric non-linearities have to be considered and for that one can adopt approximated and accureted methods. Mainly, the interest is to verify the possibility of using the simplified method as a proper tool to compute the final second order efforts of buildings, once this procedure could be included into the Brazilian Code, NB-1, which is being revised.
\end{abstract}

Keywords: Tall buildings - global instability; second order effects 


\section{CAPÍTULO 1 - INTRODUÇÃO}

\section{1 - APRESENTAÇÃO DO PROBLEMA}

Atualmente muitos fatores, dentre os quais o aumento populacional e a falta de recursos e espaço físico nos centros urbanos, forçam cada vez mais a construção de edifícios de estruturas altas e esbeltas. A própria evolução da Teoria das Estruturas possibilita o acompanhamento destes avanços. Isso vem despertando o interesse dos profissionais da área para os possíveis problemas de instabilidade e para a consideração dos deslocamentos no equilíbrio da estrutura de um edifício solicitada por ações verticais e horizontais. Estes deslocamentos, quando expressivos, causam o aparecimento de esforços adicionais, os chamados Efeitos de Segunda Ordem que, combinados com o carregamento original, podem inviabilizar o uso da estrutura por comprometer a sua estabilidade. A importância da análise da estabilidade do equilíbrio das estruturas é grande, pois a ruína pode manifestar-se repentina e violentamente, causando graves prejuízos.

Uma Análise de Segunda Ordem leva em conta esses efeitos no projeto estrutural, ou seja, considera a estrutura deformada na formulação de suas equações de equilibrio. Entretanto, não seria interessante, para aqueles projetistas que se preocupassem com a estabilidade global da estrutura, concluírem após a realização desta análise, que os efeitos de primeira ordem seriam suficientes para o dimensionamento dos elementos estruturais. Ou seja, neste caso os efeitos de segunda ordem não seriam significantes em presença dos de primeira ordem.

É, pois, necessária uma análise prévia da estrutura, a fim de estimar a grandeza dos Efeitos de Segunda Ordem. Diversos estudos têm sido realizados na intenção de estabelecer parâmetros que ajudem o projetista a prever a necessidade de se realizar uma Análise de Segunda Ordem em toda a estrutura. A importância destes 
parâmetros se evidencia ao se avaliar que, para se determinarem os efeitos de segunda ordem, são necessários recursos adicionais e tempo de análise. Neste trabalho serão discutidos alguns parâmetros usados frequentemente pelo projetista de estruturas na verificação do estado limite de deformações excessivas e da estabilidade global das estruturas dos edifícios. Serão estudados também alguns dos procedimentos usuais para se realizar uma Análise de Segunda Ordem.

\section{2 - OBJETIVO DO TRABALHO}

Utilizando-se como exemplo estruturas de edificios, que foram efetivamente projetadas, para que possam ser comparados os parâmetros usualmente adotados na verificação da estabilidade, busca-se saber se há alguma relação entre eles. A intenção principal é dar condições aos projetistas de avaliar a eficiência e o grau de confiabilidade de cada parâmetro. Outro objetivo importante do trabalho é comparar os resultados da análise de segunda ordem utilizando-se o parâmetro $\gamma_{\mathbf{z}}$ (análise pelo processo simplificado), o processo $\mathbf{P}-\Delta$ e um programa com recursos para a consideração da não-linearidade geométrica (aqui denominada análise pelo processo rigoroso). Objetiva-se com isso, principalmente, analisar o parâmetro $\gamma_{\mathrm{z}}$ como suficiente para a obtenção dos esforços finais de segunda ordem, uma vez que se pretende incluir tal procedimento na futura NB-1.

Antes disso, pretende-se principalmente expor o problema aos projetistas que só realizam alguma análise dos efeitos de ações laterais sobre as edificações, com base nas prescrições da NB-1/1978 (publicada pela Associação Brasileira de Normas Técnicas - $\mathrm{ABNT})$, "(..) no caso de estruturas com nós deslocáveis, nas quais a altura seja maior que 4 vezes a largura menor, ou em que, numa dada direção, o número de filas de pilares seja inferior a 4." (p.7). Esquecem-se, porém, que este mesmo parágrafo inicia-se assim: "Será exigida a consideração da ação do vento nas estruturas em que esta ação possa produzir efeitos estáticos ou dinâmicos importantes (...)" (NB-1/1978-ABNT, p.7). Não existe nesta norma, entretanto, nenhuma orientação para que se considere esta e outras ações laterais, nem como avaliar a necessidade desta consideração. Felizmente, a NB-1/1978(ABNT) está sendo revisada e o assunto já se encontra abordado em texto provisório (NB-1/1994ABNT). Outro problema que pode estar embutido nesta observação, é a nãoconsideração da ação do carregamento vertical sobre os deslocamentos gerados pelas 
ações laterais, causando o surgimento dos efeitos de segunda ordem que, como foi visto, podem ser significativos.

\section{3 - RESUMO DOS CAPÍTULOS}

O segundo capítulo do trabalho apresenta conceitos básicos relativos aos problemas de instabilidade que julgou-se necessários ao entendimento do fenômeno. Estes problemas são estudados citando-se, inicialmente, o exemplo de uma barra simples sob os regimes elástico linear, não-linear e plástico e, posteriormente, trazidos à realidade das estruturas de concreto armado.

O capítulo 3 expõe os diversos conceitos e considerações relativas a uma análise de segunda ordem, a relação flecha/altura, os parâmetros de instabilidade global mais conhecidos (parâmetro $\alpha$ e o coeficiente $\gamma_{z}$ ) e os procedimentos de análise de segunda ordem, dando especial atenção ao processo $\mathbf{P}-\Delta$ e à utilização de programa com recursos para análise de segunda ordem. Neste capítulo, pretende-se mostrar como calcular cada um dos parâmetros e como realizar uma análise de segunda ordem através dos procedimentos citados, utilizando-se a estrutura de um edifício como exemplo.

No capítulo 4, um número significativo de estruturas regulares de concreto armado, concebidas por projetistas diversos e cuja análise estrutural foi realizada pela TECSOF ENGENHARIA ESTRUTURAS S/C LTDA, terão calculados os seus respectivos parâmetros para que se tente descobrir a existência de alguma relação entre eles. Feito isto, serão determinados os esforços de segunda ordem em algumas dessas estruturas utilizando-se o parâmetro $\gamma_{\mathrm{z}}$ no processo simplificado, o processo P- $\Delta$ e um programa com recursos para análise de segunda ordem, para estabelecer-se uma comparação entre eles.

A partir dos resultados obtidos no capitulo 4 são apresentados, no quinto capitulo, as conclusões do trabalho. 


\section{CAPÍTULO 2 - INSTABILIDADE}

\section{1 - INTRODUÇÃO}

$\mathrm{Na}$ primeira parte do presente capítulo, serão estudados os diversos problemas de instabilidade aos quais está sujeita uma estrutura submetida a carregamento axial. Serão analisados alguns casos elementares, determinando-se o valor de cargas de flambagem $\mathbf{F}_{\text {cr}}$. Iniciaimente, será utilizada uma barra constituída de material de comportamento elástico linear. A seguir, será feita uma rápida analogia para adaptar os resultados obtidos para o caso de uma barra solicitada em regime inelástico. Finalmente, serão discutidos quais dos problemas citados seriam considerados na análise da estabilidade dos edifícios altos de concreto armado.

\section{2 - CONCEITOS BÁSICOS}

\subsection{1 - PROBLEMAS DE INSTABILIDADE}

FRANCO(1985b) divide em três, de um modo geral, os problemas de instabilidade:

\section{a) Problema de Instabilidade com Bifurcação do Equilíbrio ou Problema de Flambagem}

Seja uma barra reta, sem imperfeições geométricas, constituída de material de comportamento elástico linear e submetida a uma carga axial $\mathbf{F}$ estática crescente (Fig. 1-a). A estrutura permanece em equilíbrio estável até o instante em que a carga $\mathbf{F}$ atinge o valor $\mathbf{F}_{\mathbf{c r}}$ (carga crítica ou carga de flambagem). A carga $\mathbf{F}_{\mathbf{c r}}$ define 0 estado limite a partir do qual a barra pode tomar uma das seguintes formas: a forma 
reta, onde estará em equilíbrio instável, ou a fletida, estando então em equilíbrio estável (Fig.1-b). Isto significa que, para valores de $\mathrm{F}$ maiores que $\mathrm{F}_{\mathrm{cr}}$, se a barra permanecer reta, o surgimento de qualquer perturbação externa ou de excentricidade, inevitáveis na prática, levará a estrutura a se afastar da configuração de equilíbrio instável (reta) para uma estável (curva). Diz-se que o ponto de bifurcação do equilíbrio para o qual corresponde equilíbrio estável é um Ponto de Bifurcação Estável (ponto B na Fig.1-b).

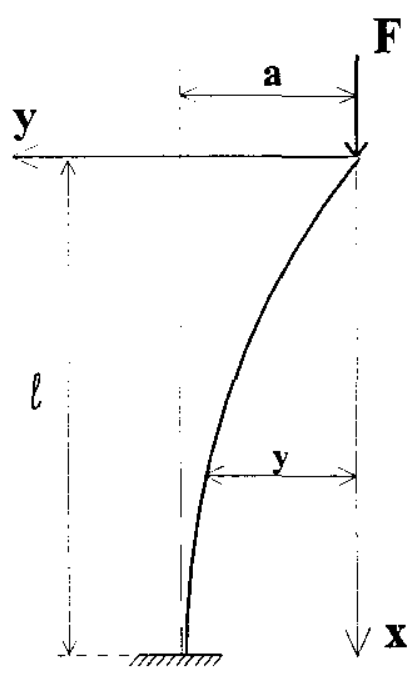

( a )

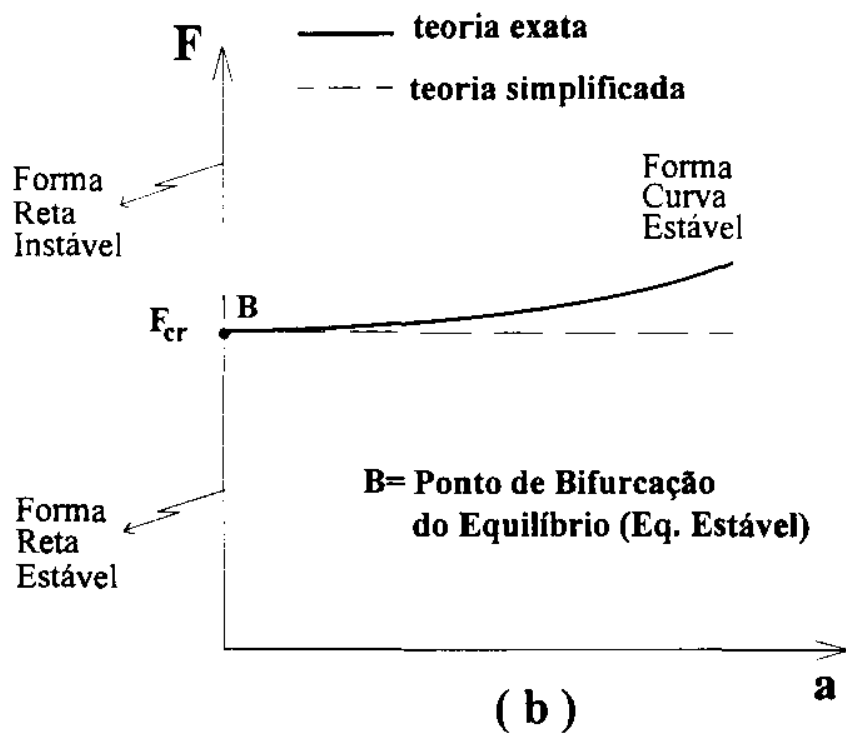

FIGURA 1 - Problema de Flambagem em Regime Elástico.

No diagrama da Fig. 1-b, que relaciona a carga $\mathbf{F}$ com a flecha máxima a, para as cargas maiores que $\mathbf{F}_{\mathbf{c r}}$, determinam-se as flechas através da Expressão Exata da Equação Diferencial da Linha Elástica (curva em traço cheio):

$$
\frac{1}{r}=\frac{\frac{d^{2} y}{d x^{2}}}{\left[1+\left(\frac{d y}{d x}\right)^{2}\right]^{3 / 2}}=-\frac{M}{E I}
$$

sendo

$1 / r$ = curvatura da barra; 
$\mathbf{E I}=$ produto de inércia relativo ao plano da flexão;

$\mathbf{M}=\mathbf{-} \mathbf{F} . \mathbf{y}$, momento fletor.

Se for utilizada a teoria simplificada, pode-se determinar apenas o valor $\mathbf{F}_{\mathbf{c r}}$ (trecho tracejado do diagrama da Fig.1-b), com as flechas indeterminadas:

$$
\frac{1}{r}=\frac{d^{2} y}{d x^{2}}=-\frac{M}{E I}
$$

Para materiais como o concreto e o aço o estado limite de flambagem é um estado limite último pois, para um pequeno acréscimo de carga acima de $\mathbf{F}_{\mathbf{c r}}$, a flecha a já atinge um valor significativo se comparado ao valor do comprimento $\ell$ da barra, que romperá por flexão composta. Enquanto $\mathbf{F}<\mathbf{F}_{\mathbf{c r}}$, a tensão máxima é proporcional à carga $\mathbf{F}$ pois $|\sigma|_{\text {máx }}=\mathbf{F} / \mathbf{A}$, onde $\mathbf{A}$ é a área da seção transversal da barra. Entretanto, a partir do instante em que $\mathbf{F}$ atinge $\mathbf{F}_{\mathbf{c r}}$, a tensão máxima passa a crescer mais rapidamente porque $|\sigma|_{\text {máx }}=\mathbf{F} / \mathbf{A}+\mathbf{F a} / \mathbf{w}$, sendo $\mathbf{w}$ o módulo de resistência à flexão da seção transversal da barra. Através da utilização de exemplo numérico, ZAGOTTIS(1980) mostra que pequenos acréscimos em $\mathbf{F}$ geram grandes acréscimos em $|\sigma|_{\text {máx }}$. No exemplo', um acréscimo de $0,007 \%$ no valor de $\mathbf{F}$ a partir de $\mathbf{F}_{\mathrm{cr}}$, faz com que a tensão máxima atinja a tensão limite de proporcionalidade $\left(f_{\mathrm{e}}\right)$. Posteriormente, a barra atinge a ruína para $\mathrm{F} \cong \mathbf{1 , 0 0 3 F}_{\mathrm{cr}}$, mesmo levando-se em conta a plastificação do material. Portanto,:

"Para todos os efeitos práticos, pode-se e deve-se considerar que a carga crítica define o esgotamento da capacidade portante da estrutura."(ZAGOTTIS, 1980 , p. 10.2)

Sendo a barra constituída de material de comportamento não-linear, quando submetida a uma carga axial, haverá também a bifurcação do equilíbrio. Entretanto, a curva carga-deslocamento, referente à forma fletida, é decrescente (Fig. 2), pois, para $\mathbf{F}<\mathbf{F}_{\mathbf{c r}}$ existem duas configurações de equilibrio possíveis: uma reta de equilibrio estável e uma curva de equilíbrio instável; para $\mathbf{F} \geq \mathbf{F}_{\mathbf{c r}}$ só existe uma única configuração de equilibrio que é a forma reta de equilibrio instável. Não existe, portanto, o equilíbrio para a forma fletida quando $\mathbf{F} \geq \mathbf{F}_{\mathbf{c r}}$; a estrutura não tem como suportar o carregamento aplicado. A $\mathbf{F}=\mathbf{F}_{\mathbf{c r}}$ corresponde, então, um Ponto de Bifurcação Instável.

${ }^{1}$ Barra prismática de aço, bi-articulada, de seção transversal retangular $20 \mathrm{~cm} \times 6 \mathrm{~cm}$ e comprimento $\ell=300 \mathrm{~cm}, \mathrm{E}=2,10 \times 10^{4} \mathrm{kN} / \mathrm{cm}^{2}$ e $f_{\mathrm{e}}=2,25 \times 10 \mathrm{kN} / \mathrm{cm}^{2}$. 


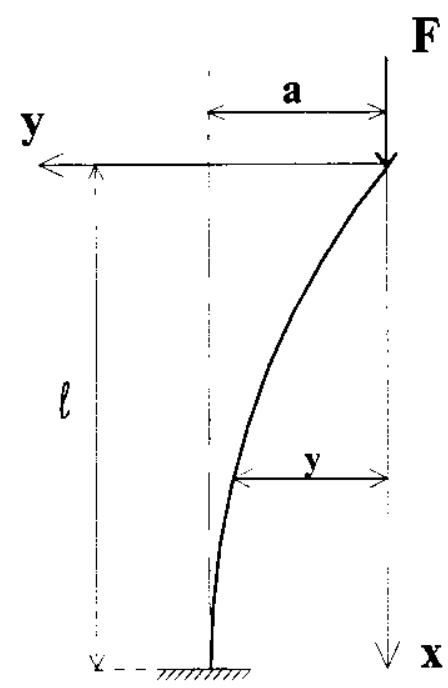

( a )

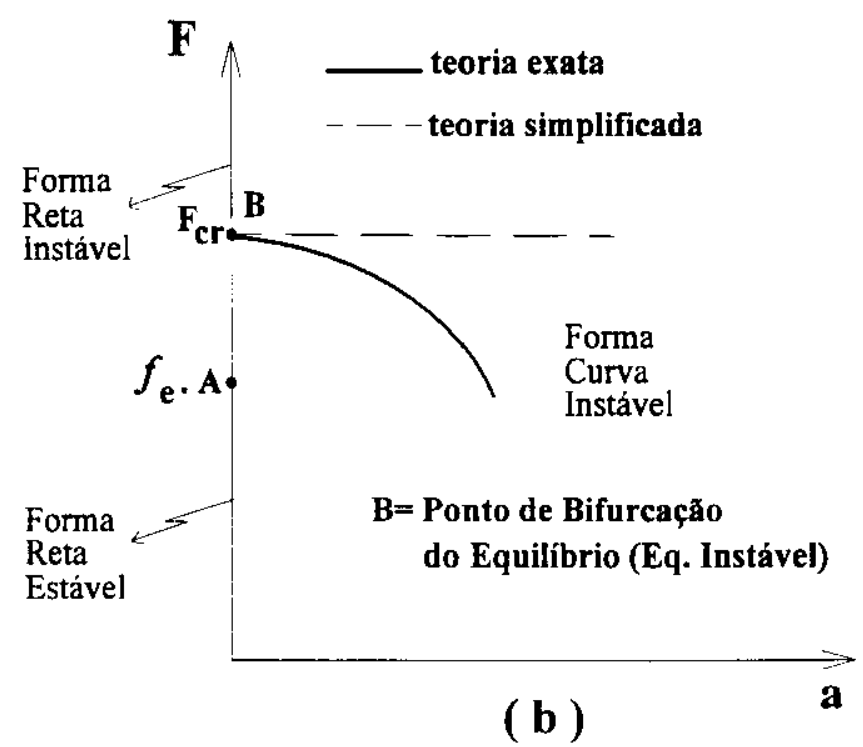

(b)

FIGURA 2- Problema de Flambagem em Regime Inelástico.

\section{b) Problema de Segunda Ordem}

Seja uma barra reta esbelta constituída de material de comportamento elástico linear e carregada com excentricidade inicial $\mathbf{e}_{\mathbf{1}}$, de primeira ordem (Fig. 3-a). Para valores crescentes de $\mathbf{F}$, a barra toma, desde o início, a forma fletida e haverá sempre uma configuração de equilibrio, a única possível para cada $\mathbf{F}$, de equilíbrio estável (Fig. 3-b). Neste caso não há bifurcação do equilíbrio. Enquanto o material permanecer no regime elástico, não haverá problema de instabilidade na flexão composta; a configuração fletida será uma configuração de equilíbrio estável e a ruina será atingida somente por ruptura do material.

Ainda aqui, a curva em traço cheio do diagrama (Fig. 3-b) representa a determinação da flecha máxima através da expressão exata da equação diferencial da linha elástica, que para $\mathbf{F}>\mathbf{F}_{\mathbf{c r}}$ tende a se aproximar da curva correspondente a $\mathbf{e}_{1}=\mathbf{0}$. A curva tracejada o faz através da teoria simplificada. A tendência ao infinito é um defeito da linearização das equações de equilíbrio. De acordo com ZAGOTTIS(1980), a partir de um certo valor de $\mathbf{F} \cong 0,5 F_{\text {cr }}$, a aproximação decorrente da linearização deixa de ser satisfatória. Entretanto, afirma ser ainda um procedimento adequado e conveniente, pois, para $\mathbf{F}<\mathbf{F}_{\mathbf{c r}}$, permite que sejam determinados os deslocamentos, sob a vantagem de oferecer equações mais simples. 


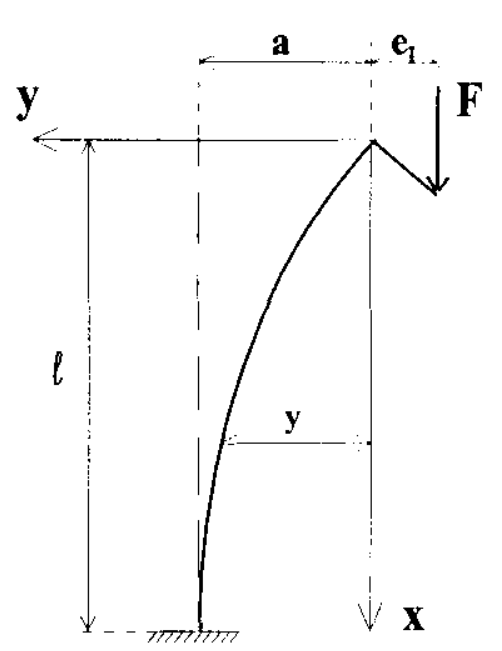

( a )

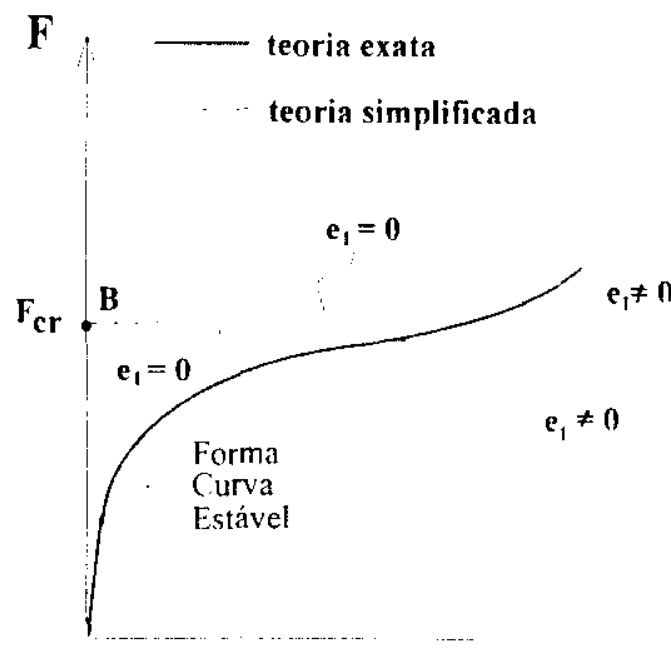

( b ) $\mathbf{a}$

FIGURA 3 - Problema de Segunda Ordem no Regime Elástico.

No caso da barra constituída de material de comportamento não-linear. submetida ao mesmo carregamento descrito acima, sendo ela uma barra curta (ver item 2.2.2), tenderá a romper por flexão composta para valores crescentes de $\mathbf{F}$ : n aumento da solicitação é maior que a capacidade resistente da seção que tende a esgotar-se. A carga $\mathbf{F}$ atinge um ponto limite sem reversão da configuração inicial da estrutura carregada.

\section{c) Problema de Ponto Limite}

Sendo a barra reta excentricamente carregada, constituida de material de comportamento não-linear e esbelta, com o crescimento da carga surgiri excentricidade de segunda ordem $\mathbf{e}_{2}$ de valor crescente, até que $\mathbf{F}$ atinja um valor $\mathbf{F}_{\mathbf{c r}}$ tal que o momento externo causado pela carga, com excentricidade $\left(\mathbf{c}_{1}+\mathbf{c}_{2}\right)$, já não possa ser equilibrado pelo momento interno da seção mais solicitada. configurando-se, então, um caso de instabilidade na flexão composta. sem bifurcaçân do equilibrio (Fig. 4-a).

Para $\mathbf{F}<\mathbf{F}_{\mathbf{c r}}$, existem duas configurações de equilibrio que correspondem ì forma fletida. A primeira, equivalente a um menor deslocamento. é de equilihrio estável; a segunda, de equilíbrio instável. À medida que $\mathbf{F}$ cresce, os valores de deslocamentos possiveis de existir (das duas formas fletidas) se aproximam. até se igualarem para um determinado $\mathbf{F}=\mathbf{F}_{\mathbf{c r}}$. Este $\mathbf{F}_{\mathbf{c r}}$ equivale a uma única configuração 
de equilíbrio possivel, que é de equilíbrio instável. Para $\mathbf{F}>\mathbf{F}_{\mathbf{c r}}$ o equilibrio é impossível e, uma vez atingido o ponto $\mathbf{B}$, só se consegue manter o equilíbrio através do sistema de deformação controlada.

Na (Fig. 4-b), o ponto B representa, então, o ponto limite e não corresponde, como se observou acima, a uma mudança de configuração do equilibrio estável e sim a uma reversão do andamento das deformações. ZAGOTTIS(1980) mostra ainda que o valor de $F_{c r}$ depende fortemente do valor da excentricidade inicial $\mathbf{e}_{1}$ e que quanto maior for $\mathbf{e}_{\mathbf{1}}$, menor será o valor de $\mathbf{F}_{\mathbf{c r}}$.

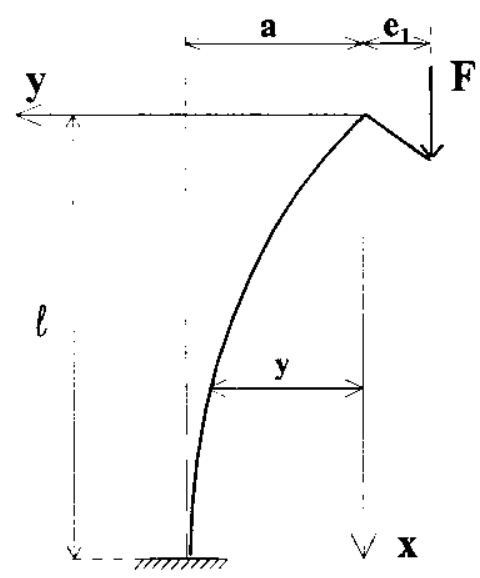

(a)

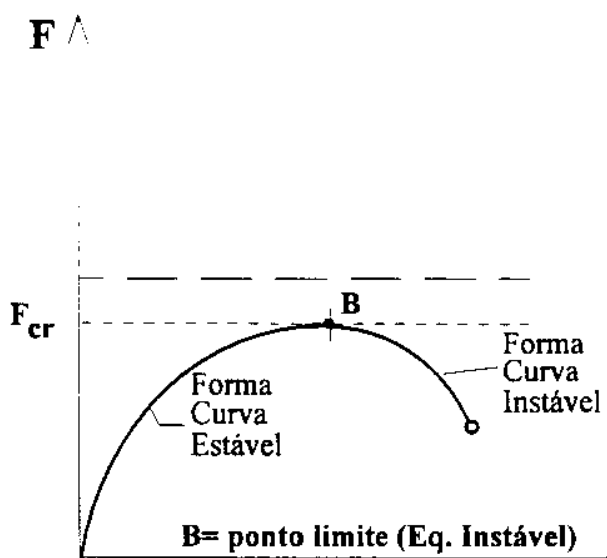

(b)

a

FIGURA 4 - Problema de Ponto Limite.

Existe ainda o exemplo clássico da treliça apresentada na Fig. 5, onde no instante em que $\mathbf{F}$ atinge um valor limite $\mathbf{F}_{\mathbf{c r}}$, "(...) o sistema passa a ter equilíbrio instável, sem ter outra configuração de equilíbrio possivel nas proximidades da configuração crítica e sem poder suportar acréscimos de $F$ a partir de $F_{c r}$ sem mudança radical na configuração do sistema. "(ZAGOTTIS, 1980, p. 10.12) 

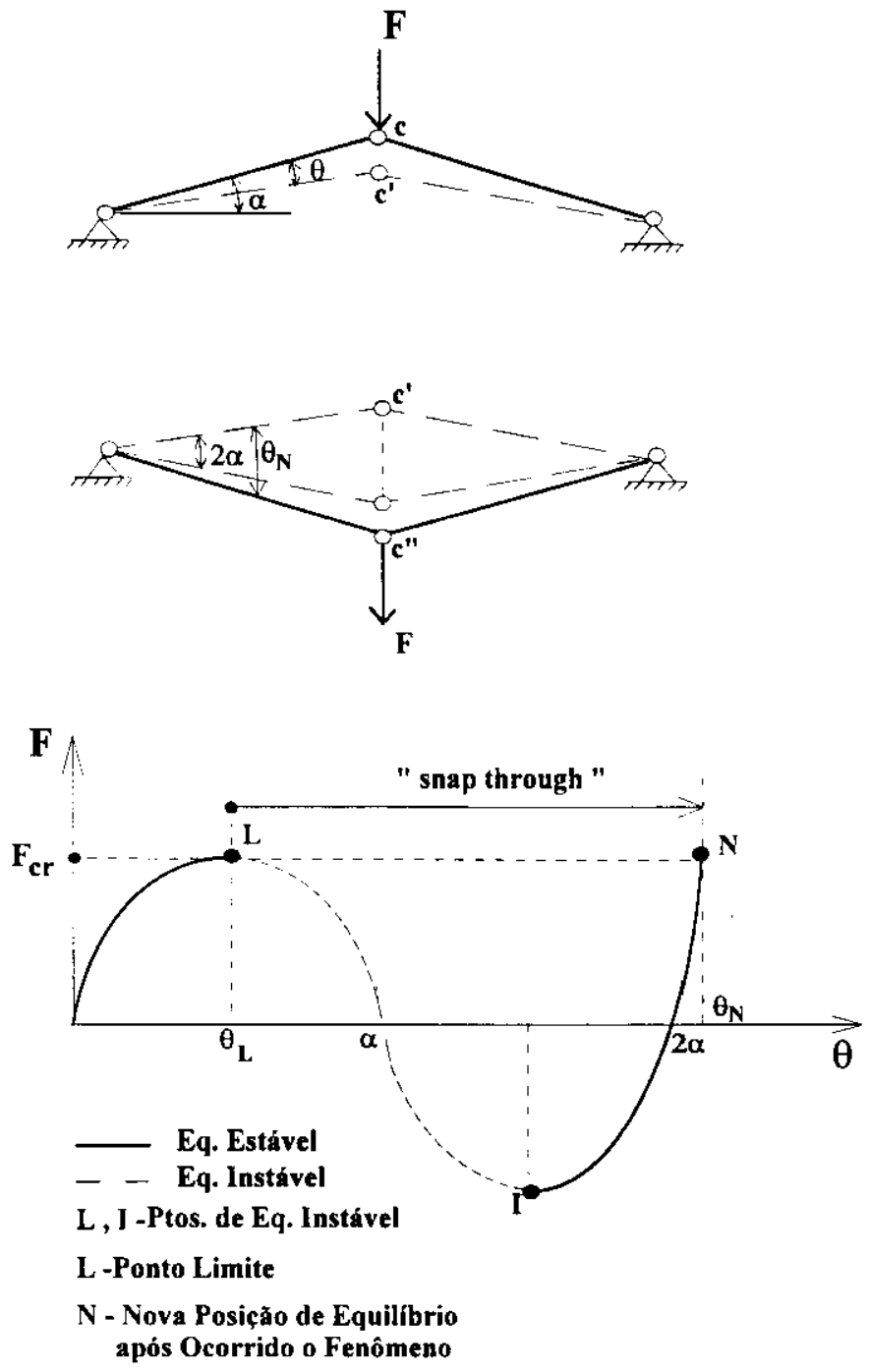

FIGURA 5 - Exemplo Clássico de Problema de Ponto Limite

ZAGOTTIS(1980) realizou análise de estabilidade dos diversos casos aqui citados, cujos resultados foram comentados oportunamente. Apresenta-se, a seguir, estes resultados resumidamente nas tabelas Tab. 1 e Tab. 2. 
Tabela 1 - Configuraçōes de Equilíbrio para Barra Axialmente Carregada

\begin{tabular}{|c|c|c|c|c|}
\hline Material & Forma & $\mathbf{F}<\mathbf{F}_{\mathbf{c r}}$ & $\mathbf{F}=\mathbf{F}_{\mathbf{c r}}$ & $\mathbf{F}>\mathbf{F}_{\mathbf{c r}}$ \\
\hline \hline M. & & & $($ a) & \\
E. & RETA & Estável & Estável & Instável \\
\cline { 2 - 5 } L. & CURVA & Não existe & Não existe & Estável \\
\hline M. & & & (b) & \\
N. & RETA & Estável & Instável & Instável \\
\cline { 2 - 5 } L. & CURVA & Instável & Não existe & Não existe \\
\hline
\end{tabular}

Tabela 2 - Configurações de Equilíbrio para Barra Excentricamente Carregada

\begin{tabular}{|c|c|c|c|c|}
\hline Material & Forma & $\mathbf{F}<\mathbf{F}_{\mathrm{cr}}$ & $\mathbf{F}=\mathbf{F}_{\mathrm{cr}}$ & $\mathbf{F}>\mathbf{F}_{\mathrm{cr}}$ \\
\hline \hline M.E.L. & CURVA & Estável & Estável & Estável \\
\hline M.N.L. & CURVA & $\begin{array}{c}\text { Estável ou } \\
\text { Instável }\end{array}$ & Instável & Impossivel \\
\hline
\end{tabular}

M.E.L. - material de comportamento elástico linear.

M.N.L. - material de comportamento não-linear.

(a) - equivalente a Ponto de Bifurcação Estável.

(b) - equivalente a Ponto de Bifurcação Instável.

\subsection{2 - CASOS ELEMENTARES - BARRA ELÁSTICA LINEAR}

No caso de edifícios altos, a deformação da estrutura devida à atuação simultânea dos carregamentos vertical e horizontal pode conduzir à instabilidade por Problema de Ponto Limite. No presente item, serão analisados alguns casos elementares do Problema de Flambagem, obtendo-se expressões que determinam o valor de $\mathbf{F}_{\mathbf{c r}}$, pois, como foi visto, é o valor para o qual tende a carga crítica de barras excentricamente carregadas quando $\mathbf{e}_{1}$ tende a zero. Serão introduzidos alguns comentários sobre a estabilidade da configuração fletida, para o caso de uma barra constituída de material de comportamento elástico linear. Em seguida, será analisado brevemente o caso da barra elástica submetida a flexão composta. 


\section{a) Instabilidade com Bifurcação do Equilíbrio na Compressão Axial}

Seja uma barra ideal (Fig. 6) ${ }^{2}$, suposta inicialmente reta e axialmente comprimida. A barra é constituída de material de comportamento elástico-linear, bastante esbelta ${ }^{3}$ e articulada nas duas extremidades.

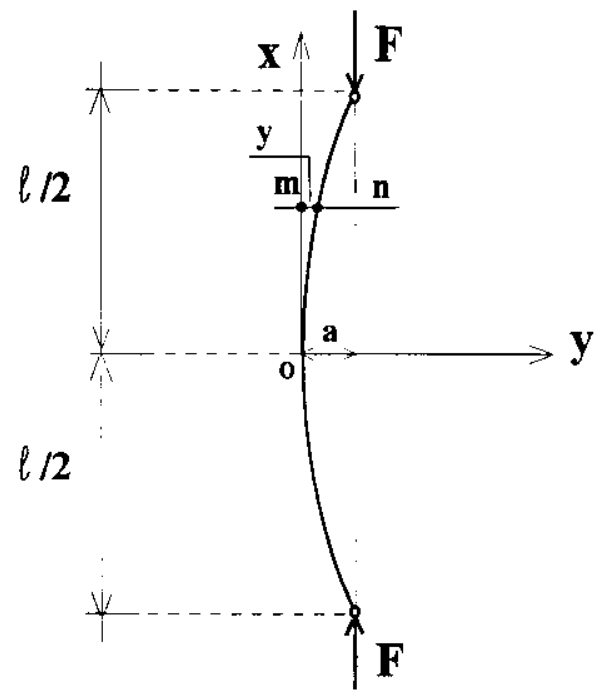

FIGURA 6 - Barra Elástica Linear Bi-Articulada.

Como foi visto no item 2.2.1-a, até $\mathbf{F}$ atingir o valor $\mathbf{F}_{\mathbf{c r}}$, a barra permanece reta e submetida apenas a compressão axial. No instante em que $\mathbf{F}=\mathbf{F}_{\mathbf{c r}}$, o equilibrio bifurca-se. A carga $\mathbf{F}_{\mathbf{c r}}$, também chamada carga de Euler, é definida como a força axial suficiente para manter a barra neste novo estado de equilíbrio.

A Expressão Exata da Equação Diferencial da Linha Elástica, a Eq. 1, possibilita a determinação das flechas das barras para $\mathbf{F}>\mathbf{F}_{\mathbf{c r}}$. Neste caso, o momento fletor numa seção transversal $\mathbf{m}-\mathbf{n}$ qualquer vale $\mathbf{M}=\mathbf{- F}(\mathbf{a}-\mathbf{y})$.

Admitindo-se que a barra sofreu pequenas rotações de suas seções transversais, pode-se utilizar a Expressão Aproximada ou Simplificada da citada equação, a Eq. 2. A linearização das equações de equilibrio é conveniente e correta para a determinação de $\mathbf{F}_{\mathbf{c r}}$, porém, é inconveniente e incorreta para caracterizar o tipo de

${ }^{2}$ O exemplo da (Fig. 6) é chamado de Caso Fundamental de Flambagem de Barras Prismáticas, pois é provavelmente o exemplo mais freqüentemente utilizado na prática. A partir da solução deste caso, pode-se obter a carga crítica para barras com outras condições de contorno.

${ }^{3}$ Esta imposição impede que a tensão crítica máxima de compressão $\left(\sigma_{c r}\right)$ seja maior que o limite de proporcionalidade $\left(f_{\mathrm{e}}\right)$, mantendo-se o problema no Regime Elástico Linear. 
equilíbrio para $\mathbf{F}=\mathbf{F}_{\mathbf{c r}}$ e para descrever o comportamento da estrutura para $\mathbf{F}>\mathbf{F}_{\mathbf{c r}}$. As flechas ficam, neste caso, indeterminadas. Definindo:

$$
\mathbf{k}^{2}=\frac{\mathbf{F}}{\mathrm{EI}}
$$

tem-se que, da Eq. 2

$$
\frac{d^{2} y}{d x^{2}}+k^{2} y=k^{2} a
$$

cuja solução geral é:

$$
y=C_{1} \cos k x+C_{2} \operatorname{sen} k x+a
$$

$\mathbf{C}_{1}$ e $\mathbf{C}_{2}$ são constantes de integração determinadas para as condições de contorno da barra da Fig. 6. Para $x=0, y=0$ e $\frac{d y}{d x}=0$, donde

$$
\mathrm{C}_{1}=-\mathrm{a}, \mathrm{C}_{2}=0
$$

e

$$
\mathbf{y}=\mathbf{a}(1-\cos k x)
$$

Para $\mathbf{x}=\frac{\ell}{2}, \mathbf{y}=\mathbf{a}$, obtém-se da Eq. 4

$$
a \cos k \frac{\ell}{2}=0
$$

Como $\mathbf{a} \neq \mathbf{0}$ (a barra está sendo considerada fletida), resta que $\cos \mathbf{k} \frac{\ell}{2}=\mathbf{0}$, ou seja,

$$
k \frac{\ell}{2}=(2 n-1) \frac{\pi}{2} \quad \text { para } n=1,2,3 \ldots
$$

O estudo da Equação Exata indica que para valores de cargas entre os valores de $\mathbf{F}$ para $\mathbf{n}=\mathbf{1}$ e para $\mathbf{n}=\mathbf{2}$, a forma reta é instável e a fletida é estável. A partir daí, todas as configurações de equilíbrio decorrentes são instáveis. Então, o carregamento crítico que interessa é o equivalente a $n=1$, o que resulta em $\mathbf{k}=\pi / \ell$. O valor de $\mathbf{F}$ obtido será, então, o menor valor de carga crítica. Definindo: 


$$
\alpha=\mathbf{k} l
$$

obtém-se que

$$
\alpha_{\mathrm{cr}}=\pi
$$

e a partir da Eq. 3

$$
\left(\frac{\alpha}{l}\right)^{2}=\frac{F_{\text {cr }}}{\mathrm{EI}}=\frac{\pi^{2}}{l^{2}}
$$

donde

$$
\mathbf{F}_{\mathrm{cr}}=\frac{\pi^{2}}{l^{2}} \mathbf{E I}
$$

que, de uma forma geral, pode ser reescrita para diferentes condições de contorno:

$$
\mathbf{F}_{\mathrm{cr}}=\frac{\pi^{2}}{l_{\mathrm{e}}^{2}} \mathbf{E I} \quad \text { (carga crítica de Euler) }
$$

onde $\ell_{e}$ é o comprimento de flambagem equivalente que varia para barras com outras condições de contorno. Para efeito de ilustração, a Fig. 7 apresenta dois outros casos:

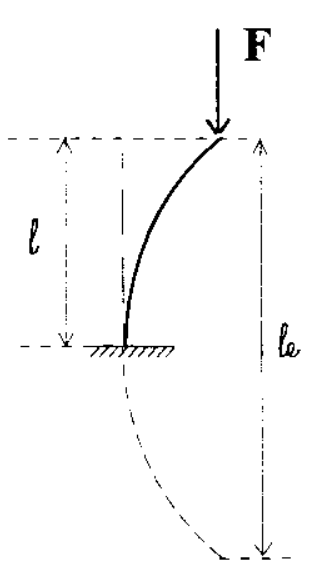

$$
\begin{aligned}
& l_{e}=2 l \\
& \mathbf{F}_{\mathrm{cr}}=\pi^{2} \mathrm{EI} / 4 l^{2} \\
& \alpha_{\mathrm{cr}}=\pi / 2
\end{aligned}
$$

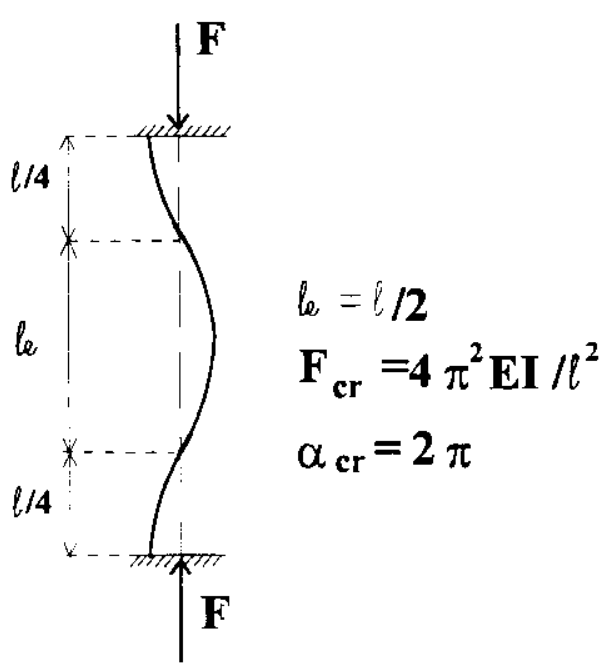

(b)

FIGURA 7 - Valores de Fcr para Alguns Exemplos de Variantes do Caso Fundamental 
Analisando-se a mesma barra da Fig. 7-a, agora submetida a carga vertical uniformemente distribuída ao longo de sua altura (Fig. 8), serão obtidos os seguintes valores:

$$
(\mathbf{q l})_{\mathrm{cr}}=7 \underset{l^{2}}{\mathrm{~s}}
$$

e

$$
\alpha_{\mathrm{cr}}^{2}=7,837 \Rightarrow \alpha_{\mathrm{cr}}=2,80
$$

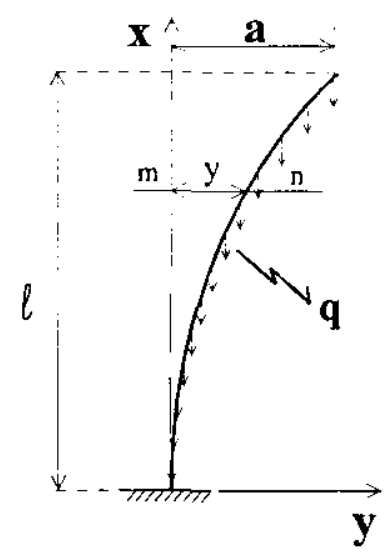

\section{FIGURA 8 - Barra Elástica Linear Submetida a Carregamento Axial} Uniformemente Distribuído

A solução deste problema é apresentada por TIMOSHENKO \& GERE(1961) através da utilização de Funções de Bessel ou pelo Método Aproximado da Energia ${ }^{4}$.

As expressões que determinam o valor de $\mathbf{F}_{\mathbf{c r}}$ foram obtidas com base na hipótese de que o problema permanece no regime elástico. Para tanto, a tensão máxima de compressão $\sigma$ na barra, decorrente de sua solicitação, não deve exceder o limite de proporcionalidade $f_{\mathrm{e}}$ do material, ou seja:

$$
\sigma \leq f_{\mathbf{e}}
$$

No instante em que $\mathbf{F}$ atinge o valor $\mathbf{F}_{\mathbf{c r}}$, a tensão $\sigma$ será $\sigma_{\mathbf{c r}}$ e valerá, em valor absoluto:

\footnotetext{
${ }^{4}$ Euler foi o primeiro a estudar este problema, não tendo, entretanto, obtido a solução satisfatória. $\mathrm{O}$ problema foi resolvido por GREENHILL, A.G., Proc. Cambridge Phil. Soc., vol. 4, 1881 apud TIMOSHENKO, S.P.; GERE, J.E (1961). Theory of elastic stability. New York, McGraw-Hill.
} 


$$
\sigma_{\mathrm{cr}}=\frac{\mathrm{F}_{\mathrm{cr}}}{\mathrm{A}}=\frac{\pi^{2} \mathrm{E}}{\lambda^{2}}
$$

onde

$$
\lambda=\frac{l_{\mathrm{e}}}{\mathrm{i}}
$$

sendo

$$
i=\sqrt{\frac{I}{A}}
$$

sendo que $\lambda$ é o índice de esbeltez da barra e i o raio de giração da seção transversal.

Conhecendo-se o módulo de elasticidade $\mathbf{E}$ do material e o seu limite de proporcionalidade $f_{\mathbf{e}}$, pode-se determinar $\lambda_{\text {lim }}$, a partir das Eq. 11 e 12 :

$$
\frac{\pi^{2} \mathbf{E}}{\lambda^{2}} \leq f_{\mathrm{e}}
$$

onde

$$
\lambda \geq \pi \sqrt{\frac{\mathbf{E}}{f_{\mathrm{e}}}}
$$

donde

$$
\lambda_{\lim }=\pi \sqrt{\frac{\mathbf{E}}{f_{\mathrm{e}}}}
$$

Daí, as expressões de $\mathbf{F}_{\text {cr }}$ deste item somente serão válidas para barras de material elástico com índice de esbeltez $\lambda \geq \lambda_{\text {lim }}$, caso contrário, a tensão de compressão atingirá $f_{\mathrm{e}}$ antes que ocorra a flambagem, ou seja, passa-se para o Regime Inelástico (ver item 2.2.3).

Pode-se representar graficamente a Eq. 12, no diagrama $\sigma_{\mathrm{cr}} \times \lambda$, como se mostra na Fig. 9. Observe-se que a curva se aproxima assintoticamente do eixo das abscissas, ou seja, $\sigma_{\mathbf{c r}} \rightarrow \mathbf{0}$ à medida que $\lambda$ cresce, o que significa que, quanto mais esbelta for a barra, menor será o valor da carga crítica. 


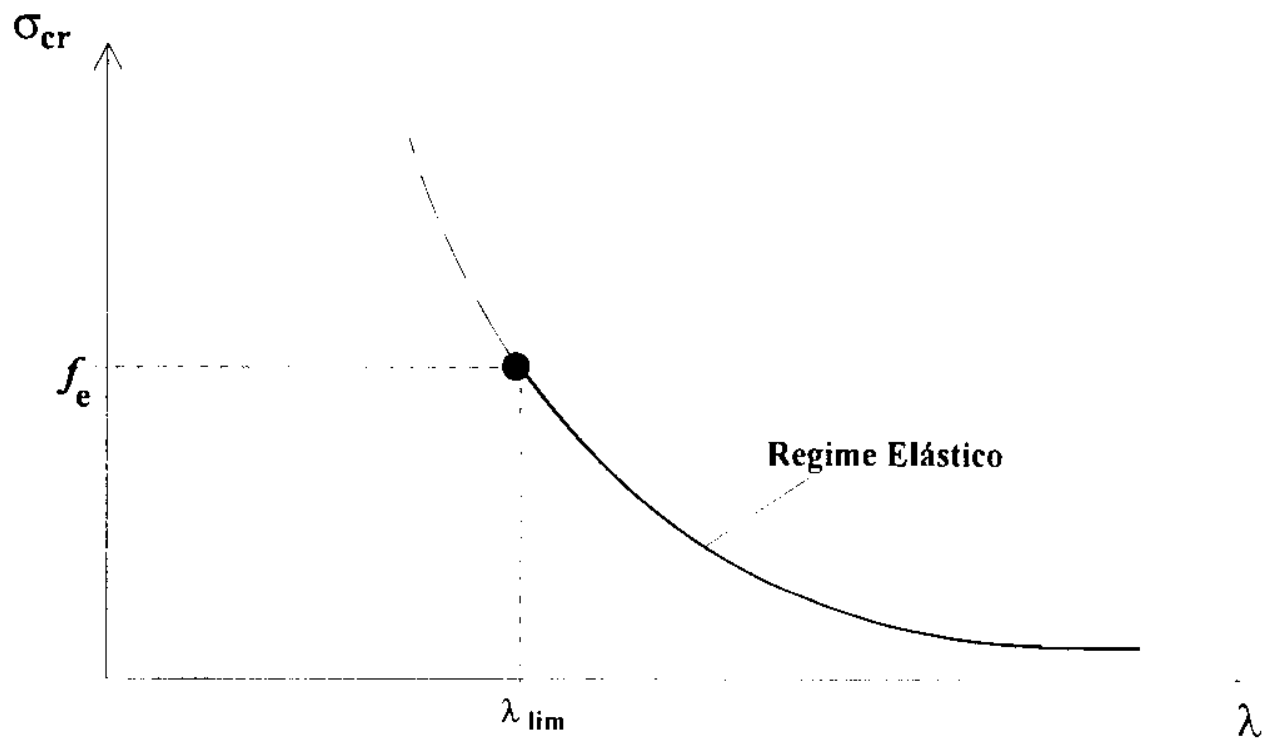

FIGURA 9 - Curva de Flambagem (Curva de Euler).

A verificação da estabilidade na forma fletida da barra suhmetidn in compressão axial é devidamente ilustrada por FUSCO(1981), onde admite-se que a forma fletida da linha elástica é senoidal e compara-se, através da utilização de gráficos, os momentos internos e externos, que deverão ser iguais para que se caracterize o equilibrio. Nesse trabalho conclui-se que, enquanto o fenômeno ocorre no regime elástico, haverá uma configuração estável de equilíbrio para cada valor de $\mathbf{F}$ maior que $\mathbf{F}_{\mathbf{c r}}$, porém somente se não ocorrer a ruptura física do material.

\section{b) Efeito de Segunda Ordem - Flexão Composta}

No caso da barra ideal (ver Fig. 3-a), esbelta e em regime elástico, suposta inicialmente reta e excentricamente carregada, as suas flechas poderão ser obtidas através da Equação Diferencial da Linha Elástica, mesmo na sua forma simplificada (Eq. 2), onde, no caso:

$$
\mathbf{M}=\mathbf{F}\left(\mathbf{e}_{1}+\mathbf{y}\right)
$$

donde vem que, da Eq. 2 


$$
\frac{d^{2} y}{d x^{2}}+k^{2} y=-k^{2} e_{1}
$$

de solução geral:

$$
y=C_{1} \cos k x+C_{2} \operatorname{sen} k x-e_{1}
$$

sendo

$$
\mathbf{k}^{2}=\frac{\mathbf{F}}{\mathbf{E I}}
$$

$\mathrm{C}_{1}$ e $\mathbf{C}_{2}$ são constantes de integração determinadas para as condições de contorno da barra da Fig. 3-a. Para $\mathbf{x}=\mathbf{0}, \mathbf{y}=\mathbf{0}$

$$
\mathbf{C}_{1}=\mathbf{e}_{1}
$$

Para $\mathbf{x}=\ell, \frac{\mathbf{d y}}{\mathbf{d x}}=\mathbf{0}$. Dai,

$$
-k e_{1} \operatorname{sen} k+k C_{2} \cos k=0 \Rightarrow C_{2}=e_{1} \operatorname{tg} k
$$

Chega-se, então, à expressão final para os deslocamentos:

$$
y=e_{1}(\cos k x+\operatorname{tg} k \mathfrak{s e n} k x-1)
$$

A flecha máxima a vale, portanto:

$$
a=y_{(x=\ell)}=e_{1}\left(\frac{1-\cos k \ell}{\cos k \ell}\right)
$$

donde é fácil verificar-se que

$$
\lim _{\mathbf{F} \rightarrow \mathbf{F}_{\text {cr }}} \mathbf{a}=\infty
$$

pois, para o caso da Fig. 3-a, $\mathbf{F}_{\mathrm{cr}}=\pi^{2} \mathrm{EI} / \mathbf{4}^{2}$, conforme a Fig. 7-a. 
FUSCO(1981) realiza a mesma análise de estabilidade mencionada no item a) para o caso de barras elásticas excentricamente carregadas. Conclui-se que, permanecendo a barra no regime elástico, sempre haverá uma configuração de equilíbrio estável e a ruína só ocorrerá com a ruptura do material. Se for ultrapassado o limite de proporcionalidade, o diagrama do momento interno será curvo, surgindo um novo fenômeno de instabilidade (ver item 2.2.1-c).

\subsection{3 - REGIME INELÁSTICO}

No item 2.2.2 comentou-se a estabilidade da configuração fletida, tendo sido determinado o valor da carga crítica para barras constituídas de material de comportamento elástico linear ou elastoplástico bastante esbeltas. A equação de Euler (Eq. 8) determinada em 2.2.2 não se aplica, portanto, aos materiais que não obedecem à lei de Hooke e nem às barras de material elastoplástico com índice de esbeltez $\lambda$ menor que $\lambda \lim$, definido em 2.2.2-a (Eq. 13). Como o fenômeno ocorre fora do Regime Elástico, observa-se que existe uma influência da plasticidade no valor de $\mathbf{F}_{\mathbf{c r}}$.

No presente item, indica-se um modo clássico de se determinar o $\mathbf{F}_{\text {cr }}$ para barras sob o Regime Inelástico (ou Plástico) que, evidentemente, se aplica também ao caso de material perfeitamente elástico de comportamento não linear ou elastoplástico $\operatorname{com} \lambda<\lambda_{\text {limm }}$.

Seja uma barra comprimida axialmente, constituída de material inelástico. A curva OBC da Fig. 10 representa o diagrama $\sigma \times \varepsilon$ para o material da barra mencionada e o ponto $\mathbf{C}$ equivale à situação crítica. A inclinação da tangente $\mathbf{C C}^{\prime}$ representa a relação entre tensão e deformação quando o carregamento atinge o valor crítico, chamada Módulo Tangente $\left(\mathbf{E}_{\mathbf{t}}\right)$, que é tal que :

$$
E_{t}=\left(\frac{d \sigma}{d \varepsilon}\right)_{\sigma=\sigma_{c r}} \Rightarrow E_{t}=E_{t}\left(\sigma_{c r}\right)
$$

Daí, da Eq. 12 


$$
\lambda=\sqrt{\frac{\pi^{2} E_{t}\left(\sigma_{c r}\right)}{\sigma_{c r}}}
$$

ZAGOTTIS(1980) apresenta algumas expressões sugeridas por outros autores para se obter $\mathbf{E}_{\mathbf{t}}$ e $\sigma_{\mathbf{c r}}$, na falta de dados experimentais mais detalhados. Esta é a chamada Teoria do Módulo Tangente. Esta teoria, no entanto, foi contestada pela seguinte observação: no instante em que a barra atinge a forma fletida ela passa a sofrer também flexão e observa-se uma redução da tensão total e inicial de compressão no lado convexo (lado tracionado) e um aumento da tensão no lado côncavo (lado comprimido) da barra. Como havia sido dito, a inclinação da tangente $\mathrm{CC}^{\prime}$ representa a relação entre $\sigma$ e $\varepsilon$ do lado côncavo, chamada Módulo Tangente $\left(\mathrm{E}_{\mathrm{t}}\right)$. A inclinação da linha $\mathbf{C C}^{\prime \prime}$, por sua vez, representa a relação entre $\sigma$ e $\varepsilon$ do lado convexo, de tensão de compressão reduzida, cujo valor se aproxima do valor do Módulo de Elasticidade Inicial (E) do material.

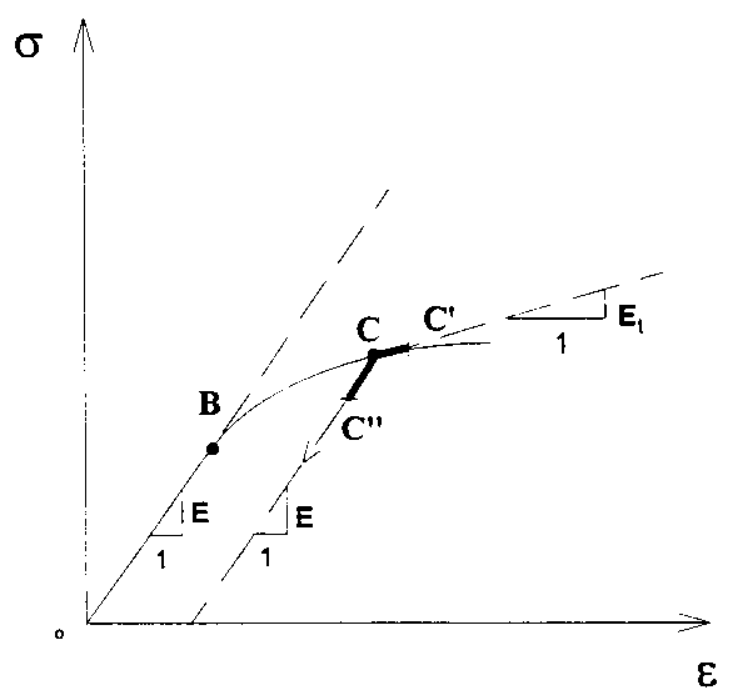

FIGURA 10 - Diagrama de Ensaio de Compressão em Barra de Material Inejástico

TIMOSHENKO \& GERE(1961) demonstram que a equação de Euler (Eq. 8) para determinação da carga crítica de uma barra elástica linear pode ser usada para os materiais não-lineares se o módulo de elasticidade $\mathbf{E}$ for substituído por $\mathbf{E}_{\mathbf{r}}$, definido como Módulo de Elasticidade Reduzido, de valor entre $\mathbf{E}$ e $\mathbf{E}_{\mathbf{t}}$, que varia de acordo com a forma da seção transversal da barra. Para seções retangulares $(\mathrm{b} \times \mathrm{h})$, por exemplo, o $\mathbf{E}_{\mathbf{r}}$ vale: 


$$
E_{r}=\frac{4 E_{t}}{\left(\sqrt{E}+\sqrt{E_{t}}\right)^{2}}
$$

Esta é a chamada Teoria do Módulo Reduzido ou do Duplo Módulo que obtém valores de $\sigma_{\mathbf{c r}}$ maiores que na teoria anterior. É aparentemente mais correta que a Teoria do Módulo Tangente por analisar melhor o fenômeno, porém, tudo isto realmente ocorreria se a carga $\mathbf{F}$ permanecesse constante após atingir o valor $\mathbf{F}_{\mathbf{c r}}$. Além disso, ZAGOTTIS(1980) afirma que as curvas $\sigma_{\mathrm{cr}} \times \lambda$ obtidas para resultados experimentais aproximam-se mais da curva relativa à Teoria do Módulo Tangente. $\mathrm{O}$ que ocorre de fato durante os testes é que a carga cresce simultaneamente com os deslocamentos laterais, mesmo após a flambagem. Daí, a redução de tensão de compressão no lado convexo é compensada pela tensão de compressão axial, continuamente crescente, aplicada diretamente à barra. Mesmo que ocorram descarregamentos apenas parciais conforme a velocidade de crescimento da força $\mathbf{F}$,os valores de $\sigma_{\mathbf{c r}}$ possíveis estarão entre os obtidos por ambas as teorias. Como $\mathbf{F}_{\mathbf{c r}}$ deve corresponder sempre ao menor valor obtido a partir do qual pode haver instabilidade, pode-se admitir que o módulo tangente $\mathbf{E}_{\mathbf{t}}$ represente a relação tensãodeformação da coluna como um todo, independentemente da forma da sua seção transversal ${ }^{5}$. Daí :

$$
\left(F_{t}\right)_{c r}=\frac{\pi^{2} E_{t}}{l_{e}^{2}} \mathbf{I}
$$

donde

$$
\left(\sigma_{t}\right)_{\mathrm{cr}}=\frac{\pi^{2} E_{t}}{\lambda^{2}}
$$

Isto permite complementar o diagrama da Fig. 9, para $\lambda<\lambda \lim$ (Fig. 11).

${ }^{5}$ A solução deste problema foi obtida teorica e experimentalmente por SHANLEY, F. R., "Inelastic Column Theory", Jour. Aeronautical Science, 1947, p.261 apud ZAGOTTIS, D., "Introdução à Teoria das Estruturas", cap.10,1980. 


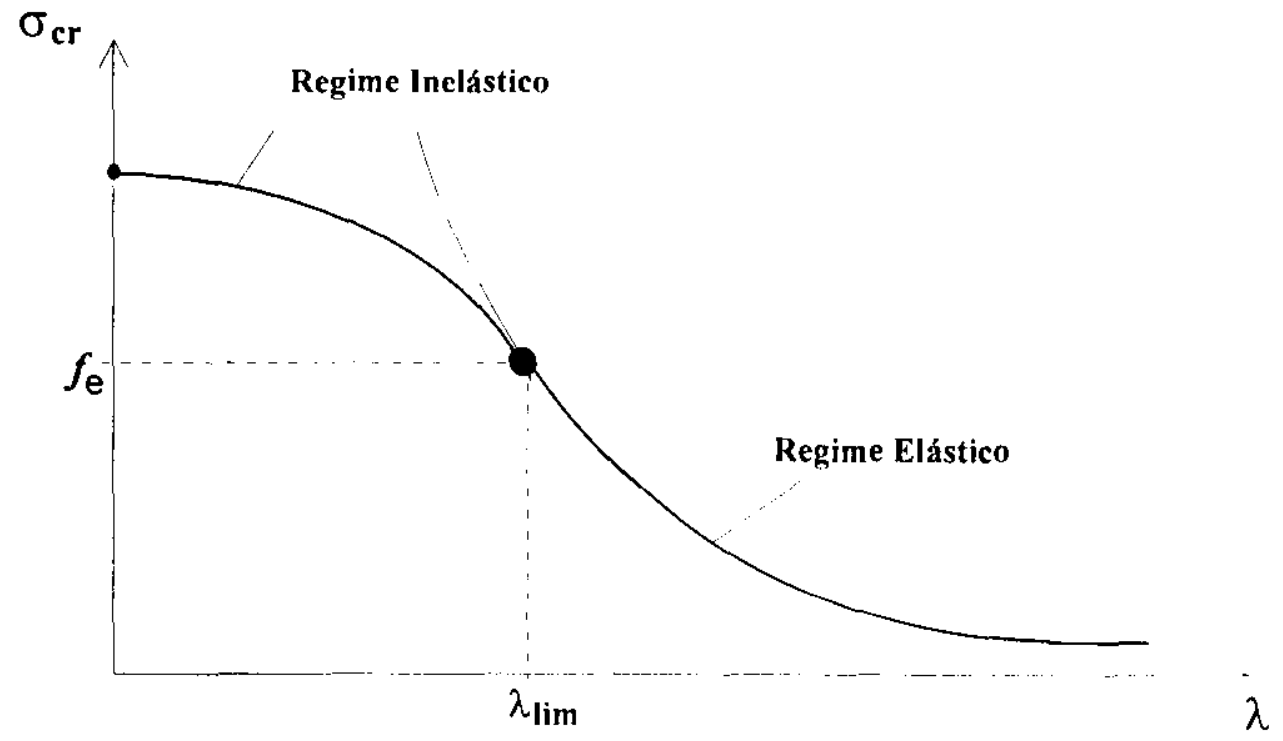

FIGURA 11 - Curva de Flambagem (Curva de Euler).

Para analisar o tipo de equilibrio das configurações de uma barra, são consideradas pequenas perturbações de posição em torno da posição de equilíbrio. ZAGOTTIS(1980), no entanto, lembra que, no caso de material em Regime Inelástico, ao se realizar esta análise, deve-se levar em conta que haverá uma deformação residual em algumas fibras quando a barra retornar à posição de equilíbrio. Neste caso, apesar de ser diferente, a nova posição de equilíbrio é muito próxima da posição anterior, o que não muda as conclusões que levaram aos resultados obtidos da análise feita para material elástico não-linear: os efeitos da plasticidade sobre a compressão axial e a flexão composta são semelhantes. Assim. da mesma forma que no regime elástico, continua ocorrendo o fenômeno de instabilidade das barras retas no Regime Inelástico.

\subsection{4 - PROBLEMAS DE INSTABILIDADE EM EDIFÍCIOS ALTOS DE CONCRETO ARMADO}

A extensão e a complexidade dos problemas ligados à instabilidade das estruturas são grandes, todos listados e descritos por ZAGOTTIS(1980). Pode-se dizer que, no caso das estruturas reticuladas usuais de edifícios, o tipo de 
instabilidade que interessa analisar é a Divergente Estática que se manifesta pelo aparecimento de pontos limites ou de bifurcação do equilíbrio. Divergente, pois a estrutura busca novos estados equilibrados, afastando-se de sua posição inicial. Estática, pois pode ser estudada por processos estáticos de análise, sendo típica de sistemas estruturais sujeitos a forças conservativas, quase sempre de origem gravitacional. A excentricidade pode surgir tanto por imperfeições geométricas contrutivas, quase sempre inevitáveis, quanto pela presença de ações externas laterais como, por exempio, a ação do vento. Existe ainda a instabilidade Divergente Dinâmica, típica de sistemas estruturais sujeitos a forças não-conservativas, como a do vento e outros fluídos, e a instabilidade Oscilatória, que manifesta-se, por exemplo, nos casos de ressonância. Estes últimos tipos de instabilidade, entretanto, não interessam ao objetivo deste trabaiho.

Imperfeições geométricas construtivas são praticamente inevitáveis, qualquer que seja $o$ ambiente em que a estrutura for construída. Estas imperfeições correspondem às excentricidades mencionadas neste trabalho. São chamadas de Estruturas Sensíveis a Imperfeições aquelas cujo valor de $\mathbf{F}_{\mathbf{c r}}$ depende do valor da excentricidade, tendo-se, portanto, que incorporá-la ao modelo adotado para simular o comportamento real da estrutura. KOITER ${ }^{6}$ apud ZAGOTTIS(1980) mostrou que a sensibilidade às imperfeições das estruturas indeformadas está relacionada com a estabilidade do seu Ponto de Bifurcação, ou seja, a estrutura será Sensível a Imperfeições quando o seu ponto de bifurcação (relativo à estrutura indeformada) for instável.

Apesar de se ter abordado inicialmente o fenômeno de instabilidade em de estrutura simples de uma barra, os conceitos são gerais para qualquer estrutura. Nas estruturas de uma barra, a sensibilidade às imperfeições vem da não-linearidade fisica. Nas estruturas usuais, porém, há um fenômeno análogo provocado pela plasticidade, e não à elasticidade não-linear, de efeito semelhante, como foi visto. As estruturas reticuladas usuais de concreto e aço são, portanto, sensíveis às imperfeições geométricas construtivas, devendo-se estudar a flexão composta da estrutura deformada para o dimensionamento. Assim, devem ser consideradas no projeto tanto a Não-Linearidade Física como a Não-Linearidade Geométrica. Levando-se em conta estes efeitos no projeto estrutural, realiza-se uma Análise

${ }^{6}$ KOITER, W.T., "Current Trends in the Theory of Buckling", Intern.Union of Theoretical and Applied Mechanics(IUTAM), Symposium on Buckling of Structures, Cambrige,USA,1974 apud ZAGOTTIS, D., "Introdução à Teoria das Estruturas", cap.10,1980. 
Estrutural de Segunda Ordem. Alguns dos procedimentos usualmente adotados para se avaliar a necessidade de se realizar este tipo de análise serão discutidos no próximo capitulo e confrontados com o auxílio de exemplos no capítulo 4 . 


\section{CAPÍTULO 3 - EFEITOS DE SEGUNDA ORDEM EM EDIFÍCIOS ALTOS}

\section{1 - INTRODUÇÃO}

As condições de equilíbrio para a estrutura deformada podem diferir muito daquelas consideradas inicialmente, ou seja, para a estrutura indeformada. Isto se deve ao fato de que, como se havia dito anteriormente, a existência de deslocamentos expressivos pode propiciar o surgimento de Efeitos de Segunda Ordem que, adicionados ao estado de solicitação original da estruturas, podem conduzí-la à instabilidade. LU et al. ${ }^{1}$ apud KALYANARAMAN(1984) mostram que efeitos de segunda ordem podem reduzir a capacidade de carga transversal do edifício em 12 a $22 \%$ e aumentar o deslocamento transversal da estrutura em 7 a $10 \%$. Neste mesmo trabalho, KALYANARAMAN(1984) cita estudos que mostram, numerica e experimentalmente, que muitos edificios de estrutura metálica de proporções usuais atingem o estado limite de instabilidade antes que se forme um mecanismo de colapso plástico.

Levando-se em conta estes efeitos no cálculo estrutural, realiza-se uma Análise de Segunda Ordem, que considera a estrutura deformada na formulação de suas equações de equilíbrio. Esta análise feita em todo o edifício, como foi visto (item 2.2.4), poderá ser evitada, juntamente com os gastos adicionais que ela requer, se puder ser prevista a relevância desses efeitos de segunda ordem. Esta "previsão" dos resultados deixa ainda ao projetista a opção de controlar a rigidez global do edifício, evitando assim esses efeitos nocivos à estabilidade da estrutura. Nunca é demais frisar, entretanto, que a perda de estabilidade pode ser causada pelo surgimento de

\footnotetext{
${ }^{1}$ LU, L. et al. Strength and drift characteristics of steel frames. Journal of Structural Division, ASCE, v. 103, n.11, p.2225 - 2241, Nov. 1977. apud KALYANARAMAN,V. (1984) P-Delta analysis of tall buildings. In: SEM. TALL STRUCT. USE PRESTR. CONC. HYDR.STRUCT., Srinagar. Preliminary Pub.
} 
efeitos globais ou locais de segunda ordem. Ou seja, a dispensa da análise de segunda ordem em toda estrutura não dá permissão para que se dispense o procedimento normal de se analisar o coeficiente de esbeltez $\lambda$ de cada peça da estrutura, como, por exemplo, um tramo de pilar.

Neste capítulo, serão descritos os procedimentos mais comuns relativos a uma análise global de segunda ordem, bem como alguns parâmetros usados na verificação da estabilidade global das estruturas e seus valores limites, de acordo com diversos regulamentos e pesquisas realizadas por estudiosos e profissionais da área.

\section{2 - CRITÉRIO DE IMOBILIDADE}

De acordo com o Critério Usual de Imobilidade, assume-se que os esforços obtidos na análise de primeira ordem são suficientemente precisos para o projeto da estrutura se não forem excedidos em mais de $10 \%$ pelos finais, ou seja, os momentos de segunda ordem poderão ser ignorados e a estrutura considerada de nós fixos se:

$$
M_{2 d} \leq 1,1 M_{1 d}
$$

onde $\mathbf{M}_{\mathbf{2 d}}$ é o valor de cálculo do momento total que inclui o momento de segunda ordem e $\mathbf{M}_{\mathbf{1 d}}$ é o valor de cálculo do momento de primeira ordem. Em caso contrário, a estrutura será classificada como de nós móveis e deverá se submeter a uma análise de segunda ordem. Argumenta-se serem desta ordem de grandeza as incertezas das hipóteses de carregamento do vento.

Como foi visto, também no item 2.2.4, alguns parâmetros foram estabelecidos para ajudar na decisão de ignorar ou não os efeitos de segunda ordem por parte dos projetistas. Os limites dos parâmetros de instabilidade são obtidos com base no citado Critério de Imobilidade. 


\section{3 - ALGUNS CONCEITOS E SIMPLIFICAÇÕES ADOTADAS}

\section{a) Modelo Simplificado}

Nos edificios muito altos, desprezando-se as suas dimensões em planta em presença da sua altura, pode-se compará-los a uma barra isolada linear, com a extremidade inferior engastada, representando a rigidez oferecida pelos blocos de fundação, e a superior livre (Fig. 12).

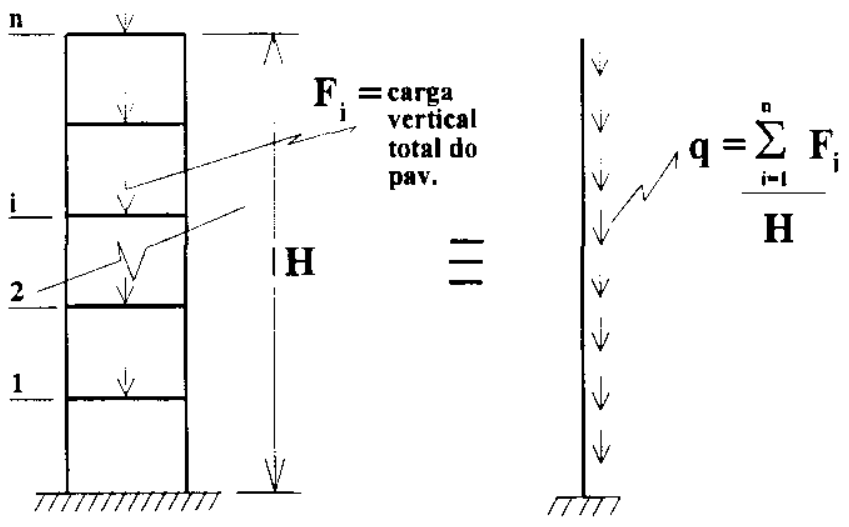

FIGURA 12 - Modelo Simplificado Utilizado na Formulação de Relaçōes Básicas.

Os pavimentos-tipo, repetidos ao longo da altura do edificio, possuem carga total individual de cada pavimento $\left(\mathbf{F}_{\mathbf{i}}\right)$ de valor aproximadamente constante. Além disso, as formas e carregamentos dos demais pavimentos (térreo, cobertura, garagem, etc...) serão assumidos com pouca diferença em relação aos pavimentos-tipo e os pilares com seção inalterada da base até o topo do edifício. Isto permite que se considere o carregamento vertical uniformemente distribuído ao longo da altura da estrutura. Então, a Fig. 12 ilustra um modelo simplificado cuja concepção, para o objetivo comparativo deste trabalho, não induz a erros significativos.

Para se realizar uma análise rigorosa de estabilidade de uma estrutura de concreto armado, ter-se-ia que levar em conta a não-linearidade da relação TensãoDeformação do material (não-linearidade física). Isto tornaria esta tarefa bastante complicada de modo que, para serem estabelecidas relações básicas, será considerado que é linear o comportamento do material. Além disso, com a hipótese de rotações pequenas, pode-se adotar a equação simplificada da linha elástica (Eq. 2) para a 
determinação da $\mathbf{F}_{\text {cr. }}$ Portanto, relembrando o que foi visto no item 2.2.2-a (das Eqs. 9 e 10), sendo para esse caso $\ell=\mathbf{H}$, tem-se que:

$$
F_{c r}=7,837 \frac{E I}{H^{2}}
$$

e

$$
\alpha_{c r}^{2}=7,837 \Rightarrow \alpha_{c r}=2,80
$$

\section{b) Análise Não-Linear}

De acordo com VASCONCELOS(1985), no estudo de estabilidade podem surgir casos em que a ruína por perda de estabilidade ocorre com solicitações bastante afastadas do regime elástico. Nestes casos, os cálculos feitos em regime elástico podem fornecer resultados contra segurança.

A realização de uma Análise Não-Linear de uma estrutura considera o comportamento não-linear dos materiais e inclui, quando necessário, os efeitos de Segunda Ordem. O primeiro problema se deve ao que se chama Não-Linearidade Física (NLF) e o segundo se deve à Não-Linearidade Geométrica (NLG), assim chamada pois está relacionada à mudança na geometria da estrutura.

Numa análise com efeitos de Segunda Ordem, procura-se evitar a perda da estabilidade, além do esgotamento da capacidade resistente, para as combinações mais desfavoráveis das ações de cálculo. No cálculo das estruturas, pretende-se sempre prever o encontro da máxima solicitação conseqüente das ações ou deformações impostas com a mínima resistência das seções transversais. De acordo com VASCONCELOS(1987), seria indiferente majorar as ações para depois calcular as solicitações ou, ao contrário, majorar as solicitações calculadas a partir de ações de serviço, se não se tratasse de problema de Segunda Ordem. O primeiro procedimento resulta em valores excessivos de solicitação, e o segundo, a valores inferiores aos que devem ser usados.

A NBR-8681/1984, publicada pela Associação Brasileira de Normas Técnicas $(\mathrm{ABNT})$, prescreve que, quando for considerada a não-linearidade geométrica, o 
coeficiente de ponderação das ações $\left(\gamma_{f}\right)$ deve ser desdobrado nos coeficientes parciais $\gamma_{f 1}, \gamma_{f 2}$ e $\gamma_{f 3}$, de forma que:

$$
S_{\mathrm{d}}=\gamma_{f 3} \cdot \mathbf{S}\left(\gamma_{f 1} \cdot \gamma_{f 2} \cdot \mathbf{F}_{\mathbf{k}}\right)
$$

sendo $\mathbf{S}_{\mathbf{d}}$ o valor de cálculo dos esforços atuantes e $\mathbf{F}_{\mathbf{k}}$ o valor característico das ações. Os coeficientes $\gamma_{f 1}, \gamma_{f 2}$ (que poderá ser indicado também por $\psi_{0}$, chamado coeficiente de combinação) e $\gamma_{f 3}$ são utilizados para obter os esforços de cálculo quando se consideram estados limites últimos. $\gamma_{f 1}$ leva em conta a variabilidade das ações. $\gamma_{f 2}$ é empregado quando existem ações variáveis de diferentes naturezas, sendo aplicado às ações variáveis secundárias. Leva em conta a baixa probabilidade de ocorrência simultânea dos valores característicos de duas ou mais ações variáveis de diferentes naturezas. $\gamma_{f 3}$ considera os possíveis erros na obtenção dos efeitos das ações, por isso é aplicado após a obtenção dos esforços calculados a partir da ação ponderada por $\gamma_{f 1}, \gamma_{f 2}$.

Através da análise da combinação dos valores fornecidos pela NBR-8681/1984 (ABNT) para os coeficientes parciais, como $\gamma_{f}=\gamma_{f 1} \cdot \gamma_{f 2} \cdot \gamma_{f 3}$, FRANCO \& VASCONCELOS(1991) chegam a valores de $\gamma_{f}$ para ações horizontais igual a 1,4 e para ações verticais igual a 1,0 em casos gerais, e 1,1 em casos especiais (bibliotecas, garagens, ...).

Durante a realização de uma Análise Não-Linear, algumas considerações relativas aos materiais constituintes também devem ser feitas. Levando-se em conta a NLF, deve-se adotar os diagramas Tensão-Deformação usados no estado limite último de ruptura, com $\gamma_{c}=1,4$ e $\gamma_{s}=1,15$. Porém, de acordo com SANTOS \& FRANCO(1993), a deformabilidade dos elementos, que depende da resistência média, deve ser calculada com base naqueles diagramas para uma tensão de pico de $0,85 \cdot 1,30 \cdot f_{\text {cd }}$. Para a verificação da capacidade resistente, que depende da resistência mínima, continua valendo a tensão de pico igual a $\mathbf{0 , 8 5} \cdot f_{\mathbf{c d}}$. Deve-se, para considerar os efeitos da não-linearidade, determinar o diagrama MomentoCurvatura para cada seção, com armadura suposta conhecida, e para o valor da força normal atuante $\mathbf{N}_{\mathbf{S d}} / \gamma_{f 3}, \operatorname{com} \gamma_{f 3}=1,12$.

${ }^{2}$ A NBR-8681/1984 (ABNT) prescreve que $\gamma_{f 3}$ seja maior ou igual a 1,1, no caso de se considerar não-linearidade geométrica. 
Os deslocamentos laterais obtidos pela análise das estruturas são afetados pela flexibilidade de todos os membros da estrutura o que determina que o valor do módulo de deformação por flexão EI usado nesta análise deve aproximar-se de um valor médio dos membros individuais. Numa análise de $2 \mathrm{a}$. ordem de estrutura, $\mathrm{o}$ valor de EI deve ser representativo das rigidezes dos membros num estado imediatamente antes do último. Neste estado, partes das vigas, lajes e paredes irá fissurar ao fletir. É bastante conservativo, entretanto, considerar o valor EI com base no momento de inércia da seção fissurada pois as vigas não irão fissurar completamente em todas as seções. Em lugar disto, o EI deveria ser calculado a partir da rigidez de cada membro, mapeando-se as regiões fissuradas e as não fissuradas ao longo do membro, de acordo com o procedimento visto acima. Ora, para edificios com 20 andares, por exemplo, com mais de 1000 membros e mais de 2000 seções críticas, seria economicamente impossível realizarem-se estes cálculos, o que requer simplificações na obtenção do produto EI.

É muito comum utilizar-se a inércia bruta em análises de estruturas. Na verdade, como foi visto, a fissuração do concreto e os outros fatores, acarretam alterações não desprezíveis na rigidez dos membros da estrutura e o comportamento não-linear dos materiais provoca reduções de segurança contra instabilidade. Deve-se portanto, tentar aproximar-se do valor real da rigidez para que os deslocamentos calculados sejam bem estimados; o valor da rigidez EI deve refletir a presença da armadura, a extensão de fissuração, a influência das forças axiais, o efeito da deformação lenta e o comportamento inelástico do aço e do concreto.

Diversos estudos foram realizados com a intenção de simplificar a consideração da NLF. KORDINA ${ }^{3}$ e HAGE ${ }^{4}$ apud MACGREGOR \& HAGE(1977) estudaram variação da rigidez de vários tipos de membros de pórticos submetidos aos momentos fletores devidos a carregamento vertical, momentos fletores devidos a carregamento horizontal e combinações dos dois casos. MACGREGOR(1993a) concluiu, com base nestes estudos, que constituiria em razoável estimativa de $\mathbf{E I}$, para uma análise de $2^{\underline{a}}$ ordem, basear-se no valor de $\mathbf{E}_{\mathbf{c}}$ de

${ }^{3}$ KORDINA, K. Discussion n.3 - Cracking and crack control. In: INTERNATIONAL CONFERENCE ON PLANNING AND DESIGN OF TALL BUILDINGS, Lehigh University, Bethlehem, USA, Aug., 1972. Proceedings. v.3, p.721-722. apud MACGREGOR, J.G.; HAGE, A.M. (1977). Stability analysis and design of concrete frames. Journal of the Structural Division(ASCE), v.103, $\mathrm{n}_{\star} \mathrm{ST} 10$, p.1953-1970, Oct.

${ }^{4}$ HAGE, S. E. The second-order analysis of reinforced concrete frames. Edmonton, Canadá, 1974. Thesis (Master of Science)-University of Alberta. apud MACGREGOR, J.G.; HAGE, A.M. (1977). 
deformação longitudinal do concreto dado pelo American Concrete Institute (ACI) Committee 318-83(1986), $I=\mathbf{0 , 4} I_{c}$ para as vigas $\mathbf{I}=\mathbf{0 , 8} I_{c}$ para os pilares.

HAGE \& MACGREGOR ${ }^{5}$ apud MACGREGOR(1993a) estudaram a variação do EI efetivo em vigas T sob carregamento vertical. Para pequenos valores de carga, o EI efetivo excede ligeiramente o $\mathbf{E}_{\mathbf{c}} \mathbf{I}_{\mathbf{c}}$ devido à presença da armadura. À

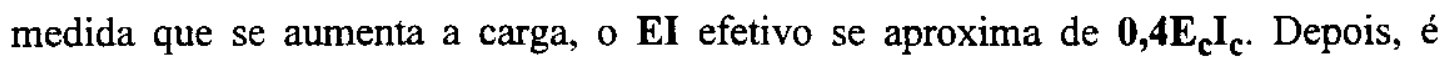
comparado o EI efetivo para vigas submetidas a esforços devidos à ação horizontal e para a combinação das cargas vertical e horizontal. Novamente nesses dois casos, o EI efetivo se aproxima de $\mathbf{0}, \mathbf{4 E _ { c }} \mathbf{I}_{\mathbf{c}}$ à medida que a carga é aumentada. São obtidos posteriormente os valores efetivos de EI para pilares através dos deslocamentos laterais de pórticos de concreto armado em testes de laboratório. A partir destes resultados é que são sugeridos os valores de rigidezes $\mathbf{0 , 4 E _ { c }} \mathbf{I}_{\mathbf{c}}$ para vigas e $\mathbf{0 , 8 E _ { c }} \mathbf{I}_{\mathbf{c}}$ para pilares. Entretanto, no decorrer de seu trabalho (que objetiva propor algumas mudanças ao ACI Building Code), MACGREGOR(1993a) introduz um fator de redução de resistência $\varphi$, a ser incluído na análise de segunda ordem, que conta com a variabilidade nos deslocamentos laterais resultante das simplificações do modelo adotado para a estrutura. Sugere que $\varphi$ seja igual a $\mathbf{0 , 8 7 5}$, o que resulta em

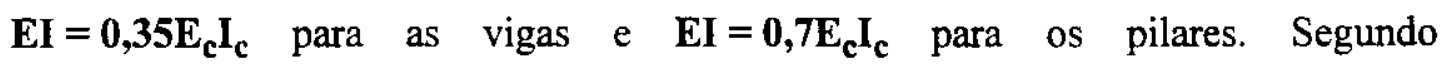
FRANCO(1995), a consideração dessa redução adicional parece ser excessivamente conservadora, não sendo levada em conta nos valores adotados pela NB1/1994(ABNT), expostos a seguir.

Para a consideração da NLF, a NB-1/1994 (ABNT), em seu texto provisório,

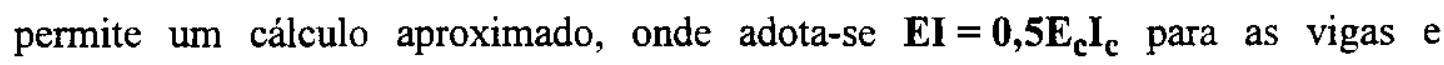

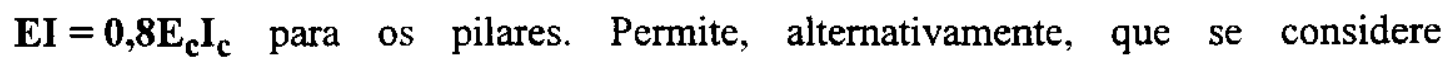

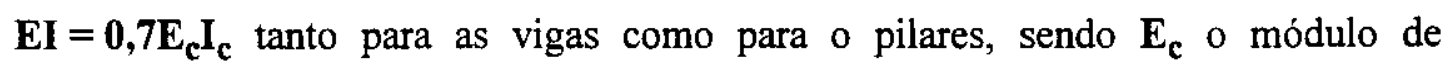
deformação longitudinal do concreto à compressão, no início da curva tensãodeformação. De acordo com SANTOS \& FRANCO(1994), estes são valores aproximados e dependem da distribuição da armadura na seção da peça.

MACGREGOR(1993a) menciona diversas outras pesquisas feitas para determinar um valor representativo de EI a ser adotado numa análise de $2 \underline{a}$ ordem $\mathrm{e}$ os resultados são variados. Acredita-se que existe, portanto, uma tendência junto aos

\footnotetext{
${ }^{5}$ HAGE, S. E.; MACGREGOR, J.G. Second order analysis of reinforced concrete frames. Edmonton, University of Alberta, Departament of Civil Engineering, Oct., 1974. 331p. (Structural Engineering Report n.9). apud MACGREGOR, J.G. (1993a). Design of slender concrete columns: Revisited. ACI Structural Journal, v.90, n.3, p.302-309, May-Jun.
} 


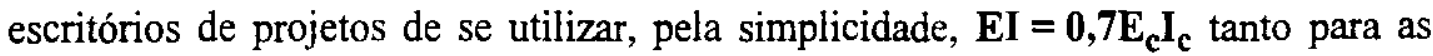
vigas como para o pilares.

Para ilustrar a variabilidade dos resultados obtidos para três dos valores sugeridos acima para $\mathbf{E}_{\mathbf{c}} \mathbf{I}_{\mathbf{c}}$, realizou-se, utilizando-se o programa PPLAN4(1991) ${ }^{6}$, o cálculo dos deslocamentos horizontais dos nós para dois exemplos (Fig. 13): o primeiro exemplo tratava-se de um pórtico plano de dezoito pavimentos, com seções dos pilares e vigas constantes até o topo; o segundo exemplo tratava-se de uma associação do pórtico anterior a uma parede de mesma altura e de seção também constante. Ambas as estruturas foram submetidas a uma força lateral uniformemente distribuída ao longo de sua altura.

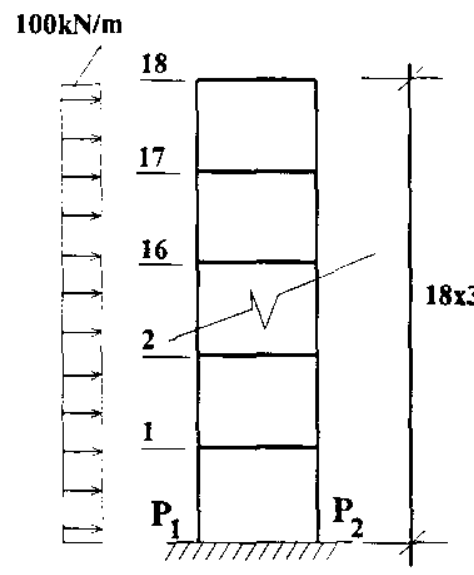

(a)

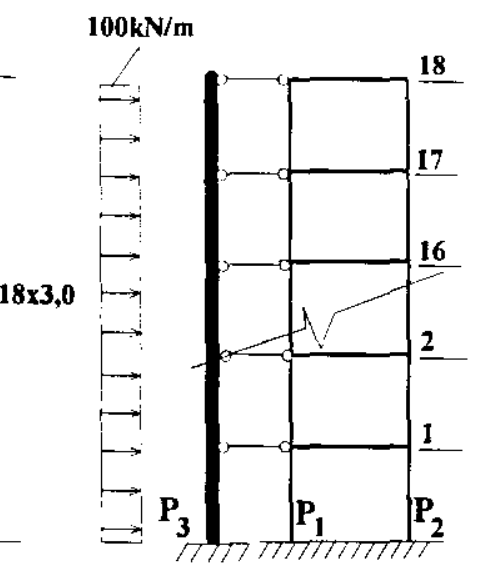

(b)
Vigas: $20 / 50$

Barras bi-rotuladas: $15 / 100$

Pilares $P_{1}$ e $P_{2}: 20 / 150$

Parede $P_{3}: 20 / 300$

FIGURA 13 - Exemplos Utilizados na Comparação dos Diversos Valores Sugeridos de Redução da Rigidez EI para a Consideração da NLF.

Consideraram-se três variações na redução do momento de inércia: na primeira variação (I), $\mathbf{E I}=\mathbf{0 , 7} \mathbf{E}_{\mathbf{c}} \mathbf{I}_{\mathbf{c}}$ para vigas e pilares, na segunda variação (II),

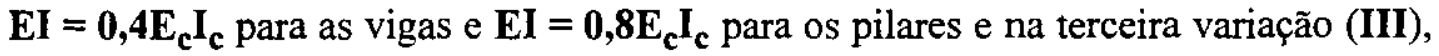

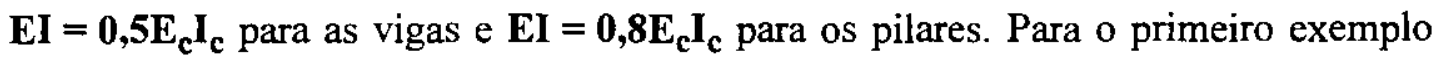
(pórtico - Fig. 13-a), a flecha no topo obtida para a segunda variação foi em torno de $44 \%$ maior que a obtida na primeira variação, e $16 \%$ maior (obviamente) que a flecha obtida para a terceira variação. Esta última também apresentou flecha no topo maior que a obtida na primeira variação em $23 \%$. Para o segundo exemplo (associação pórtico-parede - Fig. 13-b), a flecha no topo calculada para a segunda variação superou em $26 \%$ a flecha obtida na primeira variação, e foi novamente maior que a 
flecha obtida para a terceira variação em $11 \%$. A terceira variação apresentou flecha no topo $13 \%$ maior que a obtida na primeira variação. Apresenta-se abaixo (Tab. 3) um resumo dos resultados obtidos:

\section{TABELA 3 - Comparação entre Valores da Flecha no Topo para as Três Variaçōes de Redução do Produto EI}

\begin{tabular}{|c|c|c|c|c|}
\hline Variaçóes & \multicolumn{2}{|c|}{ Pórtico } & \multicolumn{2}{c|}{ Pórtico + Parede } \\
\hline \hline I & 1,00 & 0,81 & 1,00 & 0,89 \\
\hline II & 1,44 & 1,16 & 1,26 & 1,11 \\
\hline III & 1,23 & 1,00 & 1,13 & 1,00 \\
\hline
\end{tabular}

Este exemplo mostra ainda como a consideração da contribuição das vigas no sistema de contraventamento influencia nos resultados finais (ver subitem e). Usavase, anteriormente, desprezar esta contribuição, levando em conta apenas os pilares, núcleos, paredes, etc. naquele sistema. A introdução do conceito de rigidez equivalente (ver item 3.5.1) é um dos procedimentos que podem evitar o desprezo de tal contruibuição.

Outros comentários serão feitos no item 3.6.4 sobre estes valores de redução da inércia sugeridos, onde, através da utilização de um exemplo de estrutura tridimensional, verifica-se a variação dos resultados dos efeitos de segunda ordem obtidos.

\section{c) Efeitos Globais e Locais de Segunda Ordem}

Define-se por Efeitos Globais de Segunda Ordem aos esforços de segunda ordem decorrentes do deslocamento lateral dos nós da estrutura submetida às ações verticais e horizontais. Os Efeitos Locais de Segunda Ordem por sua vez, surgem nos elementos da estrutura, afetando somente os esforços solicitantes ao longo de seus comprimentos, devido aos deslocamentos dos diversos pontos de seus eixos. 


\section{d) Classificação das Estruturas}

As estruturas são classificadas em estruturas de nós fixos e estruturas de nós móveis.

d.1) Estruturas de nós fixos

As estruturas onde os Efeitos Globais de Segunda Ordem são inferiores a $10 \%$ dos respectivos esforços de primeira ordem, são chamadas estruturas de nós fixos. Nestas estruturas deverão, entretanto, ser analisados os Efeitos Locais de Segunda Ordem.

d.2) Estruturas de nós móveis

As estruturas onde os deslocamentos horizontais são expressivos propiciando o surgimento de Efeitos Globais de Segunda Ordem superiores a 10\% dos respectivos esforços de primeira ordem, são chamadas estruturas de nós móveis. Deve-se obrigatoriamente considerar tanto os Esforços de Segunda Ordem Globais como os Locais na análise dessas estruturas.

\section{e) Sub-Estruturas de Contraventamento e Elementos Contraventados}

Sub-Estruturas de Contraventamento são as sub-estruturas que possuem grande rigidez a ações horizontais, resistindo, portanto, à maior parte dos esforços decorrentes dessas ações. As caixas de elevadores e escadas e os pilares-paredes de concreto armado são exemplos deste tipo de sub-estrutura. FRANCO \& VASCONCELOS (1991) relatam, com base em sua própria experiência profissional em projetos de edifícios altos, que, mesmo elementos de pequena rigidez contribuem de certa maneira para a estabilidade lateral. Portanto, pode-se considerar que pórticos e outros elementos, em seu conjunto, também fazem parte da sub-estrutura de contraventamento da estrutura a que pertencem. As sub-estruturas de contraventamento podem ser de nós fixos ou de nós móveis.

Elementos Contraventados são os elementos que não participam da subestrutura de contraventamento. 


\section{f) Elementos isolados}

São os únicos considerados pela antiga NB-1/1978 (ABNT) para a verificação da estabilidade. São eles as peças isostáticas, os elementos contraventados, os elementos das sub-estruturas de contraventamento de nós fixos e os elementos das sub-estruturas de contraventamento de nós móveis desde que os esforços de primeira ordem nas extremidades sejam acrescidos dos esforços de segunda ordem.

\section{g) Ações Horizontais}

A ação do vento e as imperfeições geométricas ( desaprumo ) são as principais causas do surgimento de ações horizontais que devem ser consideradas na análise da estabilidade das estruturas. Existem outras ações, como por exemplo, as de origem sísmica e as causadas por vibrações de máquinas, não tratadas neste trabalho. As diversas ações horizontais são às vezes chamadas, de maneira generalizada, ações ou forças devidas ao vento pela literatura sobre o assunto.

A ação do vento nas edificações é considerada pelo cálculo de forças de vento, regido por normas específicas. No Brasil, isto é feito pela NBR-6123/1988 (ABNT).

As imperfeições geométricas podem introduzir excentricidades favoráveis ao tombamento da estrutura. Recomenda-se, normalmente, que se considere um desvio de prumo $\beta=\mathbf{( 1 / 2 0 0 )}$ radianos. Simulando-se a ação de forças horizontais $\left(\mathbf{F H}_{\mathbf{i}}\right)$ aplicadas ao topo de cada pavimento $i$, de modo que elas produzam o mesmo momento provocados pelas ações verticais na base da estrutura (deformada), é uma forma aproximada de se considerar o efeito destas imperfeições. Outra, é modelar a estrutura já considerando o desaprumo. As forças horizontais $\left(\mathbf{F H}_{\mathfrak{i}}\right)$ podem ser calculadas da seguinte forma:

$$
\mathrm{FH}_{\mathrm{i}}=\left(\mathrm{F}_{\mathrm{i}}\right) \operatorname{tg} \beta
$$

onde $\mathbf{F}_{\mathbf{i}}$ é a carga vertical total até o pavimento $\mathbf{i}$. 


\section{4 - RELAÇÃO FLECHA / ALTURA}

Cada vez mais têm-se desenvolvido novos métodos para a determinação das flechas das estruturas e de seus elementos. Entretanto, de acordo com SCANLON \& PINHEIRO(1990), é limitada a literatura que trata de deslocamentos permissíveis e os códigos em vigor possuem prescrições muito limitadas sobre o assunto. Além disso, algumas prescrições são empíricas e baseiam-se essencialmente em experiências passadas. Para o ACI 442R-71(1982) o desiocamento lateral é considerado como um dos principais critérios de utilização no dimensionamento de edifícios altos para as ações laterais. Chama-se particular atenção para os efeitos sobre a estabilidade e a fissuração dos membros.

Os deslocamentos limites são valores práticos utilizados para verificação do Estado Limite de Deformações Excessivas das estruturas, e são normalmente propostos em valores absolutos ou como uma fração do vão considerado. Segundo GALAMBOS et al.(1973), que realizaram excelente e rica pesquisa sobre os desiocamentos permissíveis, atribuiu-se a SPURR $^{7}$ a origem desta forma familiar de limitação, que tem sido usada como guia em dimensionamento para a ação de carga lateral. De acordo com eles, as limitações à inclinação lateral ("lateral drift"), especificadas como frações da altura total da edificação $\mathbf{H}$ pelos diversos regulamentos, códigos e trabalhos de pesquisa, variam desde 1/200 a 1/1200. De 1930 aos dias de hoje, o valor aceitável de a / H tem diminuído de alguma forma, provavelmente por causa das mudanças na tecnologia construtiva e nas características do edificio que ofereciam mais rigidez às estruturas antigas. REED $^{8}$ apud GALAMBOS et al.(1973) observou que a relação a / H tem sido limitada entre $\mathbf{0 , 0 0 1 5}(\cong 1 / 667)$, e $\mathbf{0 , 0 0 3 0}(\cong 1 / 333)$, considerando-se as divisórias de alvenaria apenas de vedação ou contribuinte com a rigidez da estrutura, respectivamente, sendo que estas alvenarias não são levadas em conta como elementos estruturais e que, portanto, não são incluídas no modelo matemático usado para o cálculo dos deslocamentos. Estes valores variam entre 1/300 e 1/600 para o ACI 442R-71(1982) que afirma que, por muitas décadas, foi utilizado o valor de $\mathbf{a} / \mathbf{H}=\mathbf{1 / 3 0 0}$, embora se

\footnotetext{
${ }^{7}$ SPURR, H.V.,Wind bracing, MacGraw-Hill, 1930 apud GALAMBOS,T.V. et al.(1973). Structural deflections: a literatura and state-of-the-art survey. Washington, D.C., Nacional Bureau of Standards, U.S. Departament of Commerce. (Buildings Science Series 47).

${ }^{8}$ REED, J.W., Wind induced motion and human discomfort in tall buildings. Structures publications n.310, Dept. of Civil Engeneering, M.I.T., Cambrige, Mass., Nov., 1971 apud GALAMBOS,T.V. et al.(1973).
} 
considerasse que as forças do vento fossem resistidas apenas pela estrutura reticulada do edifício.

Os limites estabelecidos para que a verificação dos deslocamentos seja realizada foram estabelecidos com base nos principais motivos que os tornam indesejáveis. O COMITÉ EUROPEÉN DU BÉTON (CEB) ${ }^{9}$ apud GALAMBOS et al.(1973) divide os efeitos dos deslocamentos sobre as estruturas naqueles que afetam ou não a sua estabilidade global. Os primeiros efeitos subdividem-se em efeitos estáticos e dinâmicos. Os demais subdividem-se em efeitos psicológicos ou estéticos, efeitos que podem produzir estragos em outras unidades não-estruturais, efeitos indiretos sobre a estabilidade de outros membros estruturais ou estruturas e efeitos dos deslocamentos sobre a utilização da estrutura.

O ACI 435.3R-68(1984) classifica os motivos que tornam os deslocamentos excessivos indesejáveis em quatro e atualmente também o faz a NB-1/1994 (ABNT), em fase de revisão. A NB-1/1994 (ABNT) inclui um capítulo sobre limites para deslocamentos (dentre outros limites), onde explica-se:

"Deslocamentos excessivos e tendência à vibração dos elementos estruturais podem ser indesejáveis por diversos motivos. Esses motivos podem ser classificados em quatro grupos básicos :

a.) Aceitabilidade sensorial. Deslocamentos excessivos podem ser responsáveis por sensações desagradáveis para os usuários da estrutura.(...)

b.) Estrutura em serviço. Os deslocamentos podem impedir a utilização adequada de um sistema estrutural.(...)

c.) Efeitos em elementos não estruturais. Deslocamentos podem ocasionar o mau funcionamento de elementos que, apesar que não fazerem parte da estrutura, estão a ela ligados.(...)

d.) Efeitos em elementos estruturais. Os deslocamentos podem afetar $o$ comportamento do elemento estrutural, provocando afastamento em relação às hipóteses de cálculo adotadas. Se forem relevantes para o elemento considerado, o efeito dos deslocamentos sobre as tensões, sobre a estabilidade da estrutura e a indução de comportamento dinâmico devem ser considerados, pela sua

${ }^{9}$ COMITÉ EUROPEÉN DU BÉTON (CEB). Deformations. Viena, 1959. 5th Session. (Report n.4). apud GALAMBOS,T.V. et al.(1973). 
incorporação ao modelo estrutural adotado. "(NB-1/1994 (ABNT), cap. 13)

Com relação ao motivo a. e analisando-se a estrutura globalmente, o ACI 435.3R-68(1984) alerta que deve-se pesquisar mais sobre a vibração lateral do edifício, causada por rajadas de vento, e as vibrações secundárias causadas pelo deslocamento lateral devido ao vento, a fim de se sugerir limitações com base na aceleração (ou desaceleração) do edifício.

No caso da análise da estrutura como um todo e envolvendo o seu deslocamento lateral, são interessantes os motivos c. e d. Para os efeitos em elementos não-estruturais (motivo c.), limita-se o movimento lateral de edifícios provocado pela ação do vento (rajada de 5 minutos) para que não seja afetado o funcionamento de paredes, esquadrias e etc. A NB-1/1994 (ABNT) e o ACI 435.3R68(1984) sugerem, então, que a flecha no topo do edifício a seja menor ou igual a $H / 500$, sendo $H$ a altura total do edifício, ou que o deslocamento relativo entre pavimentos não seja maior que 4mm ("Este limite aplica-se ao deslocamento lateral entre dois pavimentos consecutivos devido à atuação de ações horizontais. Não se devem incluir os deslocamentos devidos a ações axiais nos pilares. O limite também se aplica para o deslocamento vertical relativo das extremidades de lintéis conectados a duas paredes. "(NB-1/1994 (ABNT), cap. 13)) (Fig. 14).

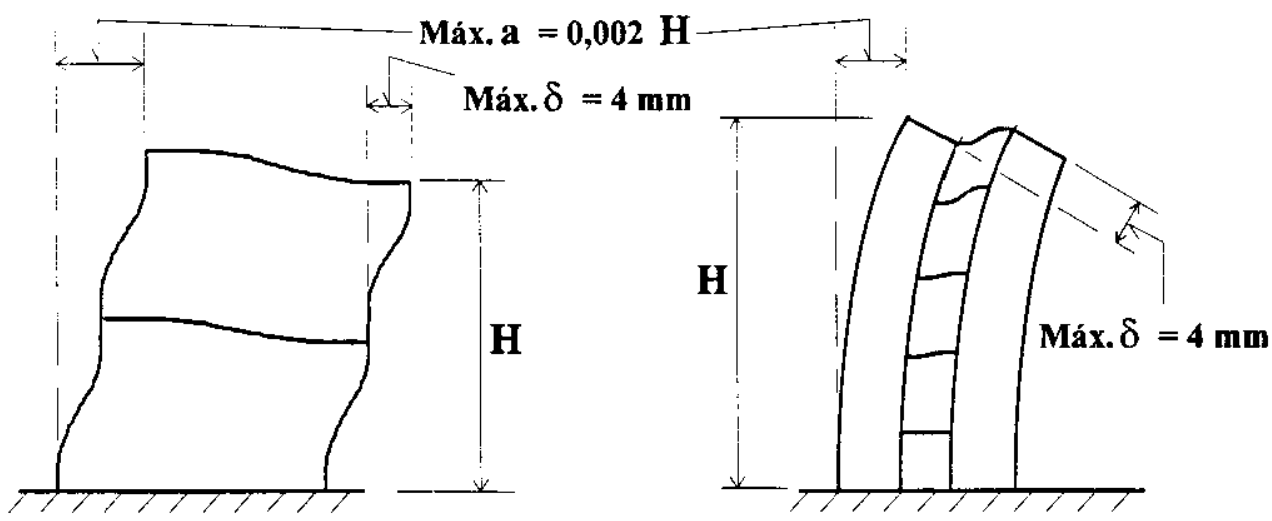

FIGURA 14 - Limitaçōes de Deslocamentos Laterais para Edifícios

Tem-se observado que a simples limitação da flecha total no topo da estrutura pode não ser adequada. Uma limitação adicional de $4 \mathrm{~mm}\left(0,15^{\prime \prime}\right)$ entre pavimentos, como foi visto, é sugerida pelo ACI 435.3R-68(1984) e pela NB-1/1994 (ABNT). 
DAVENPORT ${ }^{10}$ apud GALAMBOS et al.(1973) afirma que fissuração em divisórias de edificio de 40 andares pode ocorrer se o deslocamento relativo entre andares exceder $6 \mathrm{~mm}\left(0,25^{\prime \prime}\right)$.

Com relação aos efeitos em elementos estruturais (motivo d.), no entanto, não é sugerido nenhum valor numérico limite para a inclinação lateral, nem para partes da estrutura, nem para a estrutura como um todo.

O ACI 442R-71(1982) comenta que o desempenho de edifícios modernos recentes, projetados de acordo com o deslocamento limite para a de H/500 recomendado pelo ACI 435.3R-68(1984), vem sendo satisfatório no que diz respeito aos seguintes efeitos do movimento lateral devido à ação de vento:

1) estabilidade de pilares isolados bem como da estrutura como um todo;

2) integridade de divisórias não-estruturais e vidraças;

3) conforto dos ocupantes do edifício.

A relação flecha / altura (a / H) foi largamente utilizada por projetistas como um parâmetro para indicar se a estrutura em análise oferece rigidez suficiente para suportar as ações laterais. É ainda uma prática muito comum realizar-se uma análise da estrutura sob ação de forças horizontais (normalmente só as devidas ao vento) utilizando-se "software" bem elaborado de boa precisão para determinarem-se os valores de flechas no topo da estrutura e calcular a / H. Os demais resultados são rapidamente verificados e muitas vezes com base apenas na experiêcia do projetista. $\mathrm{Na}$ verdade, esta relação trata-se tão somente de um parâmetro de projeto e não de verificação de instabilidade. Entretanto, como foi dito, ainda existe o conceito entre alguns projetistas de que a relação a/H serve de maneira indireta para esta verificação.

Diante do grande número de valores limites para o parâmetro a / H encontrados e sugeridos pelos diversos autores e pesquisadores, observa-se que este tipo de parâmetro pode não ser adequado para a verificação da estabilidade da estrutura. Para efeito de utilização em exemplos, quando for necessário, será utilizada o valor limite mais indicado pelos regulamentos aqui citados: $\mathbf{1 / 5 0 0}$.

\footnotetext{
${ }^{10}$ DAVENPORT, A. G. The treatment of wind loading on tall buildings. In: SYMPOSIUM ON TALL BUILDINGS, Southampton, Apr., 1966. Proceedings. p.1-44. apud GALAMBOS, T.V. et al.(1973).
} 


\subsection{1 - EXEMPLO DE APLICAÇÃO}

Como exemplo do cálculo de $\mathbf{a} / \mathbf{H}$, considere-se a estrutura do edifício residencial SPAZIO UNO de dezessete pavimentos, sendo um pavimento subsolo. As dimensões dos elementos constituintes da estrutura do pavimento-tipo são apresentados em planta na Fig. 15-a e em elevação esquemática na Fig. 15-b. Foi adotado o módulo de elasticidade do concreto $\mathrm{E}_{\mathbf{c}}=3,0 \cdot 10^{7} \mathrm{kN} / \mathrm{m}^{2}$. Realizou-se a análise linear da estrutura submetida à ação do vento, segundo as duas direções principais $\mathrm{X}$ e $\mathrm{Y}$ conforme indicação na Fig. 15-a. Para determinarem-se as forças horizontais devidas à ação do vento de acordo com a NBR-6123/1988 (ABNT) e ao nível de cada pavimento, utilizaram-se os seguintes dados:

- Velocidade básica do vento: $38,0 \mathrm{~m} / \mathrm{s}$

- Classe: B

- Categoria: IV

- Fator topográfico: $\mathrm{S}_{1}=1,0$

- Fator estatístico: $S_{3}=1,0$

Foi utilizado o sistema LASER ${ }^{11}$, para a análise linear, e obtiveram-se os seguintes resultados:

$$
\begin{array}{rr}
\text { Direção } \mathbf{X} \rightarrow \mathbf{a}=0,0602 \mathrm{~m} & \text { Direção } \mathbf{Y} \rightarrow \mathbf{a}=0,0312 \mathrm{~m} \\
\mathbf{a} / \mathbf{H} \cong 1 / 813 & \mathbf{a} / \mathbf{H} \cong 1 / 1570
\end{array}
$$

Observa-se que em nenhuma das direções a relação a/H é maior que 1/500.

${ }^{1}$ O sistema LASER realiza análises lineares de estruturas tridimensionais compostos por barras sob a ação de forças nodais. Será novamente comentado no itens 3.6.1-a e 4.3. 


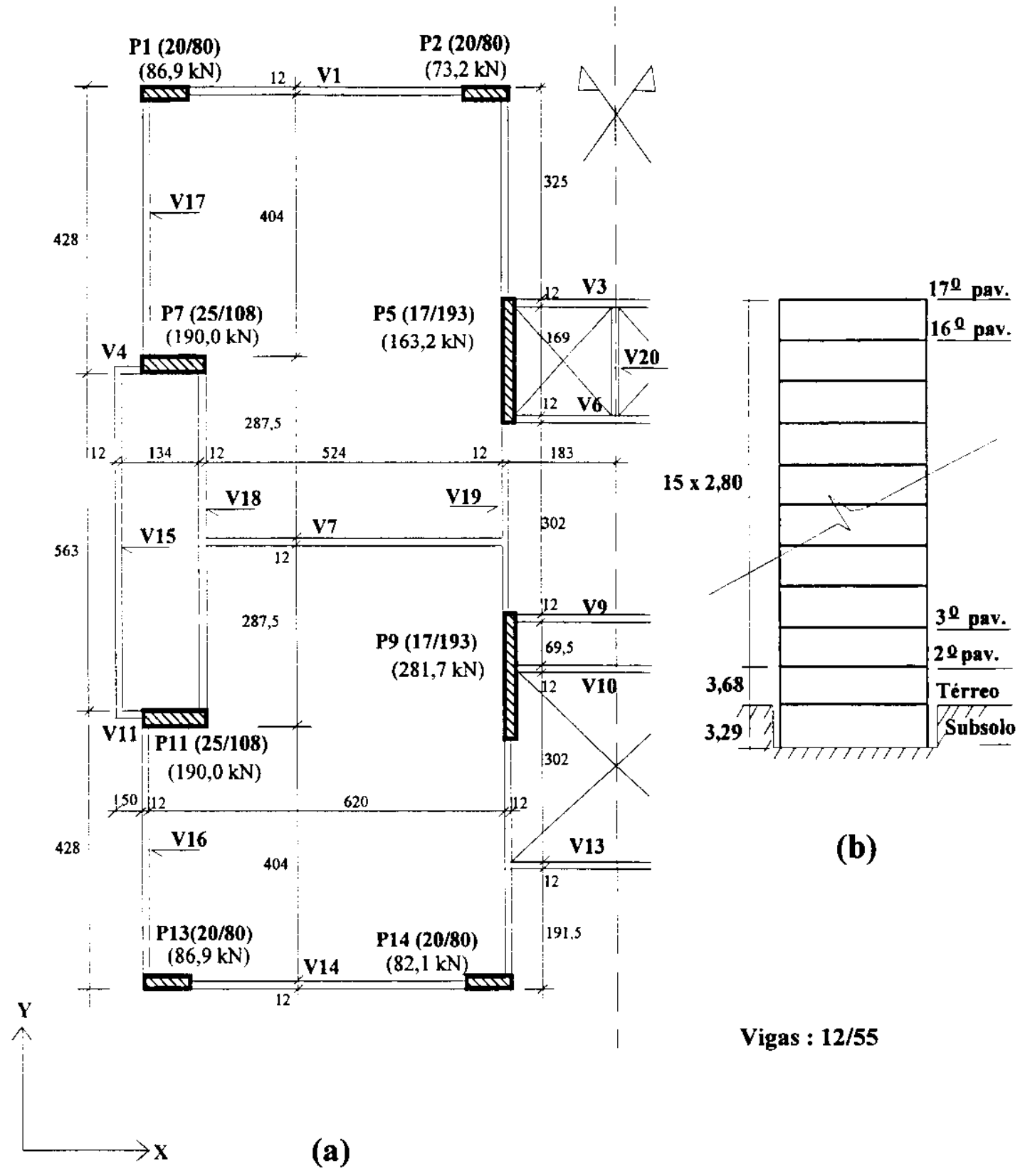

FIGURA 15 - Edifício SPAZIO UNO

(forma do pav. tipo e elevação esquemática) 


\section{5 - PARÂMETROS DE INTABILIDADE GLOBAL}

\subsection{1 - PARÂMETRO $\alpha$}

Conhecido também por Coeficiente de Instabilidade ou Parâmetro de Instabilidade, o parâmetro $\alpha$ foi primeiramente idealizado por BECK \& KÖNIG(1966) como uma grandeza de referência para julgamento da rigidez horizontal da estrutura. Eles tomaram por base a análise de pórticos rotulados contraventados por parede atuante como uma viga vertical em balanço. Em sua expressão, que pode-se obter a partir das Eqs. 6 e 3, sendo $l=H$, são reunidas grandezas que representam alguns dos muitos fatores que influenciam a estabilidade global da estrutura:

$$
\alpha=H \sqrt{\frac{F}{E I}}
$$

onde

$$
\begin{aligned}
& \mathbf{H}=\text { altura total da edificação } \\
& \mathbf{F}=\text { carga vertical total da obra } \\
& \mathbf{E I}=\text { somatório dos produtos de rigidez de todos os pilares do edifício. }
\end{aligned}
$$

A definição de $\alpha$ é válida dentro do regime elástico e pressupõe o sistema de contraventamento da estrutura constituído por pilares-paredes, desprezando-se a influência das vigas. De acordo com esta formulação, o parâmetro $\alpha$ se justifica, na prática, especiaimente no caso de estruturas pré-moldadas, de alvenaria portante ou estruturas com núcleos bastante rígidos. Entretanto, nas estruturas reticuladas existe a solidarização na ligação entre vigas e pilares (nós monolíticos), o que contribui para a diminuição no valor de $\alpha$, uma vez que ocorre um aumento no valor da rigidez ao se considerar que o EI não se refere apenas aos pilares isoladamente. VASCONCELOS(1985) mostra, com o auxílio de gráficos, que $\alpha$ pode ser reduzido em até metade de seu valor apenas alterando-se o momento de inércia das seções transversais das vigas. Pode-se, portanto, chegar ao ponto de evitar-se uma análise de segunda ordem em casos onde esta seria obrigatória. 
Há, porém, dificuldades em se avaliar corretamente o valor de EI, que não corresponde simplesmente à somatória dos produtos do módulo de elasticidade $\mathbf{E}$ pelo momento de inércia I para todos os pilares do sistema de contraventamento.

Pode-se optar por evitar este cálculo e eliminar uma adoção aproximada do valor de EI, substituindo-o pelo cálculo da carga de flambagem $\mathbf{F}_{\mathbf{c r}}$, à qual corresponde, a partir da Eq. 21, um valor $\alpha_{\text {cr }}$ :

$$
\alpha_{c r}=H \sqrt{\frac{F_{\text {cr }}}{E I}}
$$

Extrai-se EI das Eqs. 21 e 22 e igualam-se os resultados obtidos. Intruduzindose o coeficiente $v$, de segurança contra a flambagem global da estrutura, que é tal que:

$$
v=\frac{\mathbf{F}_{\mathbf{c r}}}{\mathbf{F}}
$$

obtém-se

$$
\alpha=\frac{\alpha_{\text {cr }}}{\sqrt{v}}
$$

Através da Eq. 24, válida no regime elástico, e a partir da obtenção de $\mathbf{F}_{\mathbf{c r}}$ por qualquer dos processos conhecidos para este fim, pode-se obter $\alpha$ sem a adoção aproximada de EI. Ou seja, há uma avaliação indireta de EI.

Outra forma de se evitar a adoção errônea do valor EI é interpretando-o como a rigidez equivalente (EI) eq de um pilar único em balanço (Fig. 16-b). Sob a ação de forças horizontais arbitradas, o deslocamento horizontal do topo deste pilar seria imposto igual à flecha a no topo da estrutura em estudo (Fig. 16-a) sob o mesmo carregamento. Se, por exemplo, este carregamento arbitrado for uma carga horizontal uniformemente distribuída q, sabe-se que a flecha no topo vale, para o pilar da Fig. 16-b:

$$
a=\frac{q H^{4}}{8 E I}
$$

donde 


$$
\mathrm{EI}_{\mathrm{eq}}=\frac{\mathbf{q H}}{8 \mathrm{a}}
$$

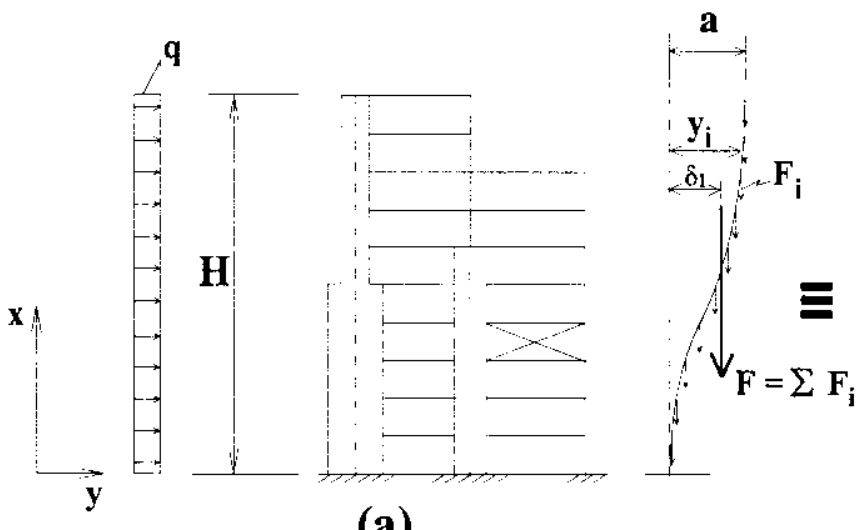

(a)

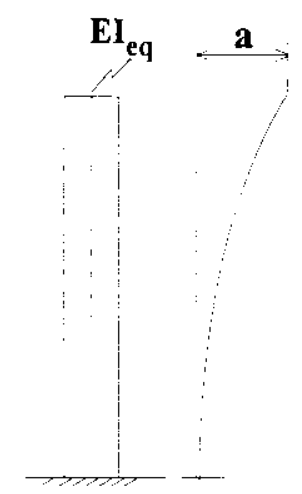

(b)

FIGURA 16 - Produto de Rigidez Equivalente

FRANÇA(1985) realiza comparação de resultados do cálculo de $\alpha$, obtidos utilizando-se o conceito de (EI) $)_{\mathbf{e q}}$, para ação arbitrada como força horizontal uniformemente distribuída ao longo da altura do edifício ou força horizontal concentrada no topo do mesmo. Os resultados, no primeiro caso, correspondem a valores de $\alpha$ um pouco maiores que os obtidos no segundo caso. FRANÇA(1985) considera que o primeiro procedimento parece ser o mais conveniente, principalmente porque as ações horizontais (definidas em 3.3-g) não se concentram no topo da estrutura.

Pode-se reescrever a Eq. 21, adicionando-se o subíndice $\mathbf{k}$ para grandezas características:

$$
\alpha_{k}=H \sqrt{\frac{F_{k}}{(E I)_{e_{k}}}}
$$

Com a introdução da rigidez equivalente $(\mathbf{E I})_{\mathbf{e q}} \mathbf{k}$, pode-se generalizar o cálculo de $\alpha$ para qualquer estrutura.

O parâmetro $\alpha$ é adotado por regulamentos como o COMITÉ EUROINTERNACIONAL DO BÉTON (CEB) (1978) e a NBR-9062/1985 (ABNT). A avaliação da estabilidade da estrutura através do parâmetro $\alpha$ é também considerada pela NB-1/1994 (ABNT), em seu texto provisório, que prescreve, como o 
CEB(1978), que sejam ignorados os efeitos de segunda ordem no dimensionamento da estrutura quando:

$$
\begin{array}{ll}
\alpha_{\mathrm{k}} \leq \mathbf{0 , 2 + 0 , 1 \mathrm { n }} & \text { para } \mathrm{n} \leq 3 ; \\
\alpha_{\mathrm{k}} \leq \mathbf{0 , 6} & \text { para } \mathrm{n} \geq \mathbf{4}
\end{array}
$$

VASCONCELOS(1986), através de seus estudos, obteve os seguintes valores limites para $\alpha_{\mathbf{k}}$ :

$\alpha_{k} \leq \mathbf{0 , 8} \rightarrow$ para estruturas de três pavimentos

$\alpha_{k} \leq \mathbf{0 , 5 5} \rightarrow$ para estruturas de dois pavimentos

$\alpha_{k} \leq \mathbf{0 , 5} \rightarrow$ para estruturas de um pavimento

Os deslocamentos horizontais, e portanto os efeitos de segunda ordem, dependem da forma da linha elástica do edifício, que varia para os diversos tipos de sistemas de contraventamento. Isto pode ser apreciado no trabalho de FRANÇA(1985) que mostra a deformada de três estruturas de diferentes modelos (modelo laje-viga, laje nervurada e laje cogumelo) e sistemas de contraventamento, lançadas para um mesmo projeto arquitetônico. Com base neste argumento, FRANCO(1985a) obteve limites diferentes para $\alpha_{k}$, de acordo com o tipo de contraventamento predominante de cada estrutura. Introduzindo o conceito do parâmetro de forma $\psi$, que é (Fig. 16):

$$
\psi=\frac{\delta_{\mathbf{1 d}}}{\mathbf{a}_{\mathbf{d}}}=\frac{\delta_{\mathbf{1 k}}}{\mathbf{a}_{\mathbf{k}}}
$$

onde $\delta_{1}$ é o deslocamento horizontal de primeira ordem do ponto de aplicação da resultante das cargas verticais $\mathbf{F}$, obteve o valor limite para $\alpha_{\mathbf{k}}$ em função de $\psi$, com base no Critério de Imobilidade, pela relação:

$$
\alpha_{k} \leq \sqrt{\frac{2}{11 \psi}}
$$

para que $\mathbf{M}_{\mathbf{2 d}}$ seja menor ou igual a $1,1 \mathbf{M}_{\mathbf{1 d}}$. Este resultado foi obtido admitindo-se $\left.(\mathbf{E I})_{\mathbf{e q}_{\mathbf{d}}}=\mathbf{0 , 7 ( E I )}\right)_{\mathbf{e q}_{\mathrm{k}}}$ (ver item 3.3-b) e $\mathbf{F}_{\mathbf{d}}=\mathbf{1 , 4} \mathrm{F}_{\mathrm{k}}$ (de acordo com a NB-1/1978$A B N T)$. No intuito de estabelecer valores numéricos limites para $\alpha_{k}$, FRANCO(1985a) agrupou os tipos de estruturas regulares em estruturas de 
contraventamento predominantemente formado por pilares-paredes, por pórticos ou sistemas mistos (pilares-paredes + pórticos ou associações de pilares-paredes). Em seguida, deduziu, sob a hipótese de pequenas rotações, que:

$$
\psi=\frac{1}{\mathbf{H} \cdot \mathbf{a}_{\mathbf{d}}}=\int_{\mathbf{n}}^{\mathbf{H}} \mathbf{y} \cdot \mathbf{d x}
$$

ajustou a deformada de cada um dos três tipos de contraventamento acima citados para parábolas do $49,3 \varrho$ e $2 \varrho$ graus, respectivamente, e chegou aos seguintes parâmetros de forma e limites para $\alpha_{k}$, para estruturas com mais de quatro pavimentos:

$$
\begin{array}{ll}
\psi=\mathbf{0 , 4} & \rightarrow \alpha_{\mathbf{k}} \leq \mathbf{0 , 7} \text { contraventamento em pilares-parede; } \\
\psi=\mathbf{0 , 6 7} & \rightarrow \alpha_{\mathbf{k}} \leq \mathbf{0 , 5} \text { contraventamento em pórticos; } \\
\psi=\mathbf{0 , 5} & \rightarrow \alpha_{\mathbf{k}} \leq \mathbf{0 , 6} \text { contraventamento misto. }
\end{array}
$$

No início do artigo, FRANCO(1985a) demonstra como se obteve o valor limite para $\alpha_{\mathrm{k}}$ de acordo com a Eq. 21 sugerida pelo CEB(1978), porém utilizando o fator de carga $\gamma_{f}=1,4$ prescrito pela NB-1/1978 (ABNT). Este valor coincide com o $\alpha_{\mathbf{k}_{\text {lim }}}=\mathbf{0 , 7}$ para contraventamento em pilares-parede.

Conhecendo-se o deslocamento lateral de cada pavimento $\mathbf{y}_{\mathbf{i k}}$ e a carga vertical $\mathbf{F}_{\mathbf{i k}}$ de cada pavimento i, pode-se reescrever a Eq. 28 :

$$
\psi=\frac{\sum_{\mathbf{i = 1}}^{\mathbf{n}} \mathbf{F}_{\mathrm{id}} \cdot \mathbf{y}_{\mathrm{id}}}{\mathbf{a}_{\mathbf{d}} \cdot \mathbf{F}_{\mathbf{d}}}=\frac{\sum_{\mathbf{i}=1}^{\mathbf{n}} \mathbf{F}_{\mathrm{ik}} \cdot \mathbf{y}_{\mathbf{i k}}}{\mathbf{a}_{\mathbf{k}} \cdot \mathbf{F}_{\mathbf{k}}}
$$

Com relação à carga $\mathbf{F}_{\mathbf{k}}$, componente da $\mathbf{E q . ~ 2 7 , ~ c o m o ~ f o i ~ d i t o , ~ e l a ~ c o r r e s p o n d e ~}$ ao somatório de todo o carregamento ou reação vertical existente na estrutura. Estudos feitos por BECK \& KÖNIG(1966) e por VASCONCELOS(1985), dentre outros, através da introdução do conceito de Força de Confinamento $(\boldsymbol{H}$, de acordo com sua notação), mostram que não importa para a estabilidade da estrutura, ou para o cálculo dessas forças, qual a distribuição da carga giobal $\mathbf{F}_{\mathbf{k}}$ entre os pilares (contraventados ou de contraventamento). Estas Forças de Confinamento são tais que, uma vez determinadas e adicionadas ao carregamento horizontal externo original, permitem calcular o pórtico com efeito de $2 \underline{a}$ ordem, pois, aplicadas ao 
sistema indeformado, elas têm o mesmo efeito que as cargas verticais aplicadas ao sistema deformado. Elas substituem, para efeito de cálculo de momentos fletores (não de esforços cortantes), o efeito do deslocamento do eixo da estrutura. No trabalho de VASCONCELOS(1985), por exemplo, é apresentado o exemplo de um pórtico plano simples de um só pavimento (Fig. 17), e posteriormente, pórticos planos de 2 e 3 pavimentos. Através de um fator $\mathbf{m}=\mathbf{P} / \mathbf{V}$, que relaciona a carga vertical $\mathbf{P}$ do pilar $\mathbf{P}_{\mathbf{2}}$ que escora e a carga vertical $\mathbf{V}$ do pilar escorado $\mathbf{P}_{\mathbf{1}}$, representa através de gráficos os valores achados para a relação entre a força de confinamento e a ação externa ( $H / W$, de acordo com a sua notação) "versus" $\alpha$ para os extremos $\mathbf{m}=\mathbf{0}$ (ou seja, $\mathbf{P = 0}$ ) e $\mathbf{m}=\infty$ (ou seja, $\mathbf{V = 0}$ ). Verifica, então, que as duas curvas são bem próximas e que esta aproximação aumenta à medida que cresce o número de pavimentos. Ele afirma, com base nestes gráficos que, para mais de 4 pavimentos, pode-se considerar exata a hipótese de se admitir que a força vertical total $(\mathbf{P}+\mathbf{V})$ é aplicada apenas no pilar que escora $\mathbf{P}_{2}$; os efeitos de segunda ordem são praticamente independentes do arranjo físico das cargas verticais de um mesmo pavimento.

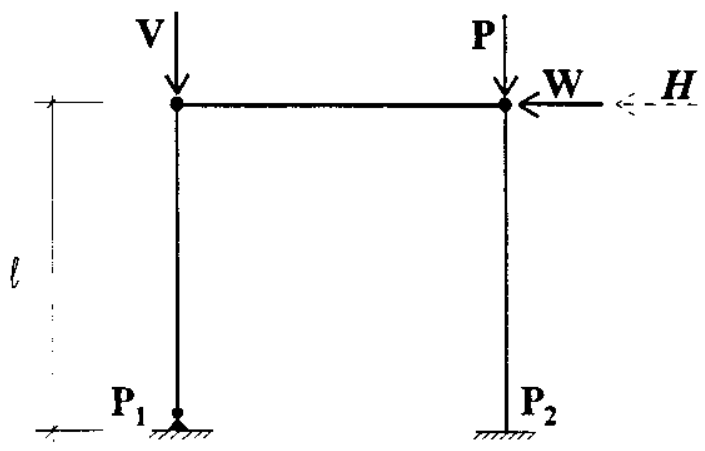

FIGURA 17 - Modelo de Um Pavimento Utilizado na Avaliaçāo da Influência da Distribuiçāo das Ações Verticais Entre os Pilares da Estrutura (notação utilizada por VASCONCELOS(1985)).

Nos tempos passados, evitava-se o cálculo dos efeitos de segunda ordem por causa das dificuldades inerentes ao processo, como, por exempio, a existência e disponibilidade de poucos equipamentos eficientes. Buscava-se uma forma prática de se considerar estes efeitos, o que procurou-se fazer através da utilização de um coeficiente multiplicativo $\mathbf{k}$ das ações horizontais, constante ao longo da altura da edificação. Foi inicialmente sugerido, para estruturas com quatro pavimentos ou mais, que:

$$
k=\frac{1}{1,275\left(\frac{7,837}{\alpha^{2}}-1\right)}
$$


sendo, a partir das Eqs. 19 e 24:

$$
\alpha=\frac{2,80}{\sqrt{v}}
$$

Ou seja, neste caso, considera-se que $\alpha_{\mathrm{cr}}=\mathbf{2 , 8}$, como foi visto em 3.3-a.

Observa-se na Eq. 31 que:

$$
\begin{array}{llll}
\alpha=\mathbf{2 , 8} & \Rightarrow & \mathbf{k} \rightarrow \infty & \text { e a estrutura se instabiliza em serviço; } \\
\alpha=\mathbf{0 , 6} & \Rightarrow & \mathbf{k} \cong \mathbf{1 , 0 0} & \text { e não há acréscimo significativo; } \\
\alpha=\mathbf{0 , 9} & \Rightarrow & \mathbf{k} \cong \mathbf{1 , 1 0} &
\end{array}
$$

A NBR-9062/1985 (ABNT) adota um coeficiente de majoração das ações horizontais semelhante a $k$. Porém, segundo VASCONCELOS(1987), a Eq. 31 somente é eficiente para estruturas com mais de 20 pavimentos. Ele atribui o erro à transformação do reticulado discreto da estrutura em contínuo para a obtenção das expressões envolvidas. Este procedimento, além disso, introduz uma resultante não nuia na fundação. Ou seja, a utilização da majoração das ações por $\mathbf{k}$ constante objetiva simular os efeitos da ação vertical sobre a estrutura deformada, o que não ocorre, entretanto, na base do edifício. A expressão de $\mathbf{k}$ fornece resultados a favor da segurança, pois utiliza um modelo de pórtico formado por dois pilares (o primeiro representa os pilares contraventados e o segundo, os pilares de contraventamento da estrutura) ligados por vigas a cada pavimento, cujas rigidezes são desprezadas. $\mathrm{O}$ procedimento correto, portanto, seria escolher um valor de $\mathbf{k}$ para cada pavimento da estrutura, de modo que se conduza à obtenção de uma resultante adicional nula na fundação.

Através do estudo de um pórtico de quatro pavimentos, considerando o modelo reticulado discreto, VASCONCELOS(1986), chega a uma expressão para $\mathbf{k}$ melhorada, porém ainda constante ao longo da altura total da edificação para cada caso, a partir das forças de confinamento:

$$
\mathbf{k}=1+\frac{1}{\mathrm{C}\left[\left(\frac{{\frac{\alpha_{\mathrm{cr}}}{\bar{\alpha}}}^{2}}{\alpha}-1\right] \gamma_{f 1}\right.}
$$


válida para $\bar{\alpha} \leq 1,3$, onde

$$
\bar{\alpha}=\alpha_{\text {cr }} / \sqrt{\bar{v}}
$$

e $\bar{v}$ é obtido a partir da Eq. 23 para as cargas de serviço multiplicadas pelo fator parcial de segurança $\gamma_{f l}$, definido no item 3.3-b; $C$ é dado na Tab. 4 em função do número de pavimentos $\mathbf{n}$. A equação empírica:

$$
\alpha_{c r}=2,8-1,1 \cdot e^{-0,22 n}
$$

fornece $\alpha_{\mathrm{cr}}$ para qualquer $\mathrm{n}>1$, e só atinge o valor de 2,8 para $\mathrm{n}$ muito grande (maior que 20). Estes resultados somente são válidos para estruturas com pilares de seção constante até o topo e de cargas concentradas iguais ao longo de sua altura.

$\mathrm{O}$ parâmetro $\alpha$, mesmo generalizado para qualquer estrutura através do conceito de produto de rigidez equivalente, em alguns casos pode não ser tão simples de ser utilizado no cálculo dos esforços de segunda ordem. Para chegar ao coeficiente de majoração das ações k pela Eq. 32, precisa-se, primeiramente, realizar uma análise de primeira ordem da estrutura submetida a carregamento horizontal arbitrado qualquer para determinar o (EI) $\mathbf{e q}_{\mathbf{k}}$. Obtém-se, assim, o valor de $\alpha$. Segue-se que, para calcular-se $\bar{v}$, é preciso determinar $\mathbf{F}_{\text {cr }}$ por qualquer processo (nolmalmente trabalhoso) e ainda $\alpha_{c r}$ é calculado por uma equação empírica. Enfim, para se obter os esforços finais que incluem os de segunda ordem, é necessário que, após realizados todos os cálculos aqui citados, uma nova análise estrutural linear seja realizada para as ações majoradas por $\mathbf{k}$. Nota-se, facilmente, o desconforto desse procedimento.

TABELA 4 - Valores de C

\begin{tabular}{|c|c|}
\hline $\mathbf{n}$ & $\mathbf{C}$ \\
\hline $\mathbf{1}$ & 0,50 \\
\hline 2 & 0,77 \\
\hline 3 & 0,91 \\
\hline 4 & 1,00 \\
\hline 5 & 1,06 \\
\hline 10 & 1,16 \\
\hline 20 & 1,22 \\
\hline$>20$ & 1,27 \\
\hline
\end{tabular}




\subsubsection{1 - EXEMPLO DE APLICAÇÃO}

Considere-se o mesmo exemplo da Fig. 15. Para o cálculo do parâmetro $\alpha$, arbitrou-se uma ação horizontal uniformemente distribuída ao longo da altura da estrutura $\mathbf{q}_{\mathbf{k}}=100,0 \mathrm{kN} / \mathrm{m}$. Para efeito de utilização do sistema LASER, esta ação foi substituída por forças concentradas ao nível de cada piso. Cada pavimento suporta, entre cargas acidentais e permanentes, $\mathbf{F}_{\mathbf{i k}}=2308,0 \mathrm{kN} / \mathrm{m}$, em valor característico, 0 que dá um total de $\mathbf{F}_{\mathbf{k}}=17 \times 2308,0=39236,0 \mathrm{kN}$ na fundação. Após uma análise linear, obtêm-se os resultados:

\section{Direção X :}

flecha no topo:

$$
\mathbf{a}_{\mathrm{k}}=0,4337 \mathrm{~m}
$$

rigidez equivalente:

$$
\mathbf{E I}_{\mathbf{e q}_{\mathbf{k}}}=\frac{\mathbf{q}_{\mathbf{k}} \mathbf{H}^{4}}{\mathbf{8 a}_{\mathbf{k}}}=\frac{100 \cdot(48,97)^{4}}{8 \cdot 0,4337}=165.745 .217,8960 \mathrm{kNm}^{2}
$$

parâmetro $\alpha$ :

$$
\alpha_{\mathbf{k}}=\mathbf{H} \sqrt{\frac{\mathbf{F}_{\mathbf{k}}}{(\mathbf{E I})_{\mathbf{e q}_{\mathbf{k}}}}}=48,97 \sqrt{\frac{39236,0}{165.745 .217,896}}=0,75
$$

\section{Direção Y :}

flecha no topo:

$$
a_{k}=0,1844 \mathrm{~m}
$$

rigidez equivalente:

$$
\mathbf{E I}_{\mathbf{e q}_{\mathbf{k}}}=\frac{\mathbf{q}_{\mathbf{k}} \mathbf{H}^{\mathbf{4}}}{\mathbf{8} \mathbf{a}_{\mathbf{k}}}=\frac{100 \cdot(48,97)^{4}}{8 \cdot 0,1844}=389.824 .842,7410 \mathrm{kNm}^{2}
$$

parâmetro $\alpha$ :

$$
\alpha_{\mathbf{k}}=\mathbf{H} \sqrt{\frac{\mathbf{F}_{\mathbf{k}}}{(\mathbf{E I})_{\mathbf{e q}_{\mathbf{k}}}}}=48,97 \sqrt{\frac{39236,0}{389.824842,7410}}=0,49
$$


De acordo com o CEB(1978), deveria ser realizada uma análise de $2^{a}$ ordem, pois, para a direção $\mathbf{X}$, o valor de $\alpha_{\mathbf{k}}$ é maior que 0,60 .

Aproveitando-se para calcular o parâmetro de forma $\psi$ da elástica da estrutura, tem-se:

Direção X :

somatório dos deslocamentos de cada pavimento i:

$$
\Sigma \mathbf{y}_{\mathrm{ik}}=4,5516 \mathrm{~m}
$$

parâmetro de forma:

$$
\psi=\frac{\mathbf{F}_{\mathbf{i k}} \sum \mathbf{y}_{\mathbf{i k}}}{\mathbf{a}_{\mathbf{k}} \cdot \mathbf{F}_{\mathbf{k}}}=\frac{2308,0 \cdot 4,5516}{0,4337 \cdot 39236,0}=0,62
$$

Direção Y :

somatório dos deslocamentos de cada pavimento i:

$$
\Sigma \mathbf{y}_{\mathbf{i k}}=1,9169 \mathrm{~m}
$$

parâmetro de forma:

$$
\psi=\frac{\mathbf{F}_{\mathbf{i k}} \sum \mathbf{y}_{\mathbf{i k}}}{\mathbf{a}_{\mathbf{k}} \cdot \mathbf{F}_{\mathbf{k}}}=\frac{2308,0 \cdot 1,9169}{0,1844 \cdot 39236,0}=0,61
$$

Em ambas as direções, verifica-se que os parâmetros de forma, neste caso, são aproximadamente iguais e enquadram a estrutura entre estruturas de contraventamento predominantemente formado por pórticos $(\psi=0,67)$ e estruturas de contraventamento misto (de $\psi=0,5$ ). Portanto, o $\alpha_{\mathrm{k}_{\mathrm{lim}}}$ estaria entre 0,5 e 0,6. Calculando-se diretamente a partir da Eq. 29, obtém-se $\alpha_{\mathbf{k}_{\mathbf{l i m}}}=0,54$. Ainda assim a estrutura é de nós móveis na direção $\mathbf{X}$.

Aproveita-se, também, para efetuar o cálculo do majorador de ações $\mathbf{k}$ pela Eq. 31:

Direção X :

$$
\mathbf{k}=\frac{1}{1,275\left(\frac{7,837}{\alpha^{2}}-1\right)}=\frac{1}{1,275\left(\frac{7,837}{0,75^{2}}-1\right)}=1,06
$$


Direção Y :

$$
k=\frac{1}{1,275\left(\frac{7,837}{\alpha^{2}}-1\right)}=\frac{1}{1,275\left(\frac{7,837}{0,49^{2}}-1\right)}=1,02
$$

Estes valores de $\mathbf{k}$, como se pode ver, não são muito expressivos e, de acordo com o que foi dito, deve ser multiplicado pelas ações horizontais. Feito isto, uma nova análise de $1^{a}$ ordem deve ser feita na estrutura para se obter os esforços totais, que incluem os de 2 a ordem.

\subsection{2 - PARÂMETRO $\gamma_{\mathrm{z}}$}

O parâmetro $\gamma_{\mathbf{z}}$ surgiu do empenho de pesquisadores em obter um método mais simples de se detectar se a estrutura é de nós móveis ou fixos, sem ter que realizar uma análise de segunda ordem, além de estimar, com boa aproximação, os esforços de segunda ordem, quando relevantes. Com a intenção de simplificar o processo de obtenção dos esforços de segunda ordem, uma vez detectada a sensibilidade da estrutura ao movimento lateral, FRANCO \& VASCONCELOS(1991) apresentaram o parâmetro $\gamma_{\mathbf{Z}}$ como um coeficiente majorador dos esforços globais de primeira ordem para obter os esforços finais que incluem os de segunda ordem.

Suponha-se que, partindo de uma análise linear para as ações horizontais, sejam calculados o momento de primeira ordem $\mathbf{M}_{1}$ em relação à base do edificio e os deslocamentos horizontais dos nós da estrutura. A presença destes deslocamentos em combinação com as ações verticais provocará o aparecimento de acréscimos de momento $\Delta \mathbf{M}_{2}$ (na primeira análise, $\mathbf{M}_{1}$ é o próprio $\Delta \mathbf{M}_{1}$ ) e geram, também, novos desiocamentos. Segue-se assim sucessivamente por várias etapas (chamadas iterações), gerando-se acréscimos de momento (que aqui está representando os esforços em geral) que diminuem até se tornarem praticamente nulos, se a estrutura for estável. Obtém-se, assim, o momento final $\mathbf{M}_{\mathbf{2}}$, incluindo o de de segunda ordem, que é tal que (ver Fig. 18):

$$
\mathbf{M}_{2}=\mathbf{M}_{1}+\Delta \mathbf{M}_{2}+\Delta \mathbf{M}_{3}+\ldots+\Delta \mathbf{M}_{\mathbf{j}}
$$


onde $\mathbf{j}$ é o número de iterações. Como sugere o CEB(1978), admitindo-se que os momentos $\mathbf{M}_{1}, \Delta \mathbf{M}_{2}, \Delta \mathbf{M}_{3}$, etc. constituam uma progressão geométrica decrescente de razão $r^{\prime} \leq 1$, tal que:

$$
r^{\prime}=\frac{\Delta \mathbf{M}_{2}}{\Delta \mathbf{M}_{1}}=\frac{\Delta \mathbf{M}_{3}}{\Delta \mathbf{M}_{2}}=\ldots \frac{\Delta \mathbf{M}_{\mathrm{j}}}{\Delta \mathbf{M}_{\mathrm{j}-1}}
$$

donde $\Delta \mathbf{M}_{\mathrm{j}}=\boldsymbol{r}^{\prime} \cdot \Delta \mathbf{M}_{\mathrm{j}-1} \cdot$ A Eq. 33 torna-se, então:

$$
\mathrm{M}_{2}=\left(1+r^{\prime}+r^{\prime 2}+r^{\prime 3}+\ldots+r^{\prime j-1}\right) \mathrm{M}_{1}
$$

\section{$\mathbf{M}$}

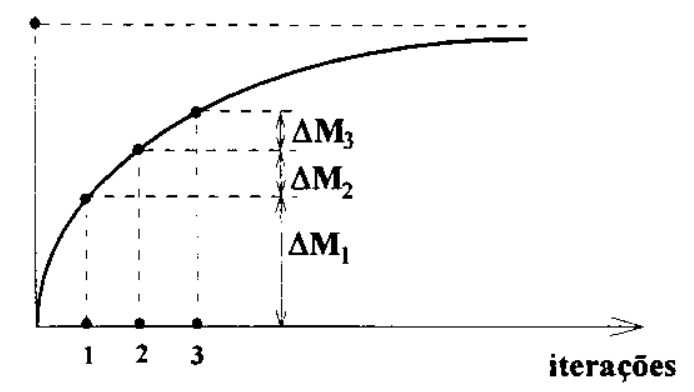

FIGURA 18 - Determinação do Coeficiente $\gamma_{z}$

A soma da progressão do segundo membro da Eq. 34 vale, no limite para $\mathbf{j}$ tendendo ao infinito:

$$
\lim _{j \rightarrow \infty}\left(1+r^{\prime}+{r^{2}}^{2}+r^{3}+\ldots r^{j-1}\right) M_{1}=\frac{1}{1-r^{\prime}} M_{1}
$$

A razão $r^{\prime}=\Delta \mathbf{M}_{\mathbf{j}} / \Delta \mathbf{M}_{\mathbf{j}-1}$ pode ser escrita simplesmente como $r^{\prime}=\Delta \mathbf{M} / \mathbf{M}_{1}$, pois, considerando-se $\mathbf{j}$ como a $1 \underline{\mathrm{a}}$ análise linear, tem-se que $\Delta \mathbf{M}_{\mathbf{j}}=\Delta \mathbf{M}_{\mathbf{2}}=\Delta \mathbf{M}$ e $\Delta \mathbf{M}_{\mathbf{j}-\mathbf{1}}=$ $\Delta \mathbf{M}_{1}=\mathbf{M}_{1}$. A Eq. 34 fica, em valores de cálculo:

$$
M_{2 d} \cong \frac{1}{1-\Delta M_{d} / M_{1 d}} M_{1 d}
$$

Chamando-se de $\gamma_{\mathbf{z}}$ a fração do segundo membro da Eq. 35, estará satisfeito o Critério de Imobilidade (Eq. 17) toda vez que: 


$$
\gamma_{\mathrm{z}} \leq 1,10
$$

sendo

$$
\gamma_{\mathrm{z}} \cong \frac{1}{1-\Delta \mathbf{M}_{\mathrm{d}} / \mathrm{M}_{1 \mathrm{~d}}}
$$

Então, em estruturas regulares, pode-se obter $\gamma_{\mathbf{z}}$, com boa aproximação, partindo de uma única análise linear para as ações horizontais de cálculo. Nesta etapa da análise, a rigidez dos membros deve ser reduzida a fim de ser levada em conta a $\mathrm{NLF}$, de acordo com o método simplificado apresentado no item 3.3-b. Calculados os esforços de primeira ordem e os deslocamentos, determina-se o acréscimo de momento desta etapa. Para o caso da Fig. 16-a, tomando-se a base do edifício como referencial, este acréscimo vale:

$$
\Delta M_{d}=F_{d} \cdot \delta_{1 d}
$$

O deslocamento $\delta_{1 \mathbf{d}}$ (de primeira ordem) do ponto de aplicação da resultante de todas cargas verticais $\mathbf{F}_{\mathbf{d}}$, pode ser calculado a partir dos deslocamentos (de primeira ordem) $\mathbf{y}_{\mathbf{i d}}$ do ponto de aplicação da resultante das cargas verticais $\mathbf{F}_{\text {id }}$ de cada pavimento $\mathbf{i}$, utilizando-se a seguinte equação:

$$
\delta_{1 \mathrm{~d}}=\frac{\sum \mathbf{F}_{\mathrm{id}} \cdot \mathbf{y}_{\mathrm{id}}}{\mathbf{F}_{\mathrm{d}}}
$$

Simplifica-se a Eq. 37 obtendo-se:

$$
\Delta \mathbf{M}_{\mathbf{d}}=\Sigma\left(\mathbf{F}_{\mathrm{id}} \cdot \mathbf{y}_{\mathrm{id}}\right)
$$

O momento de primeira ordem na base da estrutura da Fig. 16-a vale:

$$
\mathbf{M}_{1 \mathrm{~d}}=\Sigma\left(\mathbf{F}_{\text {Hid }} \cdot \mathbf{x}_{\mathrm{i}}\right)
$$

onde $\mathbf{F}_{\text {Hid }}$ é a ação horizontal no nível do pavimento $\mathbf{i}$ cuja distância à base do edifício é igual a $\mathbf{x}_{\mathbf{i}}$.

Está prevista a inclusão do coeficiente $\gamma_{\mathbf{z}}$ como parâmetro de instabilidade global na NB-1/1994 (ABNT), além do parâmetro $\alpha$. 
FRANCO \& VASCONCELOS(1991) qualificam $\gamma_{\mathrm{z}}$ como uma boa aproximação da amplificação dos esforços, podendo o projetista ter uma estimativa dos resultados de uma possível análise de segunda ordem. Afirmam ainda que utilizaram com sucesso o método em edifícios altos com $\gamma_{\mathbf{z}}$ da ordem de 1,20 ou mais. Com base nestes estudos, o texto provisório da NB-1/1994 (ABNT) prescreve que, para se levar em conta a NLG na análise de estruturas de nós móveis, além do processo $\mathbf{P}-\Delta$ (ou $\mathbf{N}-\mathbf{a}$ ) e da análise considerando modificações apropriadas na matriz de rigidez da estrutura (procedimentos descritos na próxima seção), é permitido, alternativamente, que se avaliem os esforços finais de segunda ordem, em estruturas regulares, pela multiplicação dos esforços de primeira ordem obtidos para a ação horizontal por $\gamma_{\mathbf{z}}$, desde que $\gamma_{\mathbf{z}} \leq \mathbf{1 , 2 0}$.

\subsubsection{1 - EXEMPLO DE APLICAÇÃO}

Para exemplificar o cálculo de $\gamma_{\mathbf{z}}$, utiliza-se novamente a estrutura descrita na Fig. 15. Como foi visto, dever-se-ia reduzir a inércia dos elementos constituintes da estrutura e ponderar as ações verticais por $\gamma_{f}=1,0$ e as horizontais por $\gamma_{f}=1,4$. Sabese que os deslocamentos horizontais, numa análise linear, são diretamente proporcionais às ações e inversamente proporcionais à rigidez EI. Portanto, observando-se as Eq. 36, 38 e 39, percebe-se que:

$$
\gamma_{\mathrm{z}} \cong \frac{1}{1-\frac{\sum \mathrm{F}_{\mathrm{id}} \cdot \mathbf{y}_{\mathrm{id}}}{\sum \mathrm{F}_{\mathrm{Hid}} \cdot \mathbf{x}_{\mathrm{i}}}}=\frac{1}{1-\frac{\sum 1,0 \cdot \mathrm{F}_{\mathrm{ik}} \cdot 1,4 \mathbf{y}_{\mathrm{ik}} / 0,7}{\sum 1,4 \mathrm{~F}_{\mathrm{Hik}} \cdot \mathbf{x}_{\mathrm{i}}}}
$$

ou seja, os resultados característicos obtidos na análise de 1a ordem feita em 3.4.1 para cálculo de $\mathbf{a} / \mathbf{H}$ podem ser aproveitados dividindo-se as flechas características por $\mathbf{0 , 7}$. Assim, como para o caso da estrutura em estudo, onde todos os $\mathbf{F}_{\mathbf{i k}}$ são iguais, a Eq. 40 simplifica-se, passando a:

$$
\gamma_{\mathrm{z}} \cong \frac{1}{1-\frac{\mathbf{F}_{\mathrm{ik}} \sum \mathbf{y}_{\mathbf{i k}}}{\mathbf{0 , 7}\left(\sum \mathbf{F}_{\mathbf{H i k}} \cdot \mathbf{x}_{\mathbf{i}}\right)}}
$$

A partir da análise linear, para a direção $\mathbf{X}$ : 


$$
\Sigma \mathbf{y}_{\mathbf{i k}}=0,6123 \mathrm{~m}
$$

e

$$
\Sigma \mathbf{F}_{\mathbf{i k}} \cdot \mathbf{x}_{\mathbf{i}}=16223,1 \mathrm{kN} \cdot \mathrm{m} \quad \text { (momento na base do edifício ) }
$$

tem-se

$$
\gamma_{\mathrm{z}}=1,14
$$

Para a direção $\mathbf{Y}$ :

$$
\Sigma \mathbf{y}_{\mathbf{i k}}=0,3144 \mathrm{~m}
$$

e

$$
\Sigma \mathbf{F}_{\mathbf{i k}} \cdot \mathbf{x}_{\mathbf{i}}=19754,0 \mathrm{kN} \cdot \mathrm{m} \quad \text { (momento na base do edifício ) }
$$

donde

$$
\gamma_{\mathrm{z}}=1,06
$$

De acordo com o que foi visto, os esforços finais totais que incluem os de 2a. ordem, analisando-se a estrutura na direção $\mathbf{X}$, ultrapassam os de 1 a ordem em cerca de $14 \%$, aumento este que deve ser levado em consideração no dimensionamento.

\section{6 - PROCEDIMENTOS USUAIS DE CONSIDERAÇĀO DE EFEITOS DE SEGUNDA ORDEM}

Como foi visto, sendo a estrutura considerada de nós móveis, necessita-se uma análise de conjunto levando-se em conta tanto a NLG quanto a NLF, para que os valores dos deslocamentos determinados sejam bem próximos dos que realmente ocorrem na estrutura. Estes dois problemas são tratados por análises das características das seções transversais dos elementos estruturais e por análises estruturais elásticas, respectivamente. Estas duas análises são combinadas para atender às condições de equilíbrio e de compatibilidade. Para tanto, são adotados métodos desde os rigorosos aos aproximados (que, para estruturas regulares, permitese utilizar desde que sejam respeitados alguns limites). Eles consideram essas nãolinearidades de forma diferente e o grau de sensibilidade da estrutura aos efeitos de segunda ordem é fator determinante do método a ser utilizado. 
Nesta seção, serão comentados alguns dos procedimentos utilizados para a realização de análise de segunda ordem.

\subsection{1 - PROCESSO RIGOROSO}

Neste processo considera-se a NLG e a NLF rigorosamente na análise de segunda ordem e será aqui resumidamente descrito. Porém, neste trabalho, $\underline{\varrho}$ termo rigoroso deverá ser visto com restrições, como será visto adiante.

Para considerar-se a NLF, a cada nível de carga constrói-se a relação Momento-Curvatura para cada seção com armadura suposta conhecida, utilizando-se a curva Tensão-Deformação do concreto. Ou seja, a cada valor de força axial atuante corresponde um diagrama Momento-Curvatura e a rigidez EI das barras deve ser corrigida. O CEB(1978) expõe este processo detalhadamente e FRANCO(1985b) descreve resumidamente um procedimento iterativo para este fim.

Como foi visto, numa análise com NLG, considera-se a estrutura em sua configuração deformada na formulação das equações de equilíbrio. Num sistema estrutural formado por barras isso pode ser feito considerando-se alterações finitas na geometria. As deformações não se expressam linearmente em função dos deslocamentos e a estrutura sofre alterações de rigidez de acordo com a magnitude das deformações. A matriz de rigidez obtida analisando-se a estrutura indeformada corresponde ao regime de proporcionalidade e é chamada de matriz de rigidez elástica linear. Porém, o problema a ser resolvido pode ser transformado em uma sequência de análises lineares. É possível decompor a matriz de rigidez global da estrutura em matrizes incrementais dependentes dos deslocamentos nodais. $O$ procedimento é devidamente estudado por CORREAA(1991).

Este seria o processo ideal para as estruturas de concreto armado. É apropriado quando se conhece a geometria e a armadura das peças. $O$ problema, entretanto está em aplicá-lo às estruturas de edifícios altos com muitos elementos, o que aumentaria sensivelmente o custo e o tempo de processamento. Ou seja, este método é o mais geral, porém, a consideração da NLF, da forma como foi descrita, é trabalhosa e dificil de aplicar nos casos de estruturas de grande porte. A consideração da NLG, por sua vez, não complica o processo uma vez que envolve menor número de transformações e o desenvolvimento dos equipamentos e métodos de cálculo a 
viabiliza. $O$ que se tem feito feito é desenvolver programas que realizem a modificação na matriz de rigidez da estrutura conforme foi visto, considerando a NLF através do cálculo aproximado da redução da rigidez EI, de acordo com o apresentado no item 3.3-b. Este foi o procedimento adotado neste trabalho, em que o termo rigoroso foi utilizado para nomeá-lo, embora se saiba que a consideração da NLF é feita de forma aproximada.

\section{a) Programa com Recursos para Análise de Segunda Ordem Utilizado no Trabalho}

Estudando os problemas relacionados com a NLG em que o equilíbrio se mantenha estável, CORRÊA(1991) desenvolveu uma adaptação para o sistema LASER, RAMALHO(1990), desenvolvido no Departamento de Estruturas da EESC-USP, através do Método dos Elementos Finitos. Esta adaptação permite análise considerando a NLG de sistemas estruturais compostos por barras, dispostos no espaço tridimensional e submetidos a carregamentos estáticos aplicados nos nós. O sistema LASER, originalmente, realiza análise linear. A NLF é considerada aproximadamente, através da redução da rigidez $\mathbf{E I}$.

\subsection{2 - PROCESSO P - $\Delta$ (ou N - a)}

O processo $\mathbf{P}-\Delta^{12}$ (também conhecido por $\mathbf{N}$-a) é o mais utilizado e prescrito dos processos de análise de segunda ordem.

Sob a ação das cargas laterais e verticais (Fig. 19-a), a estrutura sofre deslocamentos horizontais $\Delta \mathrm{e}$ os momentos das extremidades do pilar devem equilibrar o momento provocado pela carga horizontal e o provocado pela carga vertical:

$$
\Sigma\left(\mathbf{M}_{\text {topo }}+\mathbf{M}_{\text {base }}\right)=\mathbf{H} \cdot \ell+(\Sigma \mathbf{P}) \cdot \Delta
$$

O momento adicional $(\Sigma \mathbf{P}) \cdot \Delta$, ou $\mathbf{P}_{\mathrm{i}} \cdot \Delta$ como se prefere denominar daqui para frente, pode ser substituído por um binário de mesmo efeito, causado por forças horizontais de valor $\mathbf{P}_{\mathbf{i}} \cdot \Delta / \ell$ (Fig. 19-b). Ou seja, substitui-se o efeito de segunda ordem por um efeito de primeira ordem equivalente. A soma algébrica das forças dos

\footnotetext{
${ }^{12}$ Optou-se por preservar esta nomenclatura para justificar o nome dado ao processo
} 
pilares superior e inferior de um pavimento i resulta na força horizontal adicional ("sway force") nele atuante:

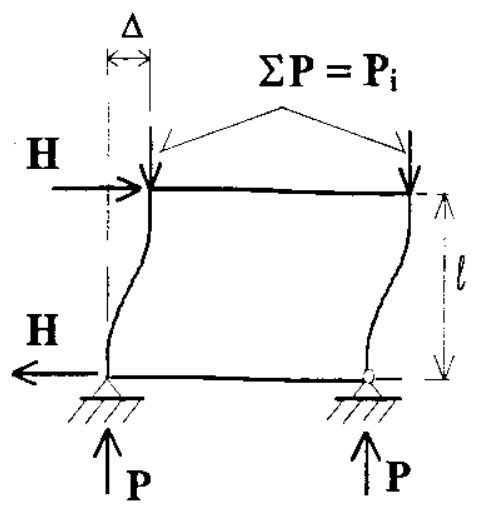

(a)

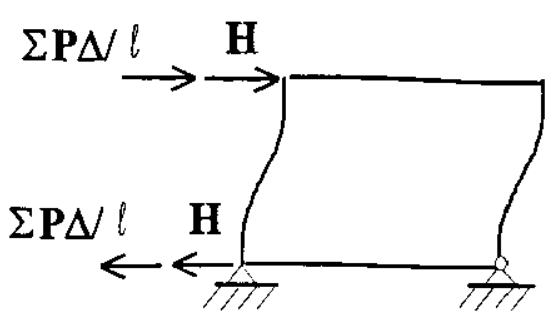

(b)

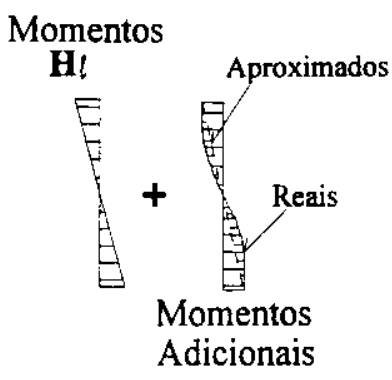

(c)

FIGURA 19 - Processo $P$ - $\Delta$.

$$
\mathbf{H}_{i}=\frac{\mathbf{P}_{\mathbf{i}} \cdot \Delta_{\mathbf{i}}}{l_{\mathbf{i}}}-\frac{\mathbf{P}_{\mathbf{i}+1} \cdot \Delta_{\mathrm{i}+1}}{l_{\mathrm{i}+1}}
$$

Para estruturas de múltiplos pavimentos, $\mathbf{P}_{\mathbf{i}}$ será o somatório de todas as resultantes verticais dos pavimentos desde o topo do edifício até o pavimento i. Somam-se as forças horizontais adicionais, determinadas pela Eq. 42, às ações laterais originais de cada pavimento, reanalisa-se a estrutura e obtêm-se novos valores de deslocamentos e momentos nos pilares. MACGREGOR(1993b) aconselha que, se os deslocamentos aumentam mais que $5 \%$, deve-se repetir o processo. Importante lembrar que as novas forças horizontais adicionais determinadas pela Eq. 42 serão sempre somadas à ação lateral original e não à soma obtida na iteração anterior. Elas podem ser negativas devido a descontinuidades de rigidez e de cargas aplicadas.

Quanto à consideração da NLF no processo $\mathbf{P}-\Delta$, o procedimento correto seria, mais uma vez, avaliar convenientemente a rigidez de cada barra da estrutura a cada iteração, em função dos esforços determinados na iteração anterior. Entretanto, como no processo rigoroso, opta-se por adotar a aproximação desta consideração, reduzindo-se as rigidezes $\mathbf{E I}$ dos elementos, de acordo com o método visto em 3.3-b. 
Segundo FRANCO(1985b) e MACGREgOR(1993b), o processo P- $\Delta$, entretanto, deve ser corrigido. Ao substituir-se o momento $\mathbf{P}_{\mathrm{i}} \cdot \Delta$, cujo real diagrama de momentos tem a forma da barra deformada (Fig.19-c), por forças horizontais fictícias, de diagrama retilíneo similar ao do momento $\mathbf{H} l$ (mostrado na mesma figura), obtêm-se deslocamentos finais menores que os reais. De acordo com MACGREGOR (1993b), o acréscimo nos deslocamentos varia de zero (para pórticos com pilares bastante rígidos e vigas bastante flexíveis) a $22 \%$ (para pilares de extremidades completamente impedidas de girar). Sugere que se use $15 \%$, valor que considera razoável nos casos usuais. Dai, o processo estará corrigido se for utilizada a força lateral fictícia igual a $\gamma \mathbf{P}_{\mathfrak{i}} \Delta / l$, onde $\gamma$, que MACGREGOR(1993b) denomina fator de flexibilidade, varia de 1,0 a 1,22 , podendo ser adotado igual a 1,15 para estruturas regulares.

\subsection{3 - PROCESSO SIMPLIFICADO}

Existem diversos procedimentos aproximados que foram apresentados por alguns autores. MACGREGOR \& HAGE(1977), por exemplo, apresentam um coeficiente de majoração de momentos que entretanto, não analisa a estrutura em conjunto e sim cada andar separadamente. VASCONCELOS(1986) apresenta um coeficiente majorador de ações horizontais com base nos estudos de BECK que é função do parâmetro $\alpha$. FUSCO(1981) apresenta um processo simplificado aplicável a pórticos relativamente simples. Neste processo, parte-se de uma análise de primeira ordem da estrutura submetida a ações de cálculo. Em etapas sucessivas, cada pilar é isoladamente analisado, da base ao topo, submetido às ações que lhe são aplicadas diretamente e aos esforços obtidos na etapa anterior, atuantes nos nós de ligação do pilar com o restante da estrutura.

A própria utilização do parâmetro $\gamma_{\mathbf{z}}$ como majorador dos momentos de primeira ordem é uma prática aproximada, que também se pretende avaliar neste trabalho. Neste processo, deve-se agir da seguinte forma:

a) Realiza-se uma análise de primeira ordem da estrutura para as ações horizontais em valores de cálculo e rigidezes dos elementos reduzidas, levando-se em conta a NLF de forma aproximada;

b) São computados os deslocamentos horizontais e os esforços de primeira ordem. 
c) O parâmetro $\gamma_{z}$ é determinado, conforme foi visto em 3.5.2, pela Eq. 36 .

d) Classifica-se a estrutura, de acordo com o item 3.3-d, em estruturas de nós fixos ou móveis. No primeiro caso, prossegue-se o detalhamento da estrutura, acrescentando-se aos esforços determinados da análise da estrutura para as ações verticais, os esforços de primeira ordem conseqüentes das ações horizontais, mencionados no item $\mathbf{b}$. Procede-se da mesma maneira no caso de estruturas de nós móveis, porém, os esforços de primeira ordem devidos às ações horizontais são multiplicados por $\gamma_{\mathbf{z}}$ sempre que $1,10<\gamma_{\mathbf{z}} \leq 1,20$. Acredita-se que, provavelmente por uma questão de cautela, VASCONCELOS \& FRANCO(1991) optaram por limitar o valor de $\gamma_{z}$ em até 1,20 .

Este procedimento já vem sendo adotado por alguns escritórios de projetos estruturais que realizam análise de segunda ordem em suas estruturas. Os efeitos devidos às ações horizontais calculados são posteriormente somados, após corrigidos (no caso de estruturas de nós móveis), aos efeitos obtidos através de uma análise da estrutura submetida às ações verticais.

\subsection{4 - EXEMPLO DE APLICAÇÃO}

Nos itens 3.5.1.1 e 3.5.2.1, verificou-se que, de acordo com os parâmetros de instabilidade global, a estrutura do edificio SPAZIO UNO (Fig. 15) é de nós móveis na direção X. Portanto, deve ser feita uma análise de segunda ordem nesta direção. Como os programas utilizados neste trabalho para a realização das análises estruturais o fazem no espaço tridimensional, os resultados segundo a direção $\mathbf{Y}$ também serão apresentados.

Uma importante colocação, entretanto, deve ser feita neste momento: numa análise de segunda ordem feita através da utilização do processo rigoroso, a estrutura é submetida aos carregamentos verticais e horizontais, simultaneamente, para que as devidas alterações na sua matriz de rigidez global sejam feitas. No processo $P-\Delta$ e no processo simplificado descrito em 3.6.3, entretanto, os efeitos de primeira e de segunda ordem (estes últimos, quando existentes) devidos às ações laterais podem ser acrescentados aos efeitos conseqüentes apenas das ações verticais. Porém, é importante observar-se que, quando não há simetria na geometria e na distribuição de ações verticais sobre o pavimento em relação ao eixo horizontal da estrutura 
perpendicular à direção de incidência do vento em análise, existe uma excentricidade do ponto de aplicação da resultante destas ações em relação ao centro elástico do pavimento. A Fig. 20 esquematiza o problema, onde a resultante das ações verticais $\mathbf{R}$ é excentricamente aplicada a uma distância e do eixo da estrutura (a seta indica o sentido positivo crescente de e). Note-se que, quando as ações horizontais, representadas na figura pela força $\mathbf{H}$, incidem no sentido crescente de e $(\mathbf{H}+)$, a resultante $\mathbf{R}$, em presença desta excentricidade, provoca um momento favorável ao momento de tombamento conseqüente das ações horizontais. O contrário, como pode ser observado na Fig. 20, ocorre quando o vento incide no sentido oposto (H-). A média entre os deslocamentos obtidos da análise para $(\mathbf{H}+)$ e $(\mathbf{H}-)$, em se tratando de uma análise linear, deve corresponder aos resultados de uma análise feita sem a presença das ações verticais (para o exemplo do edifício SPAZIO UNO, alguns destes resultados encontram-se na Tab. 10). Na prática dos escritórios de projetos estruturais, como foi dito, este é o procedimento usualmente adotado, ou seja, as análises para ações verticais e horizontais são feitas separadamente e os resultados são posteriormente reunidos.

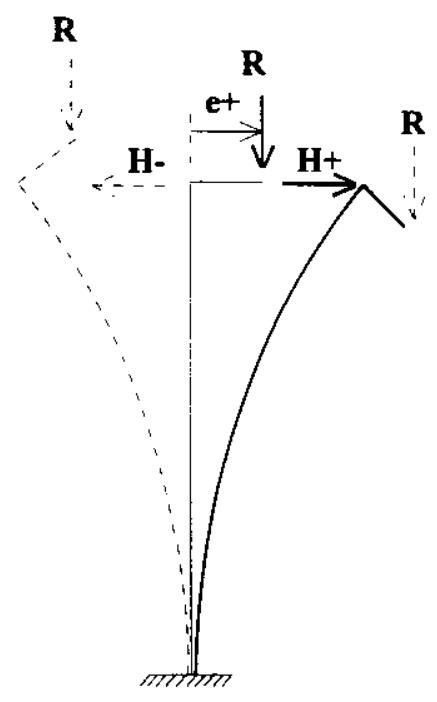

FIGURA 20 - Incidência da Ação Horizontal nos Sentidos Convencionados Positivo e Negativo.

Um procedimento mais apurado seria verificarem-se os resultados obtidos da análise segundo determinada direção para o vento incidindo em um sentido $(\mathbf{H}+)$ e no sentido contrário (H-), juntamente com as ações verticais. A direção de análise a adotar na verificação da estrutura seria a que proporcionasse valores absolutos para os resultados maiores. Para a estrutura do edifício SPAZIO UNO (Figs. 15), por 
exemplo, este problema ocorre quando o vento incide na direção $\mathbf{Y}$, indicada na Fig. 15. De acordo com a distribuição das ações verticais entre os pilares (indicada na mesma figura), a resultante destas ações tem seu ponto de aplicação deslocado para baixo em relação ao centro elástico do pavimento, ou seja, de acordo com o que foi visto, e é negativo. Isto significa que, quando a estrutura é analisada para o vento agindo no sentido positivo de $\mathbf{Y}$, a resultante das ações verticais provoca um efeito desfavorável ao tombamento provocado pelas ações horizontais. O contrário ocorre, portanto, quando o vento incide no sentido contrário (crescente com e). Este fenômeno será numericamente confirmado após os resultados dos processamentos serem apresentados adiante.

Portanto, para efeito de comparação com resultados de análises de segunda ordem utilizando-se o processo rigoroso, o processo $\mathbf{P}-\Delta$ e o processo simplificado, a estrutura será submetida simultaneamente às ações horizontais e verticais. Os processos estarão, portanto, sendo comparados em igualdade de condições. Serão apresentados, também, os resultados para o vento incidindo nas direções $\mathbf{X}$ e $\mathbf{Y}$, nos sentidos positivo e negativo no exemplo do edifício SPAZIO UNO.

Deve-se ainda observar que, como os deslocamentos sofrem alterações em presença das ações verticais em caso de não haver simetria, há também uma alteração no valor calculado de $\gamma_{\mathbf{z}}$. No caso do exemplo do edifício SPAZIO UNO (Figs. 15), observa-se que, para o vento incidindo na direção do eixo $\mathbf{Y}$ positivo, $\gamma_{\mathbf{z}}=1,05$ e que, entretanto, no sentido negativo do eixo $\mathrm{Y}, \gamma_{\mathrm{z}}$ permanece igual a 1,06 (contra $\gamma_{\mathrm{z}}=1,06$ quando atuam somente as ações horizontais). Note-se que, para estruturas regulares $e$ coerentemente projetadas, a variação entre estes valores não deve ser muito grande, como é o caso do exemplo dado.

Descrevem-se a seguir, as considerações feitas para a análise de segunda ordem de acordo com cada um dos procedimentos apresentados em 3.6. Finalmente, alguns resultados dos efeitos de primeira e segunda ordem são exibidos e comparados nas Tabs. 8 e 9, para forças horizontais atuantes nos sentidos positivo e negativo dos eixos, respectivamente. Em seguida, os resultados dos deslocamentos calculados são representados graficamente nas Figs. 21-a, b e c, para ações horizontais atuantes no sentido positivo do eixo X. Na Fig. 21-b, apresentam-se, além dos deslocamentos de primeira ordem, os deslocamentos de segunda ordem obtidos segundo o processo rigoroso nas iterações necessárias para a obtenção dos efeitos finais; a Fig. 21-a apresenta os deslocamentos de primeira ordem e os deslocamentos de segunda ordem 
obtidos através do processo P- $\Delta$ nas diversas iterações realizadas para obterem-se os efeitos finais; finaimente, na Fig. 21-c apresentam-se os deslocamentos de primeira ordem e os deslocamentos finais, que incluem os de segunda ordem, obtidos de acordo com os processos rigoroso, $\mathrm{P}-\Delta \mathrm{e}$ simplificado.

a) Processo Rigoroso

- Consideração da NLF pelo método aproximado:

$$
\begin{aligned}
& \mathbf{I}=0,7 \mathbf{I}_{\mathbf{c}} \\
& \mathbf{E}_{\mathbf{c}}=3,0 \cdot 10^{7} \mathrm{kN} / \mathrm{m}^{2}
\end{aligned}
$$

- Ações:

verticais $=$ reações verticais nos pilares (indicadas na Fig. 15)

horizontais $=$ ação do vento

- Coeficientes de Segurança:

$$
\begin{array}{ll}
\gamma_{f}=1,0 & \text { para ações verticais } \\
\gamma_{f}=1,4 & \text { para ações horizontais }
\end{array}
$$

- Foi estabelecido um número máximo de 10 iterações e estipulada uma tolerância em deslocamento ${ }^{13}$ de 0,001 , como critério de convergência para definir o fim do processo iterativo.

- Inicialmente, utilizou-se o sistema LASER original, RAMALHO(1990), para a determinação dos esforços de primeira ordem. Por sua vez, para o cálculo dos efeitos de segunda ordem, utilizou-se o sistema LASER adaptado, CORRÊA(1991), conforme foi visto em 3.6.1-a.

- Os resultados destes processamentos são apresentados nas Tabs. 8 e 9, para forças horizontais atuantes nos sentidos positivo e negativo dos eixos, respectivamente.

\footnotetext{
${ }^{13}$ Tolerância relativa à norma do vetor constituido pelas variações de todos os deslocamentos nodais.
} 
b) Processo $\mathbf{P}-\Delta$

- São adotados os mesmos valores de redução da inércia (para a consideração da NLF pelo método aproximado), das ações verticais e horizontais (como ações laterais originais), dos coeficientes de segurança e do módulo de deformação longitudinal do concreto que foram adotados no processo rigoroso.

- O número de iterações será obtido de acordo com tolerância de deslocamento estabelecida de 0,001 .

- Utilizou-se o sistema LASER original, RAMALHO(1990), para as sucessivas análises lineares que este processo requer.

- A estrutura é primeiramente analisada para as ações horizontais de vento, determinadas de acordo com os parâmetros listados em 3.4.1 e para ações verticais. As ações horizontais são apresentadas na terceira coluna das Tabs. 5, 6 e 7. Nestas mesmas tabelas, apresentam-se as forças horizontais $\mathbf{H}_{\text {id }}$ devidas ao efeito $\mathbf{P}-\Delta$ e, finalmente, a soma destas forças com as forças horizontais originais devidas ao vento. Esta soma, ao nivel de cada pavimento, é a ação horizontal que será aplicada à estrutura na iteração seguinte.

- Neste caso, chama-se de primeira iteração à primeira análise feita após a análise de primeira ordem, cujos dados utilizados para realizá-la e os resultados são apresentados na Tab. 5.

- Foram necessárias, além da primeira, mais duas iterações: os dados para a segunda iteração e os resultados são apresentados na Tab. 6; os dados para a terceira iteração e os resultados são apresentados na Tab. 7. Nestas tabelas apresentam-se apenas os valores obtidos para forças horizontais atuantes nos sentidos positivos dos eixos $\mathbf{X}$ e $\mathbf{Y}$.

- Analisa-se a estrutura submetida às forças finais obtidas para a terceira iteração para determinarem-se os esforços finais totais. Alguns resultados das últimas análises são também apresentados nas Tabs. 8 e 9 para forças 
horizontais atuantes nos sentidos positivo e negativo dos eixos, respectivamente.

c) Processo Simplificado

- Adotou-se como processo simplificado o que utiliza o coeficiente $\gamma_{\mathrm{z}}$ como majorador dos efeitos de primeira ordem.

- São novamente adotados os mesmos valores de redução da inércia na consideração da NLF, das ações horizontais e verticais, dos coeficientes de segurança e do módulo de deformação longitudinal do concreto dos processos anteriores.

- Nas Tabs. 8 e 9, para ações horizontais atuantes nos sentidos positivos e negativos dos eixos $\mathbf{X}$ e $\mathbf{Y}$, respectivamente, encontram-se os resultados obtidos por este processo, que consiste na simples multiplicação dos efeitos de primeira ordem por $\gamma_{\mathbf{z}}$. 
TABELA 5 - Processo P-A para o Exemplo do Ed. SPAZIO UNO:

1 a Iteração - (sentidos positivos dos eixos)

\begin{tabular}{|c|c|c|c|c|c|c|c|}
\hline \multicolumn{8}{|c|}{ Direção X } \\
\hline Nível & $\begin{array}{l}(\mathrm{m}) \\
\mathbf{h}_{\mathbf{i}}\end{array}$ & \begin{tabular}{|c|}
$\mathrm{xl} 0 \mathrm{kN})$ \\
$\mathrm{F}_{\text {Hid }}$
\end{tabular} & $\begin{array}{c}(\mathrm{xl} 0 \mathrm{kN}) \\
\Sigma F_{\text {id }}\end{array}$ & $\begin{array}{l}(\mathrm{m}) \\
y_{\text {id }}\end{array}$ & $\begin{array}{l}(\mathrm{m}) \\
\Delta_{\text {id }}\end{array}$ & $\begin{array}{c}\left(\mathrm{x}^{\prime} 10 \mathrm{kN}\right) \\
\mathbf{H}_{\mathbf{j d}}\end{array}$ & $\begin{array}{c}(\times 10 \mathrm{kN}) \\
F_{\text {Hid }}+H_{\text {id }}\end{array}$ \\
\hline 1 & 3,29 & 0,00 & 3923,60 & $4,193 \mathrm{E}-03$ & $4,193 \mathrm{E}-03$ & $-5,66$ & $-5,66$ \\
\hline 2 & 3,68 & 3,52 & 3692,80 & $1,482 \mathrm{E}-02$ & $1,062 \mathrm{E}-02$ & $-0,92$ & 2,60 \\
\hline 3 & 2,80 & 3,50 & 3462,00 & $2,418 \mathrm{E}-02$ & $9,367 \mathrm{E}-03$ & 0,46 & 3,96 \\
\hline 4 & 2,80 & 3,83 & 3231,20 & $3,382 \mathrm{E}-02$ & $9,635 \mathrm{E}-03$ & 0,84 & 4,68 \\
\hline 5 & 2,80 & 4,09 & 3000,40 & $4,341 \mathrm{E}-02$ & $9,587 \mathrm{E}-03$ & 1,03 & 5,12 \\
\hline 6 & 2,80 & 4,31 & 2769,60 & $5,275 \mathrm{E}-02$ & $9,345 \mathrm{E}-03$ & 1,10 & 5,41 \\
\hline 7 & 2,80 & 4,50 & 2538,80 & $6,173 \mathrm{E}-02$ & $8,979 \mathrm{E}-03$ & 1,12 & 5,62 \\
\hline 8 & 2,80 & 4,67 & 2308,00 & $7,026 \mathrm{E}-02$ & $8,524 \mathrm{E}-03$ & 1,09 & 5,76 \\
\hline 9 & 2,80 & 4,82 & 2077,20 & $7,826 \mathrm{E}-02$ & $8,007 \mathrm{E}-03$ & 1,03 & 5,86 \\
\hline 10 & 2,80 & 4,96 & 1846,40 & $8,570 \mathrm{E}-02$ & $7,439 \mathrm{E}-03$ & 0,96 & 5,92 \\
\hline 11 & 2,80 & 5,09 & 1615,60 & $9,253 \mathrm{E}-02$ & $6,833 \mathrm{E}-03$ & 0,88 & 5,97 \\
\hline 12 & 2,80 & 5,21 & 1384,80 & $9,873 \mathrm{E}-02$ & $6,198 \mathrm{E}-03$ & 0,78 & 5,98 \\
\hline 13 & 2,80 & 5,32 & 1154,00 & $1,043 \mathrm{E}-01$ & $5,544 \mathrm{E}-03$ & 0,67 & 5,99 \\
\hline 14 & 2,80 & 5,42 & 923,20 & $1,092 \mathrm{E}-01$ & $4,886 \mathrm{E}-03$ & 0,56 & 5,98 \\
\hline 15 & 2,80 & 5,52 & 692,40 & $1,134 \mathrm{E}-01$ & $4,250 \mathrm{E}-03$ & 0,44 & 5,97 \\
\hline 16 & 2,80 & 5,61 & 461,60 & $1,171 \mathrm{E}-01$ & $3,676 \mathrm{E}-03$ & 0,34 & 5,95 \\
\hline 17 & 2,80 & 5,70 & 230,80 & $1,203 \mathrm{E}-01$ & $3,250 \mathrm{E}-03$ & 0,27 & 5,97 \\
\hline $\bar{\Sigma}$ & 48,97 & & & & & & \\
\hline \multicolumn{8}{|c|}{ Direção Y } \\
\hline Nível & $\begin{array}{l}(\mathrm{m}) \\
\mathbf{h}_{\mathbf{i}}\end{array}$ & $\begin{array}{c}(\mathrm{x} 10 \mathrm{kN}) \\
\text { F }_{\text {Hid }}\end{array}$ & $\begin{array}{c}(\mathrm{x} 10 \mathrm{kN}) \\
\Sigma F_{\text {id }}\end{array}$ & $\begin{array}{l}\text { (m) } \\
y_{\text {id }}\end{array}$ & $\begin{array}{l}(\mathrm{m}) \\
\Delta_{\text {id }} \\
\end{array}$ & $\begin{array}{c}(\mathrm{x} 10 \mathrm{kN}) \\
\mathbf{H}_{\mathrm{id}}\end{array}$ & $\begin{array}{c}(\mathrm{x} 10 \mathrm{kN}) \\
\mathrm{F}_{\text {Hid }}+\mathbf{H}_{\text {id }}\end{array}$ \\
\hline $\bar{~} 1$ & 3,29 & $\overline{0,00}$ & 3923,60 & $2,061 \mathrm{E}-03$ & $2,061 \mathrm{E}-03$ & $-2,71$ & $-2,71$ \\
\hline 2 & 3,68 & 4,28 & 3692,80 & $7,208 \mathrm{E}-03$ & $5,147 \mathrm{E}-03$ & $-0,34$ & 3,94 \\
\hline 3 & 2,80 & 4,26 & 3462,00 & $1,166 \mathrm{E}-02$ & $4,452 \mathrm{E}-03$ & 0,31 & 4,57 \\
\hline 4 & 2,80 & 4,66 & 3231,20 & $1,616 \mathrm{E}-02$ & $4,500 \mathrm{E}-03$ & 0,48 & 5,14 \\
\hline 5 & 2,80 & 4,98 & 3000,40 & $2,056 \mathrm{E}-02$ & $4,399 \mathrm{E}-03$ & 0,55 & 5,53 \\
\hline 6 & 2,80 & 5,25 & 2769,60 & $2,477 \mathrm{E}-02$ & $4,209 \mathrm{E}-03$ & 0,57 & 5,82 \\
\hline 7 & 2,80 & 5,48 & 2538,80 & $2,873 \mathrm{E}-02$ & $3,963 \mathrm{E}-03$ & 0,56 & 6,03 \\
\hline 8 & 2,80 & 5,68 & 2308,00 & $3,241 \mathrm{E}-02$ & $3,682 \mathrm{E}-03$ & 0,53 & 6,21 \\
\hline 9 & 2,80 & 5,87 & 2077,20 & $3,579 \mathrm{E}-02$ & $3,376 \mathrm{E}-03$ & 0,49 & 6,36 \\
\hline 10 & 2,80 & 6,04 & 1846,40 & $3,884 \mathrm{E}-02$ & $3,050 \mathrm{E}-03$ & 0,45 & 6,49 \\
\hline 11 & 2,80 & 6,19 & 1615,60 & $4,155 \mathrm{E}-02$ & $2,711 \mathrm{E}-03$ & 0,40 & 6,59 \\
\hline 12 & 2,80 & 6,34 & 1384,80 & $4,391 \mathrm{E}-02$ & $2,362 \mathrm{E}-03$ & 0,34 & 6,68 \\
\hline 13 & 2,80 & 6,47 & 1154,00 & $4,592 \mathrm{E}-02$ & $2,008 \mathrm{E}-03$ & 0,28 & 6,75 \\
\hline 14 & 2,80 & 6,60 & 923,20 & $4,758 \mathrm{E}-02$ & $1,655 \mathrm{E}-03$ & 0,22 & 6,82 \\
\hline 15 & 2,80 & 6,72 & 692,40 & $4,889 \mathrm{E}-02$ & $1,315 \mathrm{E}-03$ & 0,16 & 6,88 \\
\hline 16 & 2,80 & 6,84 & 461,60 & $4,989 \mathrm{E}-02$ & $1,004 \mathrm{E}-03$ & 0,10 & 6,94 \\
\hline 17 & 2,80 & 6,95 & 230,80 & $5,066 \mathrm{E}-02$ & $7,610 \mathrm{E}-04$ & 0,06 & 7,01 \\
\hline $\bar{\Sigma}$ & 48,97 & & & & & & \\
\hline
\end{tabular}


TABELA 6 - Processo P-A para o Exemplo do Ed. SPAZIO UNO:

2⿳亠口冋 Iteração - (sentidos positivos dos eixos)

\begin{tabular}{|c|c|c|c|c|c|c|c|}
\hline \multicolumn{8}{|c|}{ Direção X } \\
\hline Nível & $\begin{array}{l}\text { (m) } \\
h_{\mathbf{i}}\end{array}$ & $\begin{array}{c}(\mathrm{x} 10 \mathrm{kN}) \\
\mathrm{F}_{\text {Hid }}\end{array}$ & $\begin{array}{c}(\times 10 \mathrm{kN}) \\
\Sigma \mathrm{F}_{\mathrm{id}}\end{array}$ & $\begin{array}{l}\text { (m) } \\
y_{i d}\end{array}$ & $\begin{array}{l}(m) \\
\Delta_{\text {id }}\end{array}$ & $\begin{array}{c}(\mathrm{x} 10 \mathrm{kN}) \\
\mathbf{H}_{\mathrm{id}}\end{array}$ & $\begin{array}{c}(x 10 \mathrm{kN}) \\
\mathrm{F}_{\mathbf{H i d}}+\mathbf{H}_{\mathrm{id}}\end{array}$ \\
\hline 1 & 3,29 & 0,00 & 3923,60 & $4,682 \mathrm{E}-03$ & $4,682 \mathrm{E}-03$ & $-6,53$ & $-6,52$ \\
\hline 2 & 3,68 & 3,52 & 3692,80 & $1,675 \mathrm{E}-02$ & $1,207 \mathrm{E}-02$ & $-1,16$ & 2,35 \\
\hline 3 & 2,80 & 3,50 & 3462,00 & $2,749 \mathrm{E}-02$ & $1,074 \mathrm{E}-02$ & 0,49 & 4,00 \\
\hline 4 & 2,80 & 3,83 & 3231,20 & $3,856 \mathrm{E}-02$ & $1,107 \mathrm{E}-02$ & 0,98 & 4,82 \\
\hline 5 & 2,80 & 4,09 & 3000,40 & $4,957 \mathrm{E}-02$ & $1,101 \mathrm{E}-02$ & 1,21 & 5,30 \\
\hline$\frac{6}{6}$ & 2,80 & $\overline{4,31}$ & 2769,60 & $6,027 \mathrm{E}-02$ & $1,070 \mathrm{E}-02$ & 1,31 & 5,62 \\
\hline 7 & 2,80 & 4,50 & 2538,80 & $7,050 \mathrm{E}-02$ & $1,023 \mathrm{E}-02$ & 1,31 & 5,81 \\
\hline 8 & 2,80 & 4,67 & 2308,00 & $8,016 \mathrm{E}-02$ & $9,660 \mathrm{E}-03$ & 1,27 & 5,93 \\
\hline 9 & 2,80 & 4,82 & 2077,20 & $8,917 \mathrm{E}-02$ & $9,016 \mathrm{E}-03$ & 1,20 & 6,02 \\
\hline 10 & 2,80 & 4,96 & 1846,40 & $9,750 \mathrm{E}-02$ & $8,324 \mathrm{E}-03$ & 1,11 & 6,06 \\
\hline 11 & 2,80 & 5,09 & 1615,60 & $1,05 \mathrm{IE}-01$ & $7,598 \mathrm{E}-03$ & 1,00 & 6,08 \\
\hline 12 & 2,80 & 5,21 & 1384,80 & $1,119 \mathrm{E}-01$ & $6,852 \mathrm{E}-03$ & 0,88 & 6,08 \\
\hline 13 & 2,80 & 5,32 & 1154,00 & $1,180 \mathrm{E}-01$ & $6,098 \mathrm{E}-03$ & 0,75 & 6,07 \\
\hline 14 & 2,80 & $\overline{5,42}$ & 923,20 & $1,234 \mathrm{E}-01$ & $5,354 \mathrm{E}-03$ & 0,62 & 6,03 \\
\hline 15 & 2,80 & 5,52 & 692,40 & $1,280 \mathrm{E}-01$ & $4,644 \mathrm{E}-03$ & 0,49 & 6,00 \\
\hline 16 & 2,80 & 5,61 & 461,60 & $1,321 \mathrm{E}-01$ & $4,016 \mathrm{E}-03$ & 0,37 & 5,98 \\
\hline 17 & 2,80 & 5,70 & 230,80 & $1,356 \mathrm{E}-01$ & $3,554 \mathrm{E}-03$ & 0,29 & 5,99 \\
\hline$\Sigma$ & 48,97 & & & \multicolumn{2}{|c|}{ Tolerância $=1,8 \mathrm{E}-02$} & & \\
\hline \multicolumn{8}{|c|}{ Direção Y } \\
\hline & (m) & $(\mathrm{x} 10 \mathrm{kN})$ & $(\mathrm{x} 10 \mathrm{kN})$ & (m) & (m) & $(\mathrm{x} 10 \mathrm{kN})$ & $(\mathrm{x} 10 \mathrm{kN})$ \\
\hline Nivel & $\mathbf{h}_{\mathbf{i}}$ & $\mathbf{F}_{\text {Hid }}$ & $\Sigma F_{\text {id }}$ & $\mathbf{y}_{\text {id }}$ & $\Delta_{\text {id }}$ & $\mathbf{H}_{\mathrm{id}}$ & $\mathbf{F}_{\mathbf{H i d}}+\mathbf{H}_{\mathrm{id}}$ \\
\hline$\overline{1}$ & 3,29 & 0,00 & 3923,60 & $2,158 \mathrm{E}-03$ & $2,158 \mathrm{E}-03$ & $\begin{array}{l}-2,88 \\
\end{array}$ & $-2,88$ \\
\hline 2 & 3,68 & 4,28 & 3692,80 & $7,592 \mathrm{E}-03$ & $5,434 \mathrm{E}-03$ & $\begin{array}{l}-0,38 \\
\end{array}$ & 3,90 \\
\hline 3 & 2,80 & 4,26 & 3462,00 & $1,231 \mathrm{E}-02$ & $4,719 \mathrm{E}-03$ & 0,32 & 4,58 \\
\hline 4 & 2,80 & 4,66 & 3231,20 & $1,709 \mathrm{E}-02$ & $4,778 \mathrm{E}-03$ & 0,51 & 5,17 \\
\hline 5 & 2,80 & 4,98 & 3000,40 & $2,176 \mathrm{E}-02$ & $4,670 \mathrm{E}-03$ & 0,59 & 5,57 \\
\hline 6 & 2,80 & 5,25 & 2769,60 & $2,622 \mathrm{E}-02$ & $4,463 \mathrm{E}-03$ & 0,61 & 5,86 \\
\hline 7 & 2,80 & 5,48 & 2538,80 & $3,042 \mathrm{E}-02$ & $4,195 \mathrm{E}-03$ & 0,60 & 6,08 \\
\hline 8 & 2,80 & 5,68 & 2308,00 & $3,431 \mathrm{E}-02$ & $3,890 \mathrm{E}-03$ & 0,57 & 6,25 \\
\hline 9 & 2,80 & 5,87 & 2077,20 & $3,787 \mathrm{E}-02$ & $3,558 \mathrm{E}-03$ & 0,52 & 6,39 \\
\hline 10 & 2,80 & 6,04 & 1846,40 & $4,107 \mathrm{E}-02$ & $3,208 \mathrm{E}-03$ & 0,47 & 6,51 \\
\hline 11 & 2,80 & 6,19 & 1615,60 & $4,392 \mathrm{E}-02$ & $2,846 \mathrm{E}-03$ & 0,42 & 6,61 \\
\hline 12 & 2,80 & 6,34 & 1384,80 & $4,640 \mathrm{E}-02$ & $2,477 \mathrm{E}-03$ & 0,36 & 6,70 \\
\hline 13 & 2,80 & 6,47 & 1154,00 & $4,850 \mathrm{E}-02$ & $2,104 \mathrm{E}-03$ & 0,29 & 6,76 \\
\hline 14 & 2,80 & 6,60 & 923,20 & $5,024 \mathrm{E}-02$ & $1,737 \mathrm{E}-03$ & 0,23 & 6,83 \\
\hline 15 & 2,80 & 6,72 & 692,40 & $5,162 \mathrm{E}-02$ & $1,384 \mathrm{E}-03$ & 0,17 & 6,89 \\
\hline 16 & 2,80 & 6,84 & 461,60 & $5,269 \mathrm{E}-02$ & $1,066 \mathrm{E}-03$ & 0,11 & 6,95 \\
\hline 17 & 2,80 & 6,95 & 230,80 & $5,350 \mathrm{E}-02$ & $8,170 \mathrm{E}-04$ & 0,07 & 7,01 \\
\hline$\Sigma$ & 48,97 & & & Tolerância & $3,2 \mathrm{E}-03$ & & \\
\hline
\end{tabular}


TABELA 7 - Processo P-A para o Exemplo do Ed. SPAZIO UNO:

$3^{a}$ Iteração - (sentidos positivos dos eixos)

\begin{tabular}{|c|c|c|c|c|c|c|c|}
\hline \multicolumn{8}{|c|}{ Direção X } \\
\hline Nível & $\begin{array}{l}\text { (m) } \\
\mathbf{h}_{\mathbf{i}}\end{array}$ & $\begin{array}{c}(\mathrm{x} 10 \mathrm{kN}) \\
\mathrm{F}_{\text {Hid }}\end{array}$ & $\begin{array}{c}(\mathrm{x} 10 \mathrm{kN}) \\
\Sigma \mathrm{F}_{\mathrm{id}}\end{array}$ & $\begin{array}{l}\text { (m) } \\
y_{\text {id }}\end{array}$ & $\begin{array}{l}(\mathrm{m}) \\
\Delta_{\mathrm{id}}\end{array}$ & $\begin{array}{c}(\mathrm{x} 10 \mathrm{kN}) \\
\mathrm{H}_{\text {id }}\end{array}$ & $\begin{array}{c}(\mathrm{x} 10 \mathrm{kN}) \\
\mathrm{F}_{\text {Hid }}+\mathrm{H}_{\mathrm{id}}\end{array}$ \\
\hline 1 & 3,29 & 0,00 & 3923,60 & $4,748 \mathrm{E}-03$ & $4,748 \mathrm{E}-03$ & $-6,65$ & $-6,65$ \\
\hline 2 & 3,68 & 3,52 & 3692,80 & $1,702 \mathrm{E}-02$ & $1,227 \mathrm{E}-02$ & $-1,20$ & 2,31 \\
\hline 3 & 2,80 & 3,50 & 3462,00 & $2,795 \mathrm{E}-02$ & $1,093 \mathrm{E}-02$ & 0,49 & 4,00 \\
\hline 4 & 2,80 & 3,83 & 3231,20 & $3,923 \mathrm{E}-02$ & $1,128 \mathrm{E}-02$ & 1,00 & 4,83 \\
\hline 5 & 2,80 & 4,09 & 3000,40 & $5,044 \mathrm{E}-02$ & $1,121 \mathrm{E}-02$ & 1,24 & 5,33 \\
\hline 6 & 2,80 & 4,31 & 2769,60 & $6,133 \mathrm{E}-02$ & $1,089 \mathrm{E}-02$ & 1,34 & 5,65 \\
\hline 7 & 2,80 & 4,50 & 2538,80 & $7,174 \mathrm{E}-02$ & $1,040 \mathrm{E}-02$ & 1,35 & 5,84 \\
\hline 8 & 2,80 & 4,67 & 2308,00 & $8,155 \mathrm{E}-02$ & $9,810 \mathrm{E}-03$ & 1,30 & 5,96 \\
\hline 9 & 2,80 & 4,82 & 2077,20 & $9,069 \mathrm{E}-02$ & $9,148 \mathrm{E}-03$ & 1,22 & 6,04 \\
\hline 10 & 2,80 & 4.96 & 1846,40 & $9,913 \mathrm{E}-02$ & $8,436 \mathrm{E}-03$ & 1,12 & 6,08 \\
\hline 11 & 2,80 & 5,09 & 1615,60 & $1,068 \mathrm{E}-01$ & $7,692 \mathrm{E}-03$ & 1,01 & 6,09 \\
\hline 12 & 2,80 & 5,21 & 1384,80 & $1,138 \mathrm{E}-01$ & $6,928 \mathrm{E}-03$ & 0,89 & 6,10 \\
\hline 13 & 2,80 & 5,32 & 1154,00 & $1,199 \mathrm{E}-01$ & $6,162 \mathrm{E}-03$ & 0,76 & 6,08 \\
\hline 14 & 2,80 & 5,42 & 923,20 & $1,253 \mathrm{E}-01$ & $5,408 \mathrm{E}-03$ & 0,62 & 6,04 \\
\hline 15 & 2,80 & 5,52 & 692,40 & $1,300 \mathrm{E}-01$ & $4,690 \mathrm{E}-03$ & 0,49 & 6,01 \\
\hline 16 & 2,80 & 5,61 & 461,60 & $1,341 \mathrm{E}-01$ & $4,054 \mathrm{E}-03$ & 0,37 & 5,99 \\
\hline 17 & 2,80 & 5,70 & 230,80 & $1,377 \mathrm{E}-01$ & $3,590 \mathrm{E}-03$ & 0,30 & 5,99 \\
\hline$\overline{\Sigma \Sigma}$ & 48,97 & & & \multicolumn{2}{|c|}{ Tolerância $=2,5$ E-04 } & & \\
\hline \multicolumn{8}{|c|}{ Direção Y } \\
\hline Nivel & $\begin{array}{l}\text { (m) } \\
\mathbf{h}_{\mathbf{i}}\end{array}$ & $\begin{array}{c}(\mathrm{x} 10 \mathrm{kN}) \\
\text { F }_{\text {Hid }}\end{array}$ & $\begin{array}{c}(\times 10 \mathrm{kN}) \\
\Sigma F_{\text {id }}\end{array}$ & $\begin{array}{l}\text { (m) } \\
y_{\text {id }}\end{array}$ & $\begin{array}{c}(\mathrm{m}) \\
\Delta_{\mathrm{id}}\end{array}$ & $\begin{array}{c}(\mathrm{xi0kN}) \\
\mathbf{H}_{\mathrm{id}}\end{array}$ & $\begin{array}{c}(\mathrm{xl0kN)} \\
\mathbf{F}_{\mathbf{H i d}}+\mathbf{H}_{\mathrm{id}}\end{array}$ \\
\hline$\overline{1}$ & 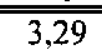 & 0,00 & 3923,60 & $2,164 \mathrm{E}-03$ & $2,164 \mathrm{E}-03$ & $-2,89$ & $-2,89$ \\
\hline 2 & 3,68 & 4,28 & 3692,80 & $7,613 \mathrm{E}-03$ & $5,449 \mathrm{E}-03$ & $-0,39$ & 3,89 \\
\hline 3 & 2,80 & 4,26 & 3462,00 & $1,235 \mathrm{E}-02$ & $4,735 \mathrm{E}-03$ & 0,32 & 4,58 \\
\hline 4 & 2,80 & 4,66 & 3231,20 & $1,714 \mathrm{E}-02$ & $4,795 \mathrm{E}-03$ & 0,51 & 5,17 \\
\hline 5 & 2,80 & 4,98 & 3000,40 & $2,183 \mathrm{E}-02$ & $4,686 \mathrm{E}-03$ & 0,59 & 5,57 \\
\hline 6 & 2,80 & 5,25 & 2769,60 & $2,631 \mathrm{E}-02$ & $4,478 \mathrm{E}-03$ & 0,61 & 5,86 \\
\hline 7 & 2,80 & 5,48 & 2538,80 & $3,052 \mathrm{E}-02$ & $4,208 \mathrm{E}-03$ & 0,60 & 6,08 \\
\hline 8 & 2,80 & 5,68 & 2308,00 & $3,442 \mathrm{E}-02$ & $3,902 \mathrm{E}-03$ & 0,57 & 6,25 \\
\hline 9 & 2,80 & 5,87 & 2077,20 & $3,799 \mathrm{E}-02$ & $3,568 \mathrm{E}-03$ & 0,53 & 6,40 \\
\hline 10 & 2,80 & 6,04 & 1846,40 & $4,120 \mathrm{E}-02$ & $3,216 \mathrm{E}-03$ & 0,47 & 6,51 \\
\hline 11 & 2,80 & 6,19 & 1615,60 & $4,406 \mathrm{E}-02$ & $2,854 \mathrm{E}-03$ & 0,42 & 6,61 \\
\hline 12 & 2,80 & 6,34 & 1384,80 & $4,654 \mathrm{E}-02$ & $2,482 \mathrm{E}-03$ & 0,36 & 6,70 \\
\hline 13 & 2,80 & 6,47 & 1154,00 & $4,865 \mathrm{E}-02$ & $2,110 \mathrm{E}-03$ & 0,30 & 6,77 \\
\hline 14 & 2,80 & 6,60 & 923,20 & $5,039 \mathrm{E}-02$ & $1,741 \mathrm{E}-03$ & 0,23 & 6,83 \\
\hline 15 & 2,80 & 6,72 & 692,40 & $5,178 \mathrm{E}-02$ & $1,388 \mathrm{E}-03$ & 0,17 & 6,89 \\
\hline 16 & 2,80 & 6,84 & 461,60 & $5,285 \mathrm{E}-02$ & $1,069 \mathrm{E}-03$ & 0,11 & 6,95 \\
\hline 17 & 2,80 & 6,95 & 230,80 & $5,367 \mathrm{E}-02$ & 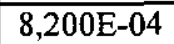 & 0,07 & 7,01 \\
\hline $\bar{\Sigma}$ & 48,97 & & & Tolerância & $9,4 \mathrm{E}-06$ & & \\
\hline
\end{tabular}


TABELA 8 - Comparação dos Resultados Obtidos Segundo os Três Processos de Análise de Segunda Ordem para o Exemplo do Ed. SPAZIO UNO.

(sentidos positivos dos eixos)

\begin{tabular}{|c|c|c|c|c|c|c|c|c|}
\hline \multirow{2}{*}{\multicolumn{2}{|c|}{ Efeitos }} & \multirow{2}{*}{$\begin{array}{c}\text { Análise de } \\
1^{\mathrm{a}} \\
\text { Ordem } \\
\end{array}$} & \multicolumn{6}{|c|}{ Processos de Análise de 2a. Ordem } \\
\hline & & & P.Rigoroso & $\%$ & $\overline{\mathbf{P}-\Delta}$ & $\%$ & P.Simplificado & $\%$ \\
\hline \multirow{2}{*}{$\begin{array}{l}\text { Flecha no } \\
\text { Topo(a)-m }\end{array}$} & $\bar{X}$ & 0,1203 & 0,1385 & 15,13 & 0,1379 & 14,63 & 0,1372 & 14,00 \\
\hline & $\bar{Y}$ & 0,0507 & 0,0538 & 6,11 & 0,0537 & 5,92 & 0,0532 & 5,00 \\
\hline \multirow{2}{*}{$\begin{array}{l}\text { Mom. na Base } \\
\text { (P5) } \times 10 \mathrm{kN} . \mathrm{m}\end{array}$} & $\bar{X}$ & 3,05 & 3,29 & 7,84 & $3, \overline{45}$ & 13,09 & 3,48 & 14,00 \\
\hline & $\bar{Y}$ & $-104,53$ & $-109,40$ & 4,57 & $-109,20$ & 4,38 & $-109,96$ & 5,00 \\
\hline \multirow{2}{*}{$\begin{array}{l}\text { Mom. na Base } \\
\text { (P11)x10kN. m }\end{array}$} & $\mathrm{X}$ & $-51,77$ & $-58,17$ & 12,37 & $-57,98$ & 12,00 & $-59,02$ & 14,00 \\
\hline & $\bar{Y}$ & $-2,28$ & $-2,32$ & 1,55 & $-2,39$ & 4,65 & $-2,40$ & 5,00 \\
\hline \multirow{2}{*}{$\begin{array}{l}\text { Normal na Base } \\
(\text { P9) } \times 10 \mathrm{kN}\end{array}$} & $\mathrm{X}$ & 471,13 & 478,30 & 14,74 & 478,50 & 15,16 & 477,95 & 14,00 \\
\hline & $\mathrm{Y}$ & 367,10 & 364,20 & 5,23 & 364,30 & 5,05 & 364,29 & 5,00 \\
\hline
\end{tabular}

TABELA 9 - Comparação dos Resultados Obtidos Segundo os Três Processos de Análise de Segunda Ordem para o Exemplo do Ed. SPAZIO UNO. (sentidos negativos dos eixos)

\begin{tabular}{|c|c|c|c|c|c|c|c|c|}
\hline \multicolumn{2}{|l|}{ feitos } & \multirow{2}{*}{$\begin{array}{l}\text { Análise } \\
\text { de 1a } \\
\text { Ordem }\end{array}$} & \multicolumn{5}{|c|}{ Processos de Análise de 2a. Ordem } & \multirow[b]{2}{*}{$\%$} \\
\hline & & & P.Rigoroso & $\%$ & $\mathbf{P}-\Delta$ & $\%$ & P.Simplificado & \\
\hline \multirow{2}{*}{$\begin{array}{l}\text { Flecha no } \\
\text { Topo(a)-m }\end{array}$} & $\bar{X}$ & $-0,1203$ & $-0,1385$ & 15,13 & $-0,1379$ & 14,63 & $-0,1372$ & 14,00 \\
\hline & $\mathrm{Y}$ & $-0,0741$ & $-0,0783$ & 5,67 & $-0,0781$ & 5,40 & $-0,0785$ & 6,00 \\
\hline \multirow{2}{*}{$\begin{array}{l}\text { Mom. na Base } \\
\text { (P5) } \times 10 \mathrm{kN} . \mathrm{m}\end{array}$} & $\bar{X}$ & $-3,05$ & $-3,33$ & 9,18 & $-3,45$ & 13,11 & -3, & 14,00 \\
\hline & $\bar{Y}$ & 0,15 & 115,60 & 5,08 & 115,40 & 4,89 & 116,65 & 6,00 \\
\hline \multirow{2}{*}{$\begin{array}{l}\text { Mom. na Base } \\
\text { (P11) } \times 10 \mathrm{kN} \cdot \mathrm{m}\end{array}$} & $\bar{X}$ & 51,74 & 58,16 & 12,40 & 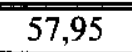 & 12,00 & 58,99 & 14,00 \\
\hline & $\bar{Y}$ & 2,50 & 2,54 & 1,67 & 2,62 & 5,02 & 2,64 & 6,00 \\
\hline \multirow{2}{*}{$\begin{array}{c}\text { Normal na Base } \\
\text { (P9) } \times 10 \mathrm{kN}\end{array}$} & $\bar{X}$ & 373,86 & 367,50 & 13,08 & 366,49 & 15,15 & 367,05 & 14,00 \\
\hline & $\bar{Y}$ & 477,89 & 481,80 & 7,06 & 481,54 & 6,59 & 481,21 & 6,00 \\
\hline
\end{tabular}

Obs.: $\quad 1$. Os valores exibidos nestas tabelas são valores de cálculo.

2. Os resultados obtidos através do processo $\mathbf{P}-\Delta$ expostos nesta tabela não contam com a correção de $\mathbf{H}_{\text {id }}$ pelo fator de flexibilidade sugerido por MACGREGOR(1993b) e FRANCO(1985b). 
3. Os resultados apresentados dos esforços são valores obtidos da análise da estrutura submetida a ações horizontais e verticais. Porém, o valores percentuais calculados dos acréscimos dos efeitos de segunda ordem sobre os de primeira, referem-se somente aos efeitos decorrentes das ações horizontais. Embora não seja válida a superposição de efeitos numa análise com não-linearidade, estes valores foram obtidos, de forma aproximada, subtraindo-se do valor total do efeito (devido às ações horizontais + ações verticais) o seu valor relativo às ações verticais e dividindo-se este último resultado pelo vaior do esforço de $1 \underline{a}$ ordem devido às ações horizontais.

TABELA 10 - Efeitos de Primeira Ordem para a Estrutura do Ed. SPAZIO UNO

Submetida Apenas a Açōes Horizontais.

\begin{tabular}{|c|c|c|}
\hline \multicolumn{2}{|l|}{ Efeitos } & Análise de \\
\hline \multirow{2}{*}{$\begin{array}{l}\text { Flecha no } \\
\text { Topo(a)-m }\end{array}$} & $\overline{\mathrm{X}}$ & 0,1203 \\
\hline & $\mathrm{Y}$ & 0,0624 \\
\hline \multirow{2}{*}{$\begin{array}{l}\text { Mom. na Base } \\
(\mathrm{P5}) \times 10 \mathrm{kN} . \mathrm{m}\end{array}$} & $\mathrm{X}$ & 3,05 \\
\hline & $\bar{Y}$ & $-107,40$ \\
\hline \multirow{2}{*}{$\begin{array}{l}\text { Mom. na Base } \\
\text { (P11) } \times 10 \mathrm{kN} \cdot \mathrm{m}\end{array}$} & $\mathrm{X}$ & $-51,76$ \\
\hline & $\mathrm{Y}$ & $-2,39$ \\
\hline \multirow{2}{*}{$\begin{array}{c}\text { Normal na Base } \\
\text { (P9) } \times 10 \mathrm{kN}\end{array}$} & $\mathrm{X}$ & 48,64 \\
\hline & $\bar{Y}$ & $-55,40$ \\
\hline
\end{tabular}

Para a consideração aproximada da NLF na análise da estrutura do exemplo aqui estudado, considerou-se uma redução da rigidez EI de $30 \%$ de seu valor equivalente à inércia da seção bruta para todos os elementos estruturais. Porém, de acordo com o que foi discutido no item 3.3-b, existem outros valores de redução sugeridos por pesquisadores. Nesse mesmo item, realizaram-se cálculos de deslocamentos em exemplos simples de estruturas planas, com a intenção de verificar, preliminarmente, a variabilidade dos resultados obtidos.

Aproveita-se agora o exemplo do edifício SPAZIO UNO para se verificar a influência destes valores de redução da rigidez nos resultados de efeitos de segunda ordem, que é justamente onde haveriam problemas, e o estudo dessas variações foi realizado utilizando-se apenas o processo rigoroso. Repetindo: a primeira variação (I) 
considera $I=\mathbf{0 , 7} I_{c}$ para vigas e pilares, a segunda variação (II), $I=\mathbf{0 , 4} I_{c}$ para as vigas e $\mathbf{I}=\mathbf{0 , 8 I _ { c }}$ para os pilares e a terceira variação (III), $\mathbf{I}=\mathbf{0 , 5} \mathrm{I}_{\mathbf{c}}$ para as vigas e $\mathbf{I}=\mathbf{0 , 8 I _ { c }}$ para os pilares. Serão utilizados para esta verificação os mesmos efeitos analisados na Tab. 8. Na Tab. 11 encontram-se expostos os valores percentuais dos acréscimos de segunda ordem destes efeitos para cada uma das três variações.

TABELA 11 - Comparação dos Resultados para as Três Variaç̃̃es de Redução da Inércia

\begin{tabular}{|c|c|c|c|c|c|c|}
\hline \multirow{2}{*}{ Efeitos } & \multicolumn{3}{|c|}{ Direção X } & \multicolumn{3}{c|}{ Direção Y } \\
\cline { 2 - 7 } & I & II & III & I & II & III \\
\hline \hline Flecha no Topo (a)\% & 15,13 & 20,74 & 17,52 & 6,11 & 7,93 & 6,88 \\
\hline Mom. na Base (P5)\% & 7,84 & 11,23 & 9,46 & 4,57 & 6,18 & 5,35 \\
\hline Mom. na Base (P11)\% & 12,37 & 16,92 & 14,41 & 1,55 & 2,44 & 2,01 \\
\hline Normal na Base (P9)\% & 14,74 & 20,38 & 17,09 & 5,23 & 7,10 & 6,12 \\
\hline
\end{tabular}

Observando-se estes resultados, percebe-se que ainda existe uma certa variação entre as três opções e que não deve ser, de forma alguma, ignorada. Outro fato que deve-se observar é que, a adoção diferenciada da redução da rigidez EI para vigas e pilares parece ser mais racional, tendo em vista que o estado de fissuração destes elementos não é o mesmo em virtude das solicitações a que eles são submetidos. Além disso, os resultados obtidos com base nos estudos experimentais de HAGE \& MACGREGOR (ver item 3.3-b) confirmam este fato. No caso dos procedimentos adotados até aqui neste trabalho, entretanto, esta observação não invalida os resultados obtidos pelo seguinte fato: seja, por exemplo, uma determinada estrutura a ser analisada cujas vigas possuam seção transversal de altura igual a $60 \mathrm{~cm}$, e pilares com uma das dimensões da seção transversal igual a $95 \mathrm{~cm}$. Se ao invés de considerar-se a redução da inércia para 0,4 vezes o seu valor bruto para as vigas e 0,8 para os pilares, venha-se a adotar a redução para $0,7 \mathbf{I}_{\mathbf{c}}$ para ambos os tipos de elementos, este procedimento equivaleria à realização da mesma análise em uma estrutura formada por vigas de altura igual a aproximadamente $50 \mathrm{~cm}$ e pilares com uma das dimensões igual a $100 \mathrm{~cm}$, que são dimensões perfeitamente possíveis de existir nas estruturas correntes.

No presente trabalho, como poderá ser verificado, todos os processamentos foram realizados com redução das inércias brutas $\left(\mathbf{I}_{c}\right)$ das vigas e pilares para $\mathbf{0 , 7} \mathbf{I}_{\mathbf{c}}$. 
Acredita-se que, para efeito de comparação e com base no comentário feita para o exemplo dado no parágrafo anterior, este procedimento não invalida as correlações aqui obtidas. Além disso, como este valor simplificado para redução da inércia para aconsideração da NLF consta na NB-1/1994(ABNT), este será provavelmente o procedimento mais utilizado pelos projetistas.

Não há dúvidas de que um estudo mais aprofundado dos valores propostos de redução de rigidez EI para a consideração aproximada da NLF precisa ser realizado. Preocupado com a diversidade desses valores, FRANCO(1995) sugere, com a avaliação que ele próprio pretende fazer, que se utilize um programa que realiza análises de segunda ordem ${ }^{14}$ que permita essa consideração utilizando as relações constitutivas do concreto e do aço.

No próximo capítulo, serão feitas comparações entre os parâmetros $\mathbf{a} / \mathbf{H}, \alpha$ e $\gamma_{\mathbf{z}}$ e entre resultados de análises de segunda ordem feitas de acordo com os três processos aqui discutidos, calculados para estruturas de trinta edifícios regulares de concreto armado. Os procedimentos utilizados para a realização destes cálculos serão os mesmos descritos no exemplo do edifício SPAZIO UNO neste capítulo. Com base na análise dos resultados aqui obtidos para este exemplo, entretanto, algumas atitudes foram tomadas para a realização daqueles processamentos, a saber:

- Serão feitas análises para ações horizontais incidentes apenas nos sentidos positivos dos eixos $\mathbf{X}$ e $\mathbf{Y}$.

- A NLF será considerada aproximadamente reduzindo-se a rigidez de todos os

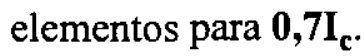

- Nas análises de segunda ordem pelo processo simplificado, não serão consideradas alterações nos coeficientes $\gamma_{\mathbf{z}}$ devido à presença das ações verticais. Como foi visto, em estruturas regulares bem elaboradas, estas alterações não são significativas.

- Nas análises de segunda ordem pelo processo P- $\Delta$, também não serão realizadas correções dos valores de $\mathbf{H}_{\mathbf{i d}}$ pelo fator de flexibilidade.

${ }^{14}$ No caso do estudo que FRANCO(1995) pretende fazer, o programa foi desenvolvido por PIMENTA, Non-linear analysis of plane frames $I$. Boletim Técnico da Escola Politécnica da USP, n.8910, São Paulo, 1990 apud FRANCO, M.(1995). Global and local instabitity of concrete tall buildings. In: SYMPOSIUM ON SPACE STRUCTURES, Milan, May. Proceedings. 
Estas atitudes, além de simplificarem os procedimentos de análise, não causam grandes alterações dos resultados, para efeito comparativo. Ainda, como foi visto, objetiva-se aproximar o esquema teórico dos procedimentos usuais dos escritórios de projetos estruturais.

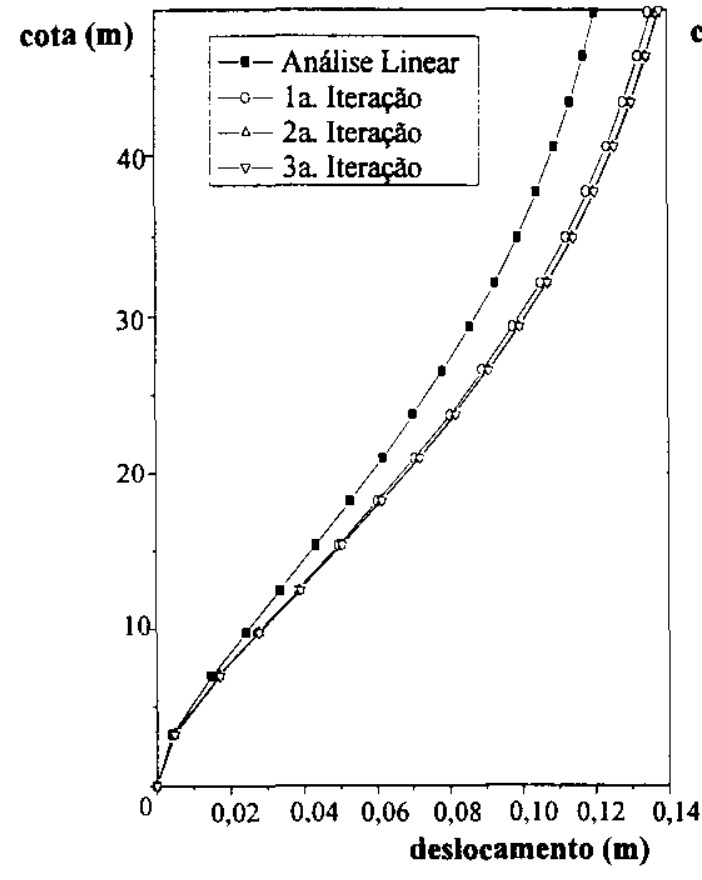

(a)

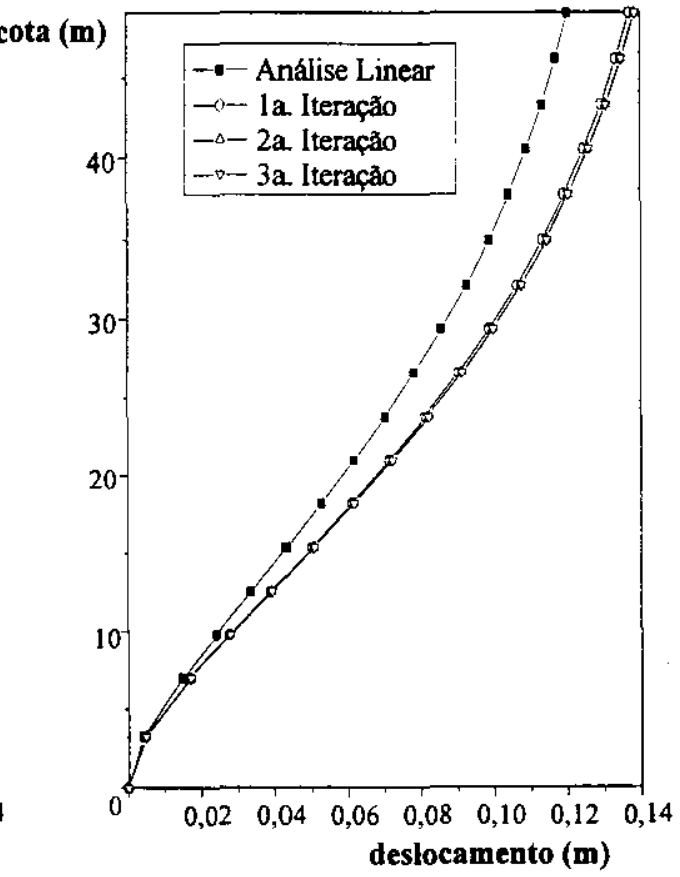

(b)

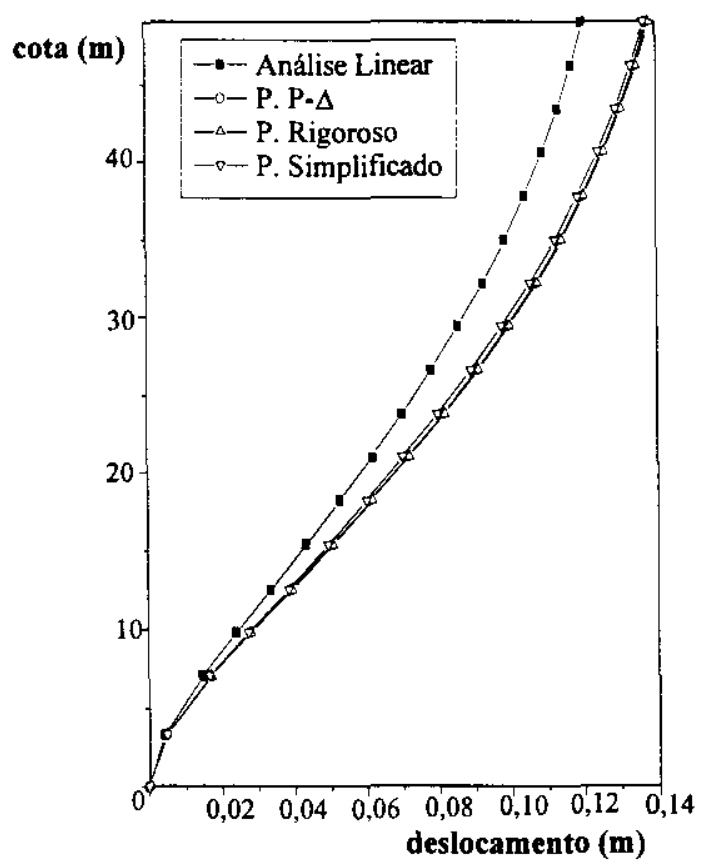

(c)

Figura 21 - Deslocamentos ao Longo da Altura do Edifício SPAZIO UNO

(das 3 iterações dos processos $P-\Delta$ (a) e rigoroso (b) e dos 3 processos (c)) 


\section{CAPÍTULO 4 - EXEMPLOS DE APLICAÇÃO EM EDIFÍCIOS USUAIS DE CONCRETO ARMADO}

\section{1 - INTRODUÇÃO}

Foram utilizadas estruturas de edifícios usuais de concreto armado elaborados por projetistas diversos, para a realização do cálculo dos parâmetros e efeitos de segunda ordem de acordo com o que foi estudado no capítulo 3. Como foi visto, pretende-se avaliar-lhes a eficiência através de sua comparação, além de buscar correlações entre eles.

Os procedimentos usados durante as análises destas estruturas são os mesmos que foram utilizados no exemplo único de aplicação do capitulo 3 , o edifício SPAZIO UNO (Fig. 15), onde apresentam-se melhor comentados. Aqui neste capítulo, portanto, somente serão apresentados os resultados finais dos parâmetros e efeitos obtidos para cada exemplar, para que se possa posteriormente estabelecer um confronto entre eles.

\section{2 - EXEMPLARES}

Os exemplos utilizados neste trabalho são estruturas de trinta (30) edifícios regulares que foram analisados pelo escritório de projetos estruturais TECSOF ENGENHARIA DE ESTRUTURAS S/C LTDA, com modelos para análise concebidos em grelha ou elementos finitos. Muitas das estruturas utilizadas correspondem à fase preliminar de projeto, sendo por isso possível observar-se que alguns possuem os valores calculados dos parâmetros $\alpha, \gamma_{\mathbf{z}}$ e $\mathbf{a} / \mathbf{H}$ fora dos limites tolerados. Isto possibilitou gerar um amplo intervalo de dados, contribuindo para a melhor observação dos resultados. 
No modelo adotado para efeito de análise destas estruturas, o sistema estrutural é considerado composto por pórticos e lajes. Todos os pilares são levados em conta e as lajes funcionam como diafragmas rígidos em seu plano e flexíveis na direção normal ao pavimento, distribuindo as ações laterais entre os painéis de contraventamento e compatibilizando os deslocamentos no seu plano.

\section{3 - PROGRAMAS}

Foram utilizados programas da biblioteca do sistema LASER, RAMALHO(1990), desenvolvido no Departamento de Estruturas da EESC-USP, para análises de pórticos tridimensionais em primeira ordem e para a determinação dos parâmetros $\alpha, \gamma_{z}, a / H$ e $\psi$, das estruturas submetidas a carregamentos nodais.

Para a análise estrutural de segunda ordem pelo processo rigoroso, utilizou-se a adaptação feita ao sistema LASER por CORRÊA(1991), que permite a análise de problemas não-lineares, com processo incremental iterativo. A consideração da NLG é feita através do Método dos Elementos Finitos, como foi comentado no item 3.6.1a, e o formalismo adotado na decomposição da matriz de rigidez foi o das matrizes incrementais. Foi estabelecido um número máximo de 10 iterações e estipulada uma tolerância em deslocamento de 0,001 como critério de convergência para definir o fim do processo iterativo. Nessa adaptação, porém, a consideração da NLF é feita aproximadamente e neste trabalho isto se fez através da redução da rigidez dos elementos para $0,7 \mathbf{E I}$ (ver itens 3.3-b e 3.6.4).

\section{4 - AÇÕES}

A ação do vento sobre as estruturas foi calculada de acordo com a NBR6123/1988 (ABNT) e utilizada para o cálculo de $\mathbf{a} / \mathbf{H}, \gamma_{\mathbf{z}}$ e nas análises estruturais de 1a e 2a ordens. As ações verticais são utilizadas nas análises de segunda ordem juntamente com as ações horizontais do vento. As ações horizontais e as verticais foram ponderadas pelos coeficientes $\gamma_{f}=1,4$ e $\gamma_{f}=1,0$ respectivamente, conforme sugestão de FRANCO \& VASCONCELOS(1991) para edifícios residenciais (ver item 3.3-b) e as estruturas foram analisadas apenas considerando-se os sentidos positivos dos eixos, conforme justificou-se em 3.6.4. 
Para o cálculo de $\alpha$ arbitrou-se uma ação horizontal uniformemente distribuída ao longo da altura de cada estrutura. Posteriormente esta ação foi transformada em forças concentradas aplicadas ao nível de cada pavimento, para efeito de utilização do sistema LASER.

Outras modalidades de ação horizontal citadas -em 3.3-g não foram consideradas nas análises, pois acredita-se que, para efeito de comparação, somente iriam aumentar a escala dos resultados, levando-se a conclusões semelhantes sobre o fenômeno.

\section{5 - SIMPLIFICAÇÕES}

O sistema LASER tem recursos para gerar o pórtico tridimensional de vários andares a partir de um pavimento básico, com as forças de vento devidamente calculadas e aplicadas. Para efeito de simplificação e principalmente de comparação, a forma de todos os pavimentos de cada estrutura foi considerada igual à do pavimento tipo, ou seja, as modificações normalmente existentes nos pavimentos de subsolo, térreo, cobertura, etc. foram desprezadas, exceto os seus pés-direitos. Além disso, as suas resultantes verticais também foram considerados iguais às do pavimento tipo.

Como foi visto, as estruturas dos edificios usados para a realização deste trabalho foram elaboradas por projetistas diferentes e para serem construídas também em locais diferentes. Ou seja, principalmente com relação ao cálculo das ações de vento e às propriedades dos materiais, os resultados requeridos seriam obtidos para situações diferentes. Por isso, entre as estruturas, algumas uniformizações foram adotadas para poder compará-las em igualdade de condições. Foram, portanto, adotados velocidade básica do vento $\mathrm{V}_{\mathbf{0}}$ igual a $38,0 \mathrm{~m} / \mathrm{s}$ e módulo de deformação longitudinal do concreto igual a $3,0 \cdot 10^{7} \mathrm{kN} / \mathrm{m}^{2}$.

\section{6 - RESULTADOS OBTIDOS}

Apresentam-se nas Tabs. 12 e 13 os valores de $\alpha, \gamma_{\mathbf{Z}}$ e a/H calculados para as estruturas citadas no item 4.2, analisando-as segundo as direções ortogonais principais $\mathbf{X}$ e $\mathbf{Y}$. A direção $\mathbf{Y}$ foi adotada como a direção perpendicular à maior 
largura em planta baixa da estrutura. Observa-se que, geralmente, a esta direção estão associadas ações de vento de maior intensidade devido à equivalente área efetiva $\left(\mathbf{A}_{\mathfrak{e}}\right)$ que se utiliza no cálculo dessas ações (Fig. 22). Além desses dados, as Tabs. 12 e 13 possuem os valores dos parâmetros de forma $\psi$ dos edificios para cada direção, o número total de pavimentos e a ação vertical resultante de cálculo do pavimento tipo de cada um deles.

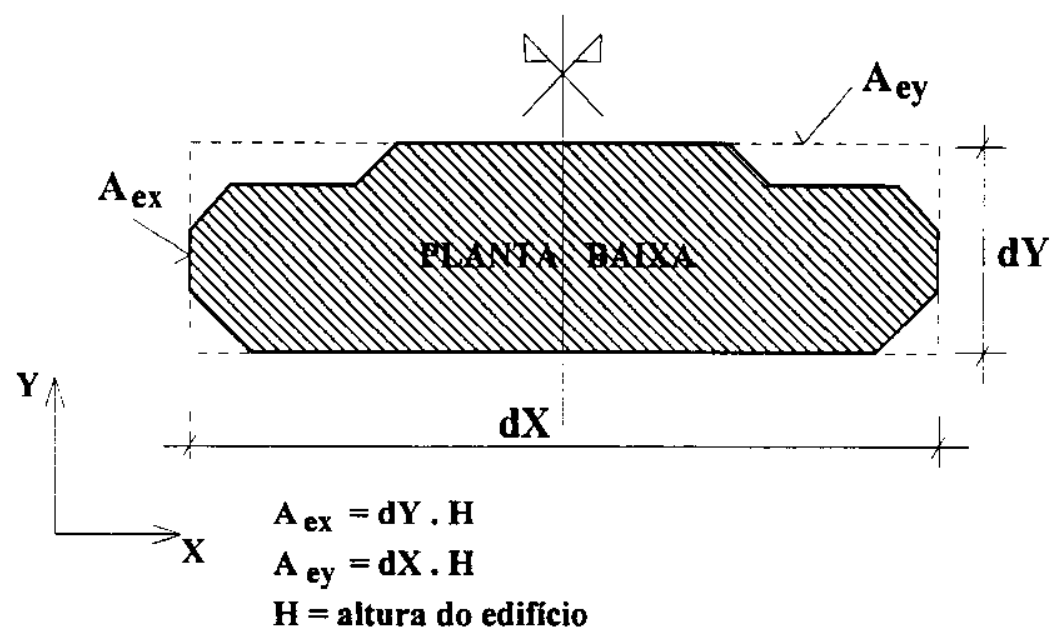

FIGURA 22 - Áreas Efetivas $\left(\mathrm{A}_{\mathrm{e}}\right.$ ) de um Edifício

Os valores dos coeficientes obtidos foram lançados em gráfico, dois a dois, para serem melhor comparados (Figs. 23-a, 23-b e 24). Para cada direção dos edifícios existem ações e respostas a estas ações diferentes, por isso, tudo funciona como se existisse, na realidade, o dobro do número de exemplares usados na obtenção dos resultados. Portanto, esses resultados calculados segundo cada direção são representados juntos em cada um dos gráficos. Ou seja, cada ponto mostrado nestes gráficos representa o resultado calculado para uma determinada direção de cada prédio, num total de sessenta pontos. 
Tabela 12 - Resultados Obtidos da Análise Segundo a Direção X

\begin{tabular}{|c|c|c|c|c|c|c|c|}
\hline \multirow{2}{*}{ No } & \multirow{2}{*}{ Edifício } & \multirow{2}{*}{$\begin{array}{r}\text { No } \\
\text { de } \\
\text { Pav. }\end{array}$} & \multirow{2}{*}{$\begin{array}{c}\text { Carga } \\
\text { Tipo } \\
(x 10 \mathrm{kN})\end{array}$} & \multicolumn{4}{|c|}{ Direção X } \\
\hline & & & & $\bar{\psi}$ & $\alpha$ & $\gamma_{z}$ & $\overline{a / H}$ \\
\hline 1 & Top Life & 20 & 220,10 & 0,597 & 0,97 & 1,23 & $1 / 581$ \\
\hline 2 & Spazio Uno & 17 & 230,80 & 0,617 & 0,75 & 1,14 & $1 / 813$ \\
\hline 3 & Av. Circular & 14 & 323,70 & 0,597 & 0,87 & 1,19 & $1 / 703$ \\
\hline 4 & Conde do Pinhal & 14 & 236,00 & 0,572 & 0,76 & 1,13 & $1 / 1014$ \\
\hline 5 & Córsega & 18 & 366,00 & 0,478 & 0,73 & 1,12 & $1 / 1408$ \\
\hline 6 & Stradus & 12 & 439,54 & 0,637 & 1,11 & 1,38 & $1 / 800$ \\
\hline 7 & San Petrus & 18 & 269,83 & 0,613 & 0,66 & 1,11 & $1 / 926$ \\
\hline 8 & M. do Bosque & 11 & 395,16 & 0,587 & 0,81 & 1,16 & $1 / 2778$ \\
\hline 9 & Ville Florence & 16 & 470,43 & 0,550 & 0,72 & 1,11 & $1 / 1390$ \\
\hline 10 & Ed. Ribeiro & 14 & 290,00 & 0,608 & 0,47 & 1,05 & $1 / 3457$ \\
\hline 11 & Butantã & 15 & 233,68 & 0,552 & 0,80 & 1,15 & $1 / 1259$ \\
\hline 12 & Condomínio III & 24 & 384,83 & 0,580 & 1,17 & 1,40 & $1 / 599$ \\
\hline 13 & Rua Indiana & 25 & 372,06 & 0,588 & 1,22 & 1,44 & $1 / 677$ \\
\hline 14 & Avant Place & 22 & 640,84 & 0,684 & 0,80 & 1,18 & $1 / 3081$ \\
\hline 15 & Maison Classic & 15 & 433,43 & 0,584 & 0,86 & 1,18 & $1 / 1531$ \\
\hline 16 & Art 1 & 19 & 346,86 & 0,638 & 0,78 & 1,16 & $1 / 1361$ \\
\hline 17 & Porto Bello & 11 & 481,12 & 0,595 & 0,70 & 1,12 & $1 / 3567$ \\
\hline 18 & José F. Guimarães & 18 & 603,67 & 0,585 & 0,99 & 1,26 & $1 / 1013$ \\
\hline 19 & Espaço S. P. II & 21 & 567,27 & 0,572 & 0,95 & 1,23 & $1 / 1012$ \\
\hline 20 & Cartier Tower & 18 & 526,81 & 0,542 & 1,03 & 1,27 & $1 / 661$ \\
\hline 21 & Franc. Amêndola & 20 & 387,11 & 0,623 & 0,84 & 1,19 & $1 / 863$ \\
\hline 22 & Premium & 15 & 385,50 & 0,657 & 0,71 & 1,13 & $1 / 2009$ \\
\hline 23 & Vermont & 17 & 175,00 & 0,525 & 0,83 & 1,15 & $1 / 1231$ \\
\hline 24 & Maison Cartier & 19 & 220,45 & 0,542 & 0,66 & 1,09 & $1 / 795$ \\
\hline 25 & Office Tower & 24 & 939,66 & 0,569 & 1,08 & 1,31 & $1 / 574$ \\
\hline 26 & Porto Ferrara & 13 & 368,32 & 0,654 & 0,69 & 1,12 & $1 / 2235$ \\
\hline 27 & Maison Etoile & 21 & 331,00 & 0,582 & 0,71 & 1,12 & $1 / 2944$ \\
\hline 28 & Corinto & 18 & 384,98 & 0,563 & 0,64 & 1,09 & $1 / 1535$ \\
\hline 29 & Ville Dijon & 15 & 391,64 & 0,569 & 0,72 & 1,12 & $1 / 1122$ \\
\hline 30 & M. Bougainville & 20 & 301,89 & 0,580 & 0,73 & 1,12 & $1 / 2239$ \\
\hline
\end{tabular}


Tabela 13 - Resultados Obtidos da Análise Segundo a Direção Y

\begin{tabular}{|c|c|c|c|c|c|c|c|}
\hline \multirow{2}{*}{ No } & \multirow{2}{*}{ Edifício } & \multirow{2}{*}{$\begin{array}{c}\text { No } \\
\text { de } \\
\text { Pav. }\end{array}$} & \multirow{2}{*}{$\begin{array}{c}\text { Carga } \\
\text { Tipo } \\
(x 10 \mathrm{kN})\end{array}$} & \multicolumn{4}{|c|}{ Direção Y } \\
\hline & & & & $\psi$ & $\bar{\alpha}$ & $\overline{\gamma_{z}}$ & $\mathrm{a} / \mathbf{H}$ \\
\hline 1 & Top Life & 20 & 220,10 & 0,626 & 0,83 & 1,18 & $1 / 608$ \\
\hline 2 & Spazio Uno & 17 & 230,80 & 0,611 & 0,49 & 1,06 & $1 / 1570$ \\
\hline 3 & Av. Circular & 14 & 323,70 & 0,606 & 0,70 & 1,12 & $1 / 1028$ \\
\hline 4 & Conde do Pinhal & 14 & 236,00 & 0,580 & 0,48 & 1,05 & $1 / 1339$ \\
\hline 5 & Córsega & 18 & 366,00 & 0,513 & 0,57 & 1,07 & $1 / 1106$ \\
\hline 6 & Stradus & 12 & 439,54 & 0,605 & 0,51 & 1,06 & $1 / 1445$ \\
\hline 7 & San Petrus & 18 & 269,83 & 0,596 & 0,60 & 1,08 & $1 / 1123$ \\
\hline 8 & M. do Bosque & 11 & 395,16 & 0,600 & 0,40 & 1,04 & $1 / 3374$ \\
\hline 9 & Ville Florence & 16 & 470,43 & 0,649 & 0,69 & 1,12 & $1 / 1214$ \\
\hline 10 & Ed. Ribeiro & 14 & 290,00 & 0,590 & 0,46 & 1,05 & $1 / 1360$ \\
\hline 11 & Butantã & 15 & 233,68 & 0,571 & 0,91 & 1,21 & $1 / 414$ \\
\hline 12 & Condomínio III & 24 & 384,83 & 0,551 & 1,14 & 1,35 & $1 / 260$ \\
\hline 13 & Rua Indiana & 25 & 372,06 & 0,515 & 0,90 & 1,18 & $1 / 337$ \\
\hline 14 & Avant Place & 22 & 640,84 & 0,623 & 0,76 & 1,15 & $1 / 582$ \\
\hline 15 & Maison Classic & 15 & 433,43 & 0,579 & 0,99 & 1,26 & $1 / 373$ \\
\hline 16 & Art 1 & 19 & 346,86 & 0,615 & 1,14 & 1,41 & $1 / 218$ \\
\hline 17 & Porto Bello & 11 & 481,12 & 0,613 & 0,63 & 1,10 & $1 / 1094$ \\
\hline 18 & José F. Guimarães & 18 & 603,67 & 0,594 & 0,78 & 1,15 & $1 / 973$ \\
\hline 19 & Espaço S. P. II & 21 & 567,27 & 0,619 & 0,78 & 1,15 & $1 / 1165$ \\
\hline 20 & Cartier Tower & 18 & 526,81 & 0,613 & 0,76 & 1,14 & $1 / 1102$ \\
\hline 21 & Franc. Amêndola & 20 & 387,11 & 0,578 & 0,66 & 1,10 & $1 / 865$ \\
\hline 22 & Premium & 15 & 385,50 & 0,587 & 0,68 & 1,11 & $1 / 599$ \\
\hline 23 & Vermont & 17 & 175,00 & 0,497 & 0,84 & 1,15 & $1 / 275$ \\
\hline 24 & Maison Cartier & 19 & 220,45 & 0,537 & 0,55 & 1,10 & $1 / 746$ \\
\hline 25 & Office Tower & 24 & 939,66 & 0,549 & 1,06 & 1,29 & $1 / 395$ \\
\hline 26 & Porto Ferrara & 13 & 368,32 & 0,594 & 0,49 & 1,05 & $1 / 1047$ \\
\hline 27 & Maison Etoile & 21 & 331,00 & 0,542 & 0,75 & 1,13 & $1 / 579$ \\
\hline 28 & Corinto & 18 & 384,98 & 0,544 & 0,78 & 1,14 & $1 / 997$ \\
\hline 29 & Ville Dijon & 15 & 391,64 & 0,593 & 0,65 & 1,10 & $1 / 1229$ \\
\hline 30 & M. Bougainville & 20 & 301,89 & 0,570 & 0,58 & 1,07 & $1 / 632$ \\
\hline
\end{tabular}




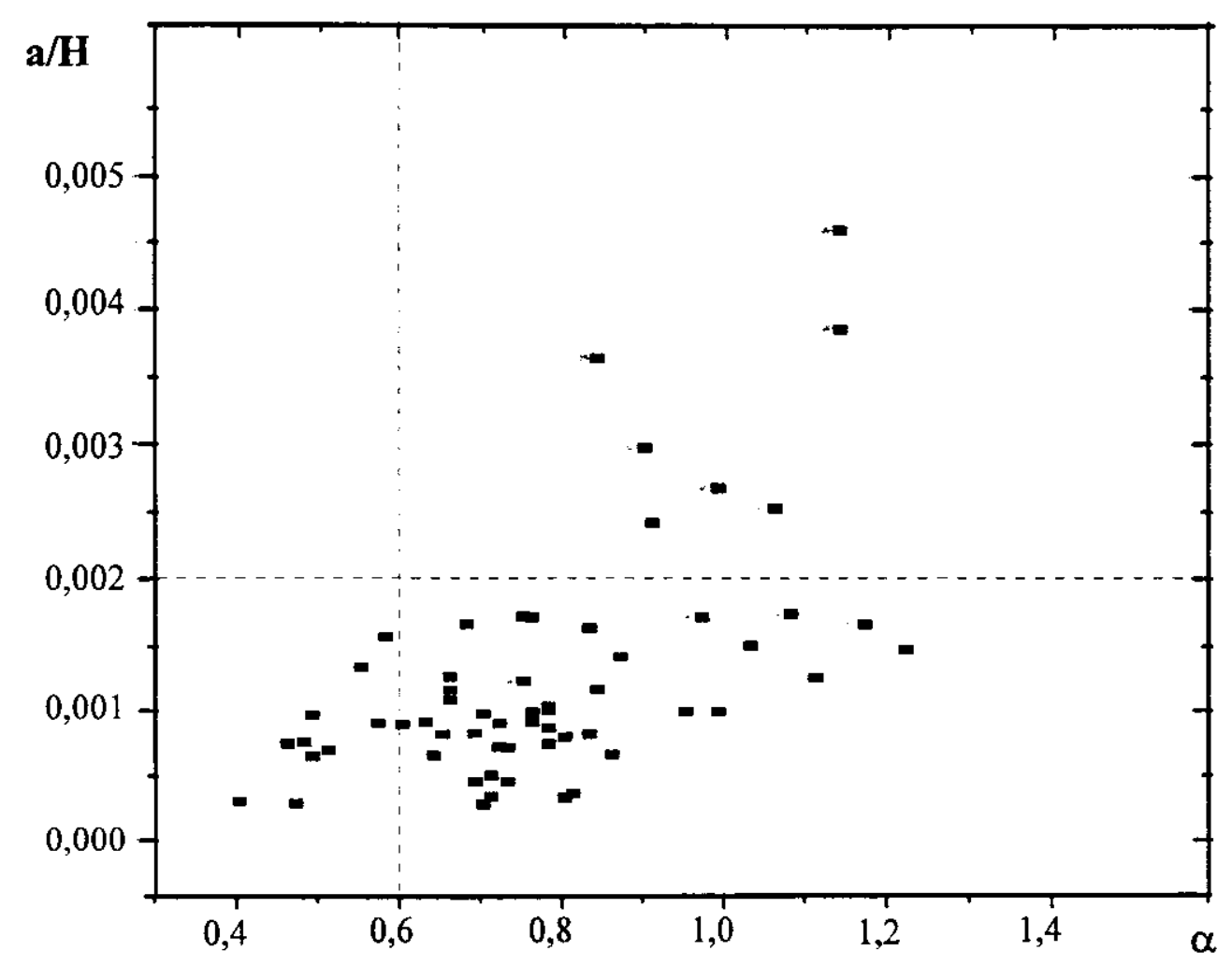

(a)

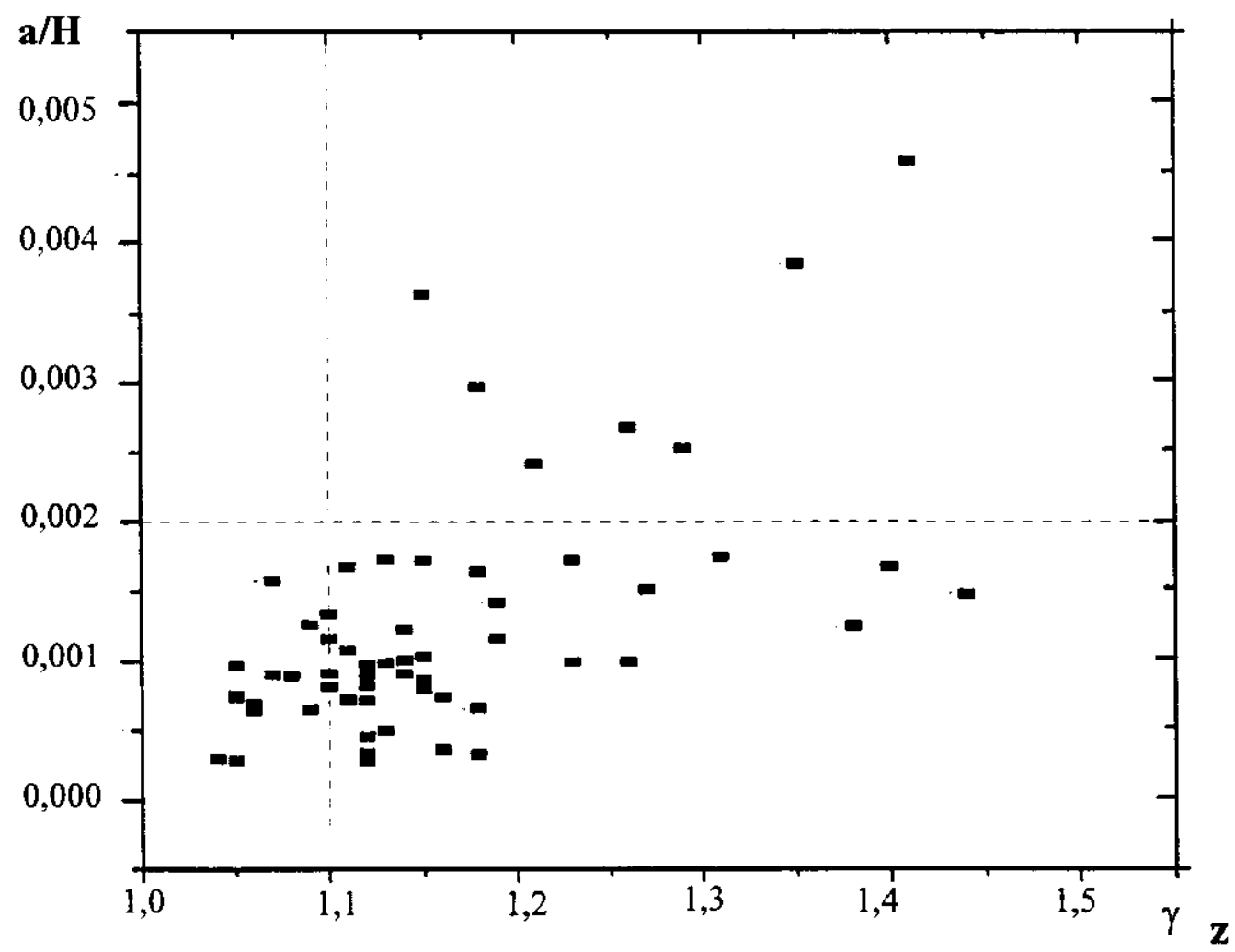

(b)

FIGURA 23 - Relaçōes $\alpha$ x a/H e $\gamma_{z} x$ a/H 


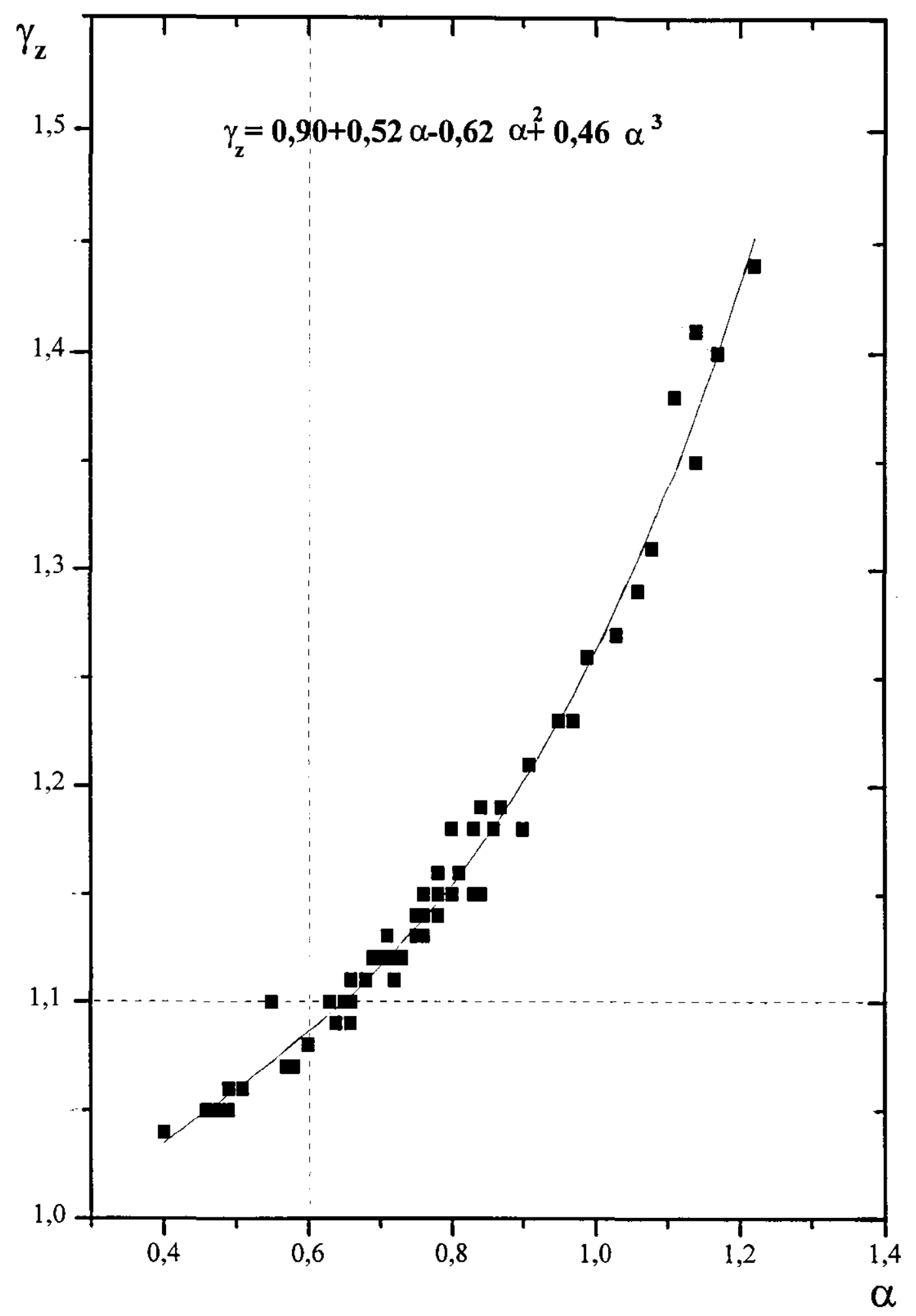

FIGURA 24- Relação $\alpha \times \gamma_{z}$ 
Observando-se os resultados, percebe-se que entre os parâmetros $\alpha$ e $\gamma_{z}$ existe uma certa correlação (Fig. 24), o que se esperava uma vez que ambos foram formulados com base em análises que consideram a deformabilidade ao se estabelecer o equilíbrio da estrutura. Entretanto, a principal observação a ser feita é que, entre a relação a/H e os outros dois coeficientes (Figs. 23-a e 23-b) não pode ser notada qualquer relação. Isto confirma a impossibilidade de utilizar-se a relação $\mathbf{a} / \mathbf{H}$ como parâmetro de instabilidade, como se havia comentado.

Analisando-se os resultados expostos nas Tabs. 12 e 13, pode-se calcular percentualmente quantos dos coeficientes calculados estariam dentro dos limites para eles estabelecidos, de acordo com o que foi visto no capitulo 3. Em relação aos parâmetros $\alpha$ (considerando-se tanto o limite de 0,6 estabelecido pelo CEB(1990) para edificações com mais de quatro pavimentos, quanto os limites estabelecidos por FRANCO(1985) de acordo com o parâmetro de forma dos edifícios, calculados pela Eq. 29 para cada um deles) e $\gamma_{\mathbf{z}}, 96,67 \%$ (29 edifícios) e 93,33\% (28 edifícios) dos edificios, respectivamente, teriam as suas estruturas consideradas de nós móveis e obrigatoriamente submetidas a uma análise não-linear, para análises feitas considerando-se as ações horizontais incidindo em pelo menos uma das suas duas direções principais. Entretanto, de acordo com a relação $\mathbf{a} / \mathbf{H}$ calculada, apenas $23,33 \%$ (7 edifícios) dos edificios, em pelo menos uma das duas direções de incidência do vento consideradas, ultrapassariam 1/500. Mais uma vez confirma-se o perigo de se utilizar a verificação do valor de $\mathbf{a} / \mathbf{H}$ como procedimento único de avaliação da rigidez lateral das estruturas. Porém, é importante frisar que o cálculo do valor de $\mathbf{a} / \mathbf{H}$ deve continuar sendo realizado para a verificação do estado limite de deformações excessivas, conforme as prescrições dos diversos regulamentos que abordam $o$ assunto.

O ajuste da curva da Fig. 23 fornece a equação aproximada que relaciona os parâmetros $\alpha$ e $\gamma_{\mathbf{Z}}$, a saber:

$$
\gamma_{Z}=0,90+0,52 \alpha-0,62 \alpha^{2}+0,46 \alpha^{3}
$$

Observe-se que, para $\alpha=0,6, \gamma_{z} \cong \mathbf{1}, 1$. Dispondo-se de uma rotina de cálculo que já permite determinar o valor do parâmetro $\alpha$, pode-se facilmente obter o coeficiente $\gamma_{z}$ pela Eq. 43 para a estrutura em estudo. 
A segunda etapa da análise dos exemplos, como foi dito, trata da comparação dos resultados de análises de segunda ordem pelos processos rigoroso, $\mathbf{P}-\Delta$ e pelo método simplificado (utilizando-se o coeficiente $\gamma_{\mathbf{z}}$ ). Esta comparação pretende verificar, principalmente, se o parâmetro $\gamma_{\mathbf{z}}$ é suficiente para a majoração dos efeitos de primeira ordem, a fim de obter os esforços finais que incluem os de segunda ordem.

Para a realização desta comparação, foram escolhidos, dentre os trinta exemplares analisados na etapa anterior, sete (7) edifícios, com diversos valores de $\gamma$ z. Observando-se a Tab. 12 ou a Tab. 13, os edifícios escolhidos foram os de número $1,2,6,12,13,20,28$ cujas formas e demais dados são apresentados no ANEXO A (exceto as dos edifícios 1 e 2 , apresentadas nas páginas 86 e 41 , respectivamente).

Uma vez realizados os processamentos, fez-se uma comparação entre os efeitos de primeira e segunda ordem calculados, estes últimos obtidos de acordo com os três processos já comentados. Esta comparação envolveu, principalmente, o deslocamento no topo do edifício em estudo e todos os esforços de sua estrutura. Apenas os esforços importantes, ou melhor, os esforços contidos no plano definido pela direção de atuação do vento em questão, foram considerados nesta avaliação. Esta atitude decorreu da grande dispersão nos resultados causada pelos esforços contidos nos planos diferentes dos planos de incidência do vento considerados na análise.

Nas Tabs. 15 a 22, para cada edifício analisado, apresentam-se separadamente os resultados em média para os elementos tipo viga, tipo pilar e a média global entre eles, analisando-se o edifício como um todo; os mesmos cálculos foram feitos por trechos em que a estrutura foi dividida ao longo de sua altura: ao nível da fundação e em três (3) faixas nos níveis restantes (incluindo o nível da fundação). Durante o dimensionamento das estruturas dos edifícios altos, o procedimento usual utiliza definir faixas da altura do mesmo para as quais adota-se igual tratamento para os elementos dos diversos pavimentos contidos na mesma faixa, a partir dos resultados dos esforços atuantes nas seções transversais mais solicitadas. Por isso, o número de faixas da altura da estrutura foi definido neste estudo observando-se o número de pavimentos dos edifícios escolhidos, que varia de doze (12) a vinte e cinco (25) pavimentos. Neste caso, o procedimento muitas vezes adotado para o dimensionamento seria definir de uma (1) a três (3) faixas da altura das estruturas. Optou-se, portanto, por estabelecer-se o total de três (3) faixas para dar igual 
tratamento aos exemplares escolhidos, já que se trata mais uma vez de um estudo comparativo de resultados. Foram enumeradas crescentemente a partir do nível da fundação, para efeito de refêrencia. Assim, a primeira faixa é aquela mais próxima da base do edifício, a segunda é a faixa intermediária e a terceira é a faixa que contém o topo da estrutura.

Antes, porém, analisem-se nas Tabs. 8 e 14 os resultados de esforços em alguns elementos isolados dos edifícios SPAZIO UNO e TOP LIFE, cujas formas se encontram expostas nas Figs. 15 e 25, respectivamente. Note-se que, geralmente, nos casos em que a direção do vento coincide com a direção de maior rigidez do elemento (direção da maior inércia do pilar ou direção do eixo da viga), a aproximação entre os resultados segundo os três processos é maior. Percebe-se que o mesmo normalmente não ocorre quando não há essa coincidência. Entretanto, estes distúrbios não prejudicam a análise da estrutura pois, quando ocorrem, estão associados a valores absolutos de esforços pequenos se comparados aos esforços atuantes na direção de maior rigidez que regem o dimensionamento.

TABELA 14 - Comparação dos Resultados Obtidos Segundo os Três Processos de Análise de Segunda Ordem para o Exemplo do Ed. TOP LIFE.

\begin{tabular}{|c|c|c|c|c|c|c|c|c|}
\hline \multicolumn{2}{|l|}{ Efeitos } & \multirow{2}{*}{$\begin{array}{c}\text { Análise } \\
\text { de 1ạ } \\
\text { Ordem }\end{array}$} & \multicolumn{6}{|c|}{ Processos de Análise de 2a. Ordem } \\
\hline & & & P.Rigoroso & $\%$ & P- $\Delta$ & $\%$ & P.Simplificado & $\%$ \\
\hline \multirow{2}{*}{$\begin{array}{l}\text { Flecha no } \\
\text { Topo(a)-m }\end{array}$} & $\overline{\mathrm{X}}$ & 0,2014 & 0,2492 & 23,72 & 0,2484 & 23,34 & $\overline{0,2477}$ & 23,00 \\
\hline & $\bar{Y}$ & 0,1922 & 0,2292 & 19,26 & 0,2284 & 18,83 & 0,2268 & 18,00 \\
\hline \multirow{2}{*}{$\begin{array}{l}\text { Mom. na Base } \\
\text { (P7) } \times 10 k N . m\end{array}$} & $\bar{X}$ & $-148,55$ & $-17 \overline{6,40}$ & 18,80 & $-17 \overline{-17,80}$ & 18,40 & $\overline{182,71}$ & 23,00 \\
\hline & $\mathrm{Y}$ & 7,71 & $8, \overline{06}$ & 4,60 & 8,96 & 16,20 & 9,10 & 18,00 \\
\hline \multirow{2}{*}{$\begin{array}{l}\text { Normal na Base } \\
\text { (P5) } \times 10 \mathrm{kN}\end{array}$} & $X$ & 421,07 & 411,60 & 24,40 & 411,80 & 23,80 & 412,09 & 23,00 \\
\hline & $\mathrm{Y}$ & 476,12 & 479,30 & 20,00 & 479,10 & 18,80 & 479,00 & 18,00 \\
\hline \multirow{2}{*}{$\begin{array}{l}\text { Momento na } \\
\text { Base (P9), } \\
\text { Nivel } 5 \\
\text { x10kNm } \\
\end{array}$} & $\bar{x}$ & $-5,66$ & $-7,23$ & 27,70 & $-7,22$ & $\overline{27,60}$ & $-6,96$ & 23,00 \\
\hline & $\bar{Y}$ & $-18,81$ & $-23,78$ & 26,40 & $-23,31$ & 27,00 & $-22,21$ & 18,00 \\
\hline \multirow{2}{*}{$\begin{array}{c}\text { Momento num } \\
\text { Extremo } \\
\text { de vão(V9), } \\
\text { Nível 5-x10kNm }\end{array}$} & $\mathrm{X}$ & $-15,81$ & $-19,68$ & $24, \overline{50}$ & $-19,62$ & 24,10 & 19,45 & $23, \overline{00}$ \\
\hline & $\bar{Y}$ & $-2,67$ & $-2,78$ & 4,30 & $-2,78$ & 4,30 & 3,15 & 18,00 \\
\hline
\end{tabular}




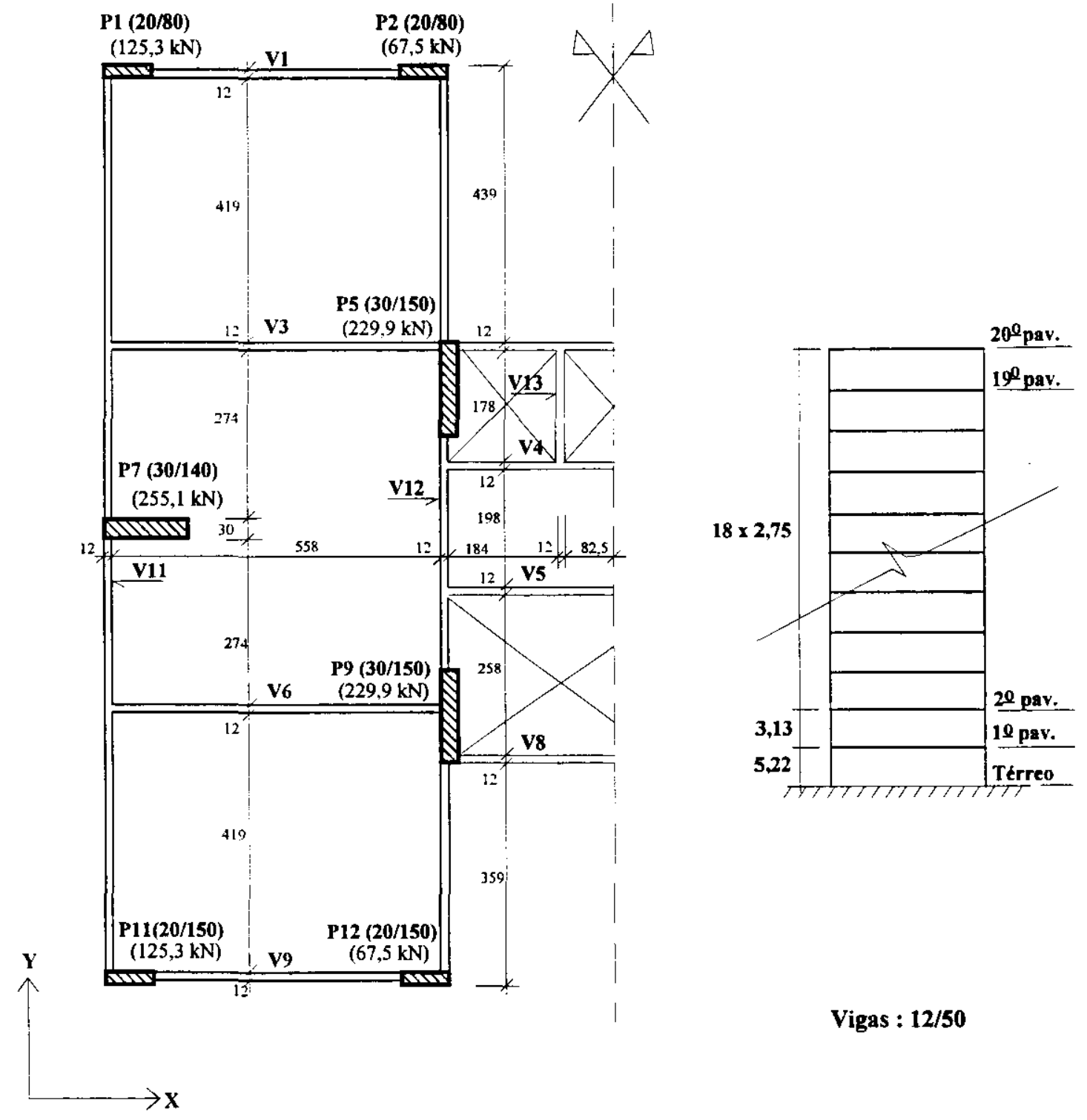

FIGURA 25 - Edifício TOP LIFE

(forma do pav. tipo e elevação esquemática) 
TABELA 15 - Comparação dos Resultados Obtidos Segundo os Três Processos de Análise de Segunda Ordem para o Exemplo do Ed. TOP LIFE

\begin{tabular}{|c|c|c|c|c|c|c|c|c|}
\hline \multicolumn{3}{|c|}{ Direçăo } & \multicolumn{3}{|c|}{ X $\quad(\psi=0,597)$} & \multicolumn{3}{|c|}{$Y \quad(\psi=0,626)$} \\
\hline \multirow{2}{*}{\multicolumn{3}{|c|}{ Efeitos }} & \multicolumn{3}{|c|}{ Processos (\%) } & \multicolumn{3}{|c|}{ Processos (\%) } \\
\hline & & & Rigoroso & P-Delta & Simplif. & Rigoroso & P-Delta & Simplif. \\
\hline \multicolumn{3}{|c|}{ Flecha no Topo } & 23,7 & 23,3 & 23,0 & 19,3 & 18,8 & 18,0 \\
\hline \multicolumn{3}{|c|}{ Fundaçào } & 19,8 & 21,2 & 23,0 & 12,4 & 17,6 & 18,0 \\
\hline \multirow{3}{*}{$\mathbf{F}$} & \multirow{3}{*}{$\begin{array}{c}\text { Entre os niveis } \\
\qquad 1 \text { e } 6\end{array}$} & $\mathbf{P}$ & 28,2 & 27,6 & 23,0 & 21,1 & 20,8 & 18,0 \\
\hline & & $\mathbf{v}$ & 26,9 & 26,2 & 23,0 & 21,9 & 21.5 & 18,0 \\
\hline & & $\mathbf{G}$ & 27,8 & 27,2 & 23,0 & 21,4 & 21,1 & 18,0 \\
\hline \multirow{3}{*}{ i } & \multirow{3}{*}{$\begin{array}{l}\text { Entre os niveis } \\
\qquad 7 \text { e } 13\end{array}$} & $\mathbf{P}$ & 22,9 & 22,7 & 23,0 & 20,3 & 20,1 & 18,0 \\
\hline & & $\mathbf{v}$ & 26,1 & 25,9 & 23,0 & 19,0 & 18,9 & 18,0 \\
\hline & & $\mathbf{G}$ & 23,9 & 23,7 & 23,0 & 19,7 & 19,6 & 18,0 \\
\hline \multirow[t]{3}{*}{$\mathbf{s}$} & \multirow{3}{*}{$\begin{array}{l}\text { Entre os niveis } \\
\qquad 14 \text { e } 20\end{array}$} & $\mathbf{P}$ & 20,6 & 20,4 & 23,0 & 12,5 & 12,5 & 18,0 \\
\hline & & $\mathbf{v}$ & 11,7 & 11,7 & 23,0 & 11,8 & 11,8 & 18,0 \\
\hline & & $\mathbf{G}$ & 18,0 & 17,9 & 23,0 & 12,2 & 12,2 & 18,0 \\
\hline \multirow{3}{*}{$\begin{array}{l}\mathbf{G} \\
\mathrm{e} \\
\mathrm{r} \\
\mathrm{a} \\
\mathrm{I}\end{array}$} & \multicolumn{2}{|l|}{ Pilares (P) } & 23,7 & 23,4 & 23,0 & 17,8 & 17,6 & 18,0 \\
\hline & \multicolumn{2}{|l|}{ Vigas $(\mathrm{V})$} & 21,5 & 21,2 & 23,0 & 17,4 & 17,2 & 18,0 \\
\hline & \multicolumn{2}{|l|}{ Global (G) } & 23,0 & 22,7 & 23,0 & 17,6 & 17,5 & 18,0 \\
\hline
\end{tabular}


TABELA 16 - Comparação dos Resultados Obtidos Segundo os Três Processos de Análise de Segunda Ordem para o Exemplo do Ed. SPAZIO UNO

\begin{tabular}{|c|c|c|c|c|c|c|c|c|}
\hline \multicolumn{3}{|c|}{ Direçăo } & \multicolumn{3}{|c|}{$\mathrm{X} \quad(\psi=0,617)$} & \multicolumn{3}{|c|}{$Y \quad(\psi=0,611)$} \\
\hline \multirow{2}{*}{\multicolumn{3}{|c|}{ Efeitos }} & \multicolumn{3}{|c|}{ Processos (\%) } & \multicolumn{3}{|c|}{ Processos (\%) } \\
\hline & & & Rigoroso & P-Delta & Simplif. & Rigoroso & P-Delta & Simplif. \\
\hline \multicolumn{3}{|c|}{ Flecha no Topo } & 15,1 & 14,6 & 14,0 & 6,1 & 5,9 & 6,0 \\
\hline \multicolumn{3}{|c|}{ Fundaçăo } & 13,0 & 13,6 & 14,0 & 3,7 & 4,9 & 6,0 \\
\hline \multirow{3}{*}{$\begin{array}{l}\mathbf{F} \\
\mathbf{a}\end{array}$} & \multirow{3}{*}{$\begin{array}{l}\text { Entre os niveis } \\
\qquad 1 \text { e } 5\end{array}$} & $\mathbf{P}$ & 17,4 & 17,3 & 14,0 & 4,8 & 5,1 & 6,0 \\
\hline & & $\mathbf{v}$ & 16,5 & 16,8 & 14,0 & 6,1 & 6,3 & 6,0 \\
\hline & & G & 17,1 & 17,1 & 14,0 & 5,4 & 5,6 & 6,0 \\
\hline \multirow{3}{*}{$\begin{array}{l}\mathrm{x} \\
\mathbf{a}\end{array}$} & \multirow{3}{*}{$\begin{array}{l}\text { Entre os níveis } \\
\qquad 6 \text { e } 11\end{array}$} & $\mathbf{P}$ & 15,3 & 15,1 & 14,0 & 4,6 & 4,0 & 6,0 \\
\hline & & $\mathbf{v}$ & 14,4 & 14,5 & 14,0 & 7,3 & 7,3 & 6,0 \\
\hline & & $\mathbf{G}$ & 15,0 & 14,9 & 14,0 & 5,8 & 5,4 & 6,0 \\
\hline \multirow[t]{3}{*}{$\mathbf{s}$} & \multirow{3}{*}{$\begin{array}{l}\text { Entre os níveis } \\
\qquad 12 \text { e } 17\end{array}$} & $\mathbf{P}$ & 10,2 & 10,3 & 14,0 & 2,7 & 2,7 & 6,0 \\
\hline & & $\mathbf{v}$ & 9,0 & 8,8 & 14,0 & 0,5 & 0,5 & 6,0 \\
\hline & & $\mathbf{G}$ & 9,8 & 9,8 & 14,0 & 1,8 & 1,7 & 6,0 \\
\hline \multirow{3}{*}{$\begin{array}{l}\mathbf{G} \\
\mathbf{e} \\
\mathbf{r} \\
\mathbf{a} \\
\mathbf{I}\end{array}$} & \multicolumn{2}{|l|}{ Pilares (P) } & 14,2 & 14,1 & 14,0 & 4,0 & 3,8 & 6,0 \\
\hline & \multicolumn{2}{|l|}{ Vigas (V) } & 13,1 & 13,2 & 14,0 & 4,5 & 4,6 & 6,0 \\
\hline & \multicolumn{2}{|l|}{ Global (G) } & 13,8 & 13,8 & 14,0 & 4,2 & 4,2 & 6,0 \\
\hline
\end{tabular}


TABELA 17 - Comparação dos Resultados Obtidos Segundo os Três Processos de Análise de Segunda Ordem para o Exemplo do Ed. STRADUS

\begin{tabular}{|c|c|c|c|c|c|c|c|c|}
\hline \multicolumn{3}{|c|}{ Direção } & \multicolumn{3}{|c|}{ X $\quad(\psi=0,637)$} & \multicolumn{3}{|c|}{$Y \quad(\psi=0,605)$} \\
\hline \multirow{2}{*}{\multicolumn{3}{|c|}{ Efeitos }} & \multicolumn{3}{|c|}{ Processos (\%) } & \multicolumn{3}{|c|}{ Processos (\%) } \\
\hline & & & Rigoroso & P-Delta & Simplif. & Rigoroso & P-Delta & Simplif. \\
\hline \multicolumn{3}{|c|}{ Flecha no Topo } & 41,1 & 38,2 & 38,0 & 6,1 & 6,0 & 6,0 \\
\hline \multicolumn{3}{|c|}{ Fundação } & 34,9 & 36,1 & 38,0 & 3,9 & 6,2 & 6,0 \\
\hline \multirow{3}{*}{$\begin{array}{l}\mathbf{F} \\
\mathbf{a}\end{array}$} & \multirow{3}{*}{$\begin{array}{l}\text { Entre os niveis } \\
\qquad 1 \text { e } 4\end{array}$} & $\mathbf{P}$ & 58,0 & 57,2 & 38,0 & 7,0 & 7,5 & 6,0 \\
\hline & & $\mathbf{v}$ & 48,5 & 45,2 & 38,0 & 6,8 & 6,7 & 6,0 \\
\hline & & $\mathbf{G}$ & 56,0 & 54,7 & 38,0 & 7,0 & 7,3 & 6,0 \\
\hline \multirow{3}{*}{$\begin{array}{l}\mathrm{i} \\
\mathrm{x} \\
\mathbf{a}\end{array}$} & \multirow{3}{*}{$\begin{array}{c}\text { Entre os niveis } \\
5 \text { e } 8\end{array}$} & $\mathbf{P}$ & 52,0 & 49,4 & 38,0 & 6,9 & 7,0 & 6,0 \\
\hline & & $\mathbf{v}$ & 37,4 & 35,9 & 38,0 & 6,5 & 6,5 & 6,0 \\
\hline & & $\mathbf{G}$ & 49,0 & 46,6 & 38,0 & 6,8 & 6,8 & 6,0 \\
\hline \multirow[t]{3}{*}{$s$} & \multirow{3}{*}{$\begin{array}{l}\text { Entre os níveis } \\
\qquad 9 \text { e } 12\end{array}$} & $\mathbf{P}$ & 32,9 & 28,9 & 38,0 & 5,5 & 5,5 & 6,0 \\
\hline & & $\mathbf{v}$ & 19,3 & 18,6 & 38,0 & 5,0 & 4,9 & 6,0 \\
\hline & & G & 30,0 & 26,7 & 38,0 & 5,3 & 5,3 & 6,0 \\
\hline \multirow{3}{*}{$\begin{array}{l}\mathbf{G} \\
\text { e } \\
\mathbf{r} \\
\mathbf{a} \\
\mathbf{1}\end{array}$} & \multicolumn{2}{|l|}{ Pilares (P) } & 47,8 & 45,3 & 38,0 & 6,5 & 6,7 & 6,0 \\
\hline & \multicolumn{2}{|l|}{ Vigas (V) } & 35,0 & 33,2 & 38,0 & 6,1 & 6,0 & 6,0 \\
\hline & \multicolumn{2}{|l|}{ Global (G) } & 45,1 & 42,8 & 38,0 & 6,4 & 6,5 & 6,0 \\
\hline
\end{tabular}


TABELA 18 - Comparação dos Resultados Obtidos Segundo os Três Processos de Análise de Segunda Ordem para o Exemplo do Ed. CONDOMÍNIO III

\begin{tabular}{|c|c|c|c|c|c|c|c|c|}
\hline \multicolumn{3}{|c|}{ Direção } & \multicolumn{3}{|c|}{$\mathbf{X} \quad(\psi=0,580)$} & \multicolumn{3}{|c|}{$\mathbf{Y} \quad(\psi=0,551)$} \\
\hline \multirow{2}{*}{\multicolumn{3}{|c|}{ Efeitos }} & \multicolumn{3}{|c|}{ Processos (\%) } & \multicolumn{3}{|c|}{ Processos $(\%)$} \\
\hline & & & Rigoroso & P-Delta & Simplif. & Rigoroso & P-Delta & Simplif. \\
\hline \multicolumn{3}{|c|}{ Flecha no Topo } & 42,1 & 41,6 & 40,0 & 38,4 & 37,6 & 35,0 \\
\hline \multicolumn{3}{|c|}{ Fundaç̃̃o } & 35,2 & 38,2 & 40,0 & 30,1 & 32,1 & 35,0 \\
\hline \multirow{3}{*}{$\begin{array}{l}\mathbf{F} \\
\mathbf{a}\end{array}$} & \multirow{3}{*}{$\begin{array}{c}\text { Entre os níveis } \\
1 \text { e } 7\end{array}$} & $\mathbf{P}$ & 45,1 & 45,7 & 40,0 & 38,3 & 39,6 & 35,0 \\
\hline & & $\mathrm{v}$ & 49,2 & 49,6 & 40,0 & 38,5 & 38,4 & 35,0 \\
\hline & & G & 46,7 & 47,2 & 40,0 & 38,4 & 39,2 & 35,0 \\
\hline \multirow{3}{*}{$\begin{array}{l}\mathbf{i} \\
\mathbf{x} \\
\mathbf{a}\end{array}$} & \multirow{3}{*}{$\begin{array}{l}\text { Entre os niveis } \\
\qquad 8 \text { e } 15\end{array}$} & $\mathbf{P}$ & 42,2 & 42,7 & 40,0 & 37,8 & 38,2 & 35,0 \\
\hline & & $\mathbf{v}$ & 46,5 & 46,9 & 40,0 & 40,5 & 40,1 & 35,0 \\
\hline & & G & 43,9 & 44,3 & 40,0 & 38,7 & 38,9 & 35,0 \\
\hline \multirow[t]{3}{*}{ s } & \multirow{3}{*}{$\begin{array}{c}\text { Entre os niveis } \\
\qquad 16 \text { e } 24\end{array}$} & $\mathbf{P}$ & 33,0 & 35,5 & 40,0 & 34,8 & 33,7 & 35,0 \\
\hline & & $\mathbf{v}$ & 11,2 & 11,3 & 40,0 & 31,3 & 30,9 & 35,0 \\
\hline & & G & 24,4 & 26,0 & 40,0 & 33,6 & 32,8 & 35,0 \\
\hline \multirow{3}{*}{$\begin{array}{l}\mathbf{G} \\
\mathrm{e} \\
\mathrm{r} \\
\mathrm{a} \\
\mathrm{I}\end{array}$} & \multicolumn{2}{|l|}{ Pilares (P) } & 39,6 & 40,8 & 40,0 & 36,8 & 37,0 & 35,0 \\
\hline & \multicolumn{2}{|l|}{ Vigas (V) } & 34,1 & 34,4 & 40,0 & 36,5 & 36,2 & 35,0 \\
\hline & \multicolumn{2}{|l|}{ Global (G) } & 37,4 & 38,3 & 40,0 & 36,7 & 36,7 & 35,0 \\
\hline
\end{tabular}


TABELA 19 - Comparação dos Resultados Obtidos Segundo os Três Processos de Análise de Segunda Ordem para o Exemplo do Ed. RUA INDIANA

\begin{tabular}{|c|c|c|c|c|c|c|c|c|}
\hline \multicolumn{3}{|c|}{ Direção } & \multicolumn{3}{|c|}{ X $\quad(\psi=0,588)$} & \multicolumn{3}{|c|}{$Y \quad(\psi=0,515)$} \\
\hline \multirow{2}{*}{\multicolumn{3}{|c|}{ Efeitos }} & \multicolumn{3}{|c|}{ Processos (\%) } & \multicolumn{3}{|c|}{ Processos (\%) } \\
\hline & & & Rigoroso & P-Delta & Simplif. & Rigoroso & P-Delta & Simplif. \\
\hline \multicolumn{3}{|c|}{ Flecha no Topo } & 46,7 & 43,8 & 44,0 & 18,6 & 18,3 & 18,0 \\
\hline \multicolumn{3}{|c|}{ Fundação } & 42,6 & 43,9 & 44,0 & 13,0 & 15,6 & 18,0 \\
\hline \multirow{3}{*}{$\begin{array}{l}\mathbf{F} \\
\text { a }\end{array}$} & \multirow{3}{*}{$\begin{array}{c}\text { Entre os niveis } \\
1 \text { e } 7\end{array}$} & $\mathbf{P}$ & 54,9 & 54,4 & 44,0 & 18,0 & 19,6 & 18,0 \\
\hline & & $\mathbf{v}$ & 62,2 & 58,7 & 44,0 & 18,9 & 18.8 & 18,0 \\
\hline & & $\mathrm{G}$ & 57,5 & 55,9 & 44,0 & 18,3 & 19,4 & 18,0 \\
\hline \multirow{3}{*}{$\begin{array}{l}i \\
x \\
a\end{array}$} & \multirow{3}{*}{$\begin{array}{l}\text { Entre os niveis } \\
\qquad 8 \text { e } 16\end{array}$} & $\mathbf{p}$ & 58,8 & 57,0 & 44,0 & 16,9 & 17,8 & 18,0 \\
\hline & & $\mathbf{v}$ & 55,3 & 52,8 & 44,0 & 19,8 & 19,7 & 18,0 \\
\hline & & $\mathbf{G}$ & 57,6 & 55,5 & 44,0 & 17,8 & 18,4 & 18,0 \\
\hline \multirow[t]{3}{*}{$s$} & \multirow{3}{*}{$\begin{array}{l}\text { Entre os níveis } \\
\qquad 17 \text { e } 25\end{array}$} & $\mathbf{P}$ & 27,3 & 26,4 & 44,0 & 19,3 & 19,0 & 18,0 \\
\hline & & $\mathbf{v}$ & 15,6 & 15,0 & 44,0 & 14,5 & 14,5 & 18,0 \\
\hline & & $\mathbf{G}$ & 23,3 & 22,5 & 44,0 & 17,8 & 17,6 & 18,0 \\
\hline \multirow{3}{*}{$\begin{array}{l}\mathbf{G} \\
\mathbf{e} \\
\mathbf{r} \\
\mathbf{a} \\
\mathbf{l}\end{array}$} & \multicolumn{2}{|l|}{ Pilares (P) } & 46,2 & 45,1 & 44,0 & 18,1 & 18,8 & 18,0 \\
\hline & \multicolumn{2}{|l|}{ Vigas (V) } & 43,4 & 41,3 & 44,0 & 17,6 & 17,6 & 18,0 \\
\hline & \multicolumn{2}{|l|}{ Global (G) } & 45,3 & 43,8 & 44,0 & 18,0 & 18,4 & 18,0 \\
\hline
\end{tabular}


TABELA 20 - Comparação dos Resultados Obtidos Segundo os Três Processos de Análise de Segunda Ordem para o Exemplo do Ed. CARTIER TOWER

\begin{tabular}{|c|c|c|c|c|c|c|c|c|}
\hline \multicolumn{3}{|c|}{ Direção } & \multicolumn{3}{|c|}{$\mathrm{X} \quad(\psi=0,542)$} & \multicolumn{3}{|c|}{$\mathbf{Y} \quad(\psi=0,613)$} \\
\hline \multirow{2}{*}{\multicolumn{3}{|c|}{ Efeitos }} & \multicolumn{3}{|c|}{ Processos (\%) } & \multicolumn{3}{|c|}{ Processos $(\%)$} \\
\hline & & & Rigoroso & P-Deita & Simplif. & Rigoroso & P-Delta & Simplif. \\
\hline \multicolumn{3}{|c|}{ Flecha no Topo } & 29,6 & 28,9 & 27,0 & 15,3 & 14,8 & 14,0 \\
\hline \multicolumn{3}{|c|}{ Fundaçẫo } & 24,6 & 25,3 & 27,0 & 13,1 & 14,1 & 14,0 \\
\hline \multirow{3}{*}{ F } & \multirow{3}{*}{$\begin{array}{c}\text { Entre os niveis } \\
1 \text { e } 5\end{array}$} & $\mathbf{P}$ & 31,0 & 30,4 & 27,0 & 15,8 & 15,4 & 14,0 \\
\hline & & $\mathrm{v}$ & 28,7 & 28,4 & 27,0 & 17,4 & 17,4 & 14,0 \\
\hline & & $\mathbf{G}$ & 30,5 & 29,9 & 27,0 & 16,5 & 16,3 & 14,0 \\
\hline \multirow{3}{*}{$x$} & \multirow{3}{*}{$\begin{array}{l}\text { Entre os niveis } \\
\qquad 6 \text { e } 11\end{array}$} & $\mathbf{P}$ & 34,1 & 33,8 & 27,0 & 14,9 & 14,7 & 14,0 \\
\hline & & $\mathbf{v}$ & 31,6 & 31,1 & 27,0 & 17,0 & 17,0 & 14,0 \\
\hline & & G & 33,5 & 33,1 & 27,0 & 15,8 & 15,7 & 14,0 \\
\hline \multirow[t]{3}{*}{$s$} & \multirow{3}{*}{$\begin{array}{c}\text { Entre os niveis } \\
12 \text { e } 18\end{array}$} & $\mathbf{P}$ & 29,8 & 29,3 & 27,0 & 11,0 & 11,2 & 14,0 \\
\hline & & $\mathbf{v}$ & 27,6 & 27,2 & 27,0 & 9,2 & 9,1 & 14,0 \\
\hline & & G & 29,3 & 28,8 & 27,0 & 10,2 & 10,3 & 14,0 \\
\hline \multirow{3}{*}{$\begin{array}{l}\mathbf{G} \\
\mathbf{e} \\
\mathbf{r} \\
\mathbf{a} \\
\mathrm{I}\end{array}$} & \multicolumn{2}{|l|}{ Pilares (P) } & 31,6 & 31,1 & 27,0 & 13,6 & 13,6 & 14,0 \\
\hline & \multicolumn{2}{|l|}{ Vigas (V) } & 29,3 & 28,8 & 27,0 & 14,1 & 14,0 & 14,0 \\
\hline & \multicolumn{2}{|l|}{ Global (G) } & 31,0 & 30,5 & 27,0 & 13,8 & 13,8 & 14,0 \\
\hline
\end{tabular}


TABELA 21 - Comparação dos Resultados Obtidos Segundo os Três Processos de Análise de Segunda Ordem para o Exempio do Ed. CORINTO

\begin{tabular}{|c|c|c|c|c|c|c|c|c|}
\hline \multicolumn{3}{|c|}{ Direção } & \multicolumn{3}{|c|}{$X \quad(\psi=0,563)$} & \multicolumn{3}{|c|}{ Y $\quad(\psi=0,544)$} \\
\hline \multirow{2}{*}{\multicolumn{3}{|c|}{ Efeitos }} & \multicolumn{3}{|c|}{ Processos (\%) } & \multicolumn{3}{|c|}{ Processos (\%) } \\
\hline & & & Rigoroso & P-Deita & Simplif. & Rigoroso & P-Delta & Simplif \\
\hline \multicolumn{3}{|c|}{ Flecha no Topo } & 9,6 & 9,4 & 9,0 & 14,8 & 14,3 & 14,0 \\
\hline \multicolumn{3}{|c|}{ Fundação } & 5,7 & 8,6 & 9,0 & 12,0 & 13,4 & 14,0 \\
\hline \multirow{3}{*}{$\begin{array}{l}\mathbf{F} \\
\mathbf{a}\end{array}$} & \multirow{3}{*}{$\begin{array}{c}\text { Entre os niveis } \\
1 \text { e } 6\end{array}$} & $\mathbf{P}$ & 8,3 & 10,3 & 9,0 & 15,1 & 15,0 & 14,0 \\
\hline & & $\mathbf{v}$ & 9,7 & 9,7 & 9,0 & 14,2 & 14,8 & 14,0 \\
\hline & & $\mathbf{G}$ & 8,8 & 10,1 & 9,0 & 14,8 & 14,9 & 14,0 \\
\hline \multirow{3}{*}{$\mathbf{i}$} & \multirow{3}{*}{$\begin{array}{c}\text { Entre os níveis } \\
7 \text { e } 12\end{array}$} & $\mathbf{P}$ & 12,1 & 12,2 & 9,0 & 17,8 & 17,6 & 14,0 \\
\hline & & $\mathbf{v}$ & 13,6 & 13,5 & 9,0 & 14,2 & 14,3 & 14,0 \\
\hline & & G & 12,7 & 12,7 & 9,0 & 16,5 & 16,4 & 14,0 \\
\hline \multirow[t]{3}{*}{$\mathbf{s}$} & \multirow{3}{*}{$\begin{array}{c}\text { Entre os niveis } \\
\qquad 13 \text { e } 18\end{array}$} & $\mathbf{P}$ & 9,9 & 9,8 & 9,0 & 13,7 & 13,6 & 14,0 \\
\hline & & $\mathbf{v}$ & $-1,0$ & $-1,0$ & 9,0 & 13,3 & 13,0 & 14,0 \\
\hline & & G & 5,7 & 5,7 & 9,0 & 13,6 & 13,4 & 14,0 \\
\hline \multirow{3}{*}{$\begin{array}{l}\text { G } \\
\text { e } \\
\text { r } \\
\text { a } \\
\text { I }\end{array}$} & \multicolumn{2}{|l|}{ Pilares (P) } & 10,1 & 10,8 & 9,0 & 15,5 & 15,4 & 14,0 \\
\hline & \multicolumn{2}{|l|}{ Vigas (V) } & 7,4 & 7,4 & 9,0 & 13,9 & 14,1 & 14,0 \\
\hline & \multicolumn{2}{|l|}{ Global (G) } & 9,1 & 9,5 & 9,0 & 14,9 & 14,9 & 14,0 \\
\hline
\end{tabular}


Resolveu-se confrontar nos gráficos das Figs. 26 a 39, na forma de percentuais de acréscimo aos esforços de primeira ordem, os resultados obtidos pelos três processos, que já foram listados nas Tabs. 15 a 21. Nessas figuras, os números no eixo das abscissas correspondem a uma determinada direção de cada edifício, enumeradas conforme a Tab. 22.

A primeira observação a ser feita diante dos resultados apresentados é que a utilização do processo simplificado para a majoração dos esforços ao nível da fundação é segura, pois, em todos os casos, os valores percentuais de acréscimo de esforços em relação aos de primeira ordem obtidos por este método é maior que os calculados pelo processo rigoroso, como se pode ver na Fig. 26. Neste caso, o exemplo que apresenta maior diferença entre estes resultados é o de $\mathrm{n}^{0} 7$, onde $\mathrm{o}$ processo simplificado leva a esforços de segunda ordem em média $5 \%$ maiores que os obtidos pelo processo rigoroso. Os resultados calculados pelo processo simplificado são semelhantes aos calculados pelo processo $\mathbf{P}-\Delta$. Vale lembrar que, como se havia comentado, a obtenção do parâmetro $\gamma_{\mathbf{z}}$ pode ser comparada a uma projeção dos resultados a serem obtidos pelo processo $\mathbf{P}-\Delta$ a partir de uma primeira iteração, e o seu cálculo é feito utilizando-se os esforços provocados pelas ações laterais na base do edifício.

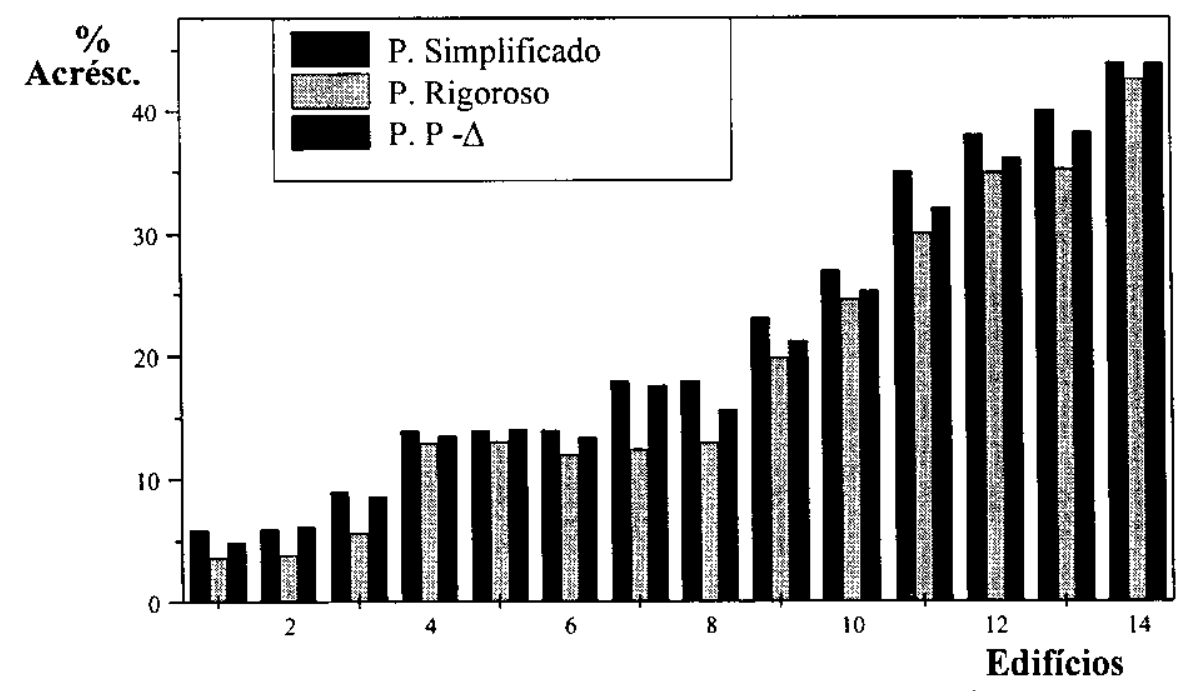

FIGURA 26 - Comparação entre os Resultados na Fundação 
Os resultados para as flechas no topo calculados pelo processo simplificado também são satisfatórios pois, mesmo tendo sido ultrapassados pelos resultados obtidos pelos outros processos na grande maioria das vezes, a diferença entre os valores não é significativa (Fig. 27). No exemplo de no 11 , onde ocorre a maior diferença entre os resultados, os valores de flecha no topo obtidos pelos processos rigoroso e P- $\Delta$ são, em média, cerca de $2,5 \%$ maiores que os calculados pelo processo simplificado. Comparando-se os valores de flechas no topo obtidos de acordo com o processo $\mathbf{P}-\Delta$ com os obtidos pelo processo rigoroso, continuam não sendo significativas as diferenças, sendo que o primeiro conduz a resultados de flecha no topo em média $2 \%$ menores que os calculados pelo segundo, no pior caso (exemplo $\mathrm{n}^{\text {ㅇ }} 12$ ).

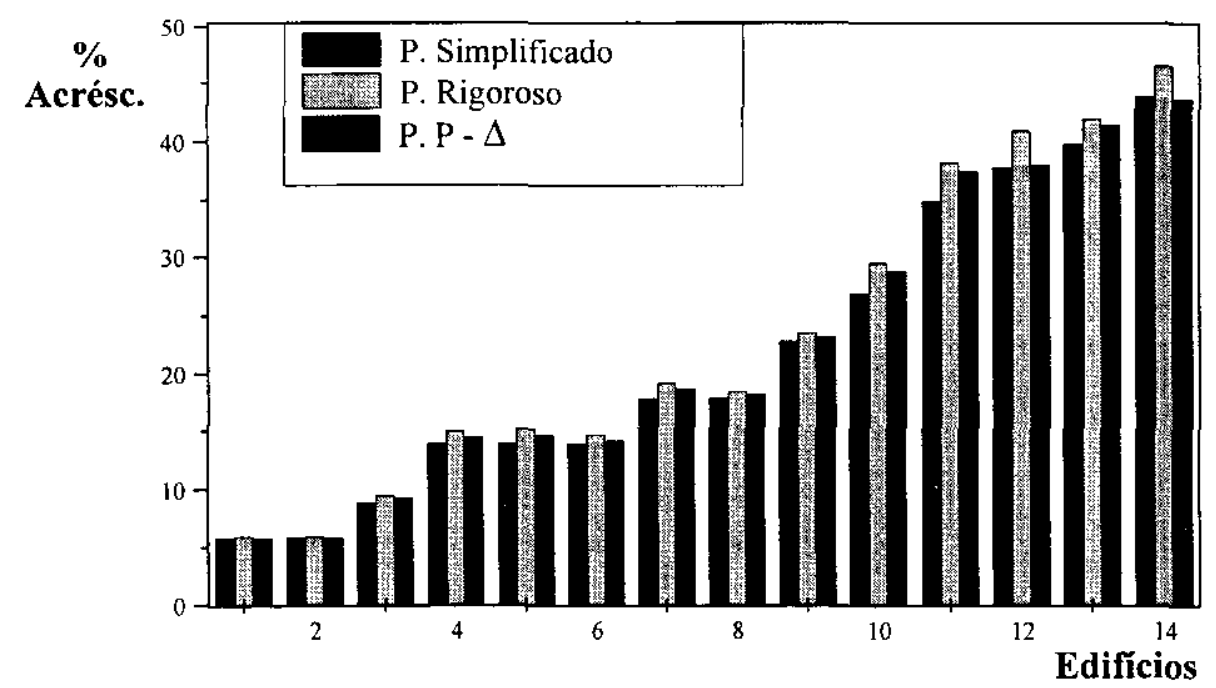

FIGURA 27 - Comparação entre os Resultados para Flechas no Topo

Avaliando-se os esforços no âmbito global, os resultados calculados pelo processo simplificado são muito próximos aos obtidos pelos outros dois processos para todos os valores de $\gamma_{\mathbf{z}}$, mesmo nos casos em que eles são menores. Estes resultados foram transcritos na Tab. 22 em ordem crescente de $\gamma_{\mathbf{z}}$, na forma de multiplicadores de efeitos de primeira ordem. No gráfico da Fig. 28, além desta afirmação, pode-se observar que o distanciamento entre os resultados obtidos pelo processo simplificado e os demais processos aumenta a partir de valores de $\gamma_{\mathbf{z}}$ maiores que aproximadamente 1,301 , sendo que, nestes casos, o majorador dos

\footnotetext{
${ }^{1}$ Note-se que todos os valores numéricos aqui citados referem-se ao universo de valores utilizados como exemplo para a presente análise, sem o compromisso inicial de estabelecerem-se limites exatos para os diversos casos aqui analisados.
} 
efeitos calculado pelo processo simplificado é, na grande maioria das vezes, ultrapassado pelos obtidos de acordo com os outros processos. A maior diferença em média, neste caso, corresponde ao exemplo de ne 12 e é de aproximadamente $5 \%$, em relação ao processo rigoroso. Para valores de $\gamma_{z}$ menores que 1,30 , a maior diferença é de $3 \%$ (exemplo no 10 ). Percebe-se também que o processo $\mathrm{P}-\Delta$ e o processo rigoroso fornecem resultados semelhantes para qualquer valor de acréscimo aos efeitos de primeira ordem.

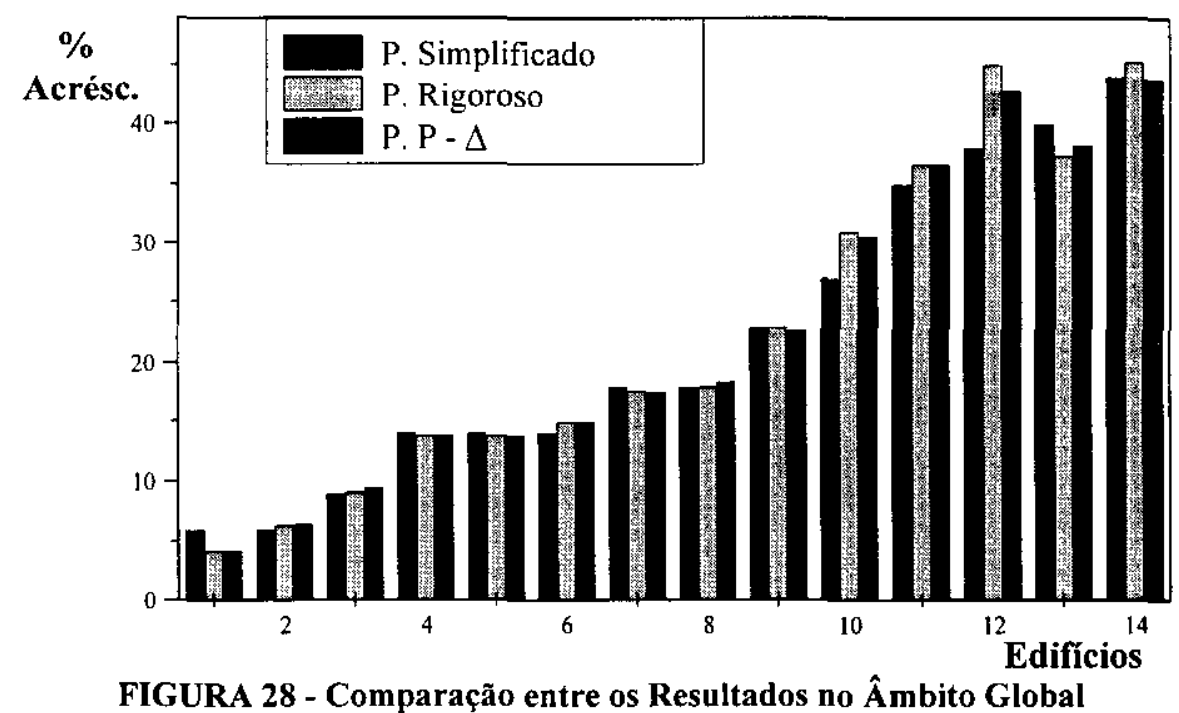

TABELA 22 - Majoradores Globais dos Efeitos de Primeira Ordem de Acordo com Três Processos de Análise de Segunda Ordem

\begin{tabular}{|c|l|c|c|c|c|c|}
\hline No & Edifício & Dir. & $\Psi$ & P.Simplif. & P.Rigor. & P. P- $\Delta$ \\
\hline \hline 1 & Spazio Uno & $\mathrm{Y}$ & 0,611 & 1,06 & 1,04 & 1,04 \\
\hline 2 & Stradus & $\mathrm{Y}$ & 0,605 & 1,06 & 1,06 & 1,07 \\
\hline 3 & Corinto & $\mathrm{X}$ & 0,563 & 1,09 & 1,09 & 1,10 \\
\hline 4 & Spazio Uno & $\mathrm{X}$ & 0,617 & 1,14 & 1,14 & 1,14 \\
\hline 5 & Cartier Tower & $\mathrm{Y}$ & 0,613 & 1,14 & 1,14 & 1,14 \\
\hline 6 & Corinto & $\mathrm{Y}$ & 0,544 & 1,14 & 1,15 & 1,15 \\
\hline 7 & Top Life & $\mathrm{Y}$ & 0,626 & 1,18 & 1,18 & 1,18 \\
\hline 8 & R. Indiana & $\mathrm{Y}$ & 0,515 & 1,18 & 1,18 & 1,18 \\
\hline 9 & Top Life & $\mathrm{X}$ & 0,597 & 1,23 & 1,23 & 1,23 \\
\hline 10 & Cartier Tower & $\mathrm{X}$ & 0,542 & 1,27 & 1,31 & 1,31 \\
\hline 11 & Cond. III & $\mathrm{Y}$ & 0,551 & 1,35 & 1,37 & 1,37 \\
\hline 12 & Stradus & $\mathrm{X}$ & 0,637 & 1,38 & 1,45 & 1,43 \\
\hline 13 & Cond. III & $\mathrm{X}$ & 0,580 & 1,40 & 1,37 & 1,38 \\
\hline 14 & R. Indiana & $\mathrm{X}$ & 0,588 & 1,44 & 1,45 & 1,44 \\
\hline
\end{tabular}


Observe-se, agora, a análise feita em faixas da altura de cada um dos edifícios (Figs. 29, 30 e 31). Na primeira faixa, que normalmente inclui o pavimento onde se encontram os maiores valores de esforços nas vigas (que fica aproximadamente a $25 \%$ da altura total do edifício) a grande maioria dos resultados obtidos pelo processo simplificado é ultrapassada pelos resultados segundo os outros processos. Entretanto, o processo simplificado leva a resultados muito bons para valores de $\gamma_{\mathbf{z}}$ próximos de 1,35 , com valores obtidos pelos outros processos pouco maiores que os valores obtidos pelo processo simplificado. No pior caso ( $\mathrm{n} \varrho 9$ ), os processos rigoroso e $\mathrm{P}-\Delta$ determinam esforços de segunda ordem cerca de $4 \%$ maiores que os obtidos pelo processo simplificado. Acima de $\gamma_{\mathbf{z}}=\mathbf{1 , 3 5}$ surgem diferenças mais significativas. A maior diferença corresponde ao exemplo de $\mathrm{n}^{\mathrm{Q}} 12$ onde os dois processos levam ao cálculo de esforços de segunda ordem em torno de $13 \%$ maiores, em média, que os calculados pelo processo simplificado. $O$ mesmo pode ser dito dos resultados relativos à segunda faixa, onde o pior caso corresponde ao exemplo de no 14 e os resultados do processo simplificado são $9 \%$ menores que os outros, para $\gamma_{\mathbf{z}}>\mathbf{1 , 3 5}$. Na última faixa, entretanto, percebe-se que os resultados obtidos pelo processo simplificado são, quase sempre, maiores (em alguns casos até muito maiores) que os resultados calculados pelos outros processos para todos os valores de $\gamma_{\mathbf{z}}$ analisados. Quando isto não ocorre, a diferença é pequena (cerca de $2 \%$ menor que os resultados dos outros processos) o que qualifica o processo como satisfatório nos trechos mais elevados das estruturas. Também, mais uma vez se verifica a proximidade entre os resultados do processo $\mathbf{P}-\Delta$ e do rigoroso em todas as faixas e para todos os valores de acréscimo aos efeitos de primeira ordem.

Entre os elementos tipo viga e tipo pilar, analisando-se os valores médios calculados para todos os elementos da estrutura, mais uma vez chega-se às mesmas conclusões a que se chegou observando-os conjuntamente nos resultados globais, quando se trata dos pilares (Fig. 32). Isto é, observa-se que as maiores divergências entre os resultados surgem a partir de valores de $\gamma_{\mathrm{z}} \cong \mathbf{1 , 3 0}$. O pior caso para $\gamma_{\mathrm{z}}>\mathbf{1 , 3 0}$ corresponde a uma diferença média de $7 \%$ ( $\left.\mathrm{n}^{\varrho} 12\right)$ e para $\gamma_{\mathbf{z}}<\mathbf{1 , 3 0}$, de $3 \%$ ( $\left.\mathrm{n}^{\mathrm{Q}} 10\right)$. Para as vigas, a Fig. 33 mostra que o processo simplificado é razoável para todos os valores de $\gamma_{\mathbf{z}}$ analisados, mesmo quando eles são uitrapassados (o que não leva a diferenças maiores que $2 \%$ - exemplo $\mathrm{n} \varrho 10$ - em relação ao processo rigoroso). A comparação entre os resultados do cálculo pelo processo $\mathrm{P}-\Delta$ e pelo rigoroso mostra que eles têm o mesmo andamento para todos os valores percentuais dos acréscimos aos esforços de primeira ordem no caso das vigas e dos pilares. A análise destes resultados, entretanto, não permite que se afirme que, para este ou aquele tipo de 
elemento, sempre, ou na maioria das vezes ou para determinados intervalos de valores de acréscimo aos esforços de primeira ordem, o valor de $\gamma_{\mathrm{Z}}$ é ultrapassado ou não pelos majoradores obtidos segundo os outros dois processos. Pode-se dizer apenas que, pelo menos dentro das limitações do universo de dados que se dispõe, mesmo quando ultrapassado o valor de $\gamma_{\mathrm{Z}}$ pelos demais majoradores de esforços de primeira ordem, não existem grandes diferenças entre os resultados para $\gamma_{\mathbf{z}}<\mathbf{1 , 3 0}$, analisando-se isoladamente os pilares e as vigas.

A análise dos resultados obtidos separadamente para pilares e vigas contidos nas faixas definidas neste estudo comparativo (Figs. 34 a 39), levam às mesmas observações feitas quando estes mesmos resultados foram estudados em conjunto. Não é possível, novamente, afirmar-se que as diferenças entre os resultados calculados para um determinado tipo de elemento pelo processo simplificado e os demais processos se destaca em relação às diferenças obtidas para o outro. Na última faixa, entretanto o que se observa é que, no caso das vigas, para a maioria dos valores de majoradores de esforços de primeira ordem, o processo simplificado pode levar a resultados de esforços finais exagerados, principalmente quando os valores de $\gamma_{z}$ são muito elevados. Para os pilares os resultados daquele processo pode ser considerado satisfatório, embora muitas vezes ultrapasse demais os resultados dos outros processos. Vale lembrar que, geralmente nesta faixa da altura do edifício, os valores de esforços devidos às ações laterais são pequenos, o que leva a baixas taxas de armadura. Neste caso, o exagero não seria muito prejudicial. Uma última observação a se fazer nesta análise por faixas é que, para todas elas, os resultados das análises pelos processos rigoroso e $\mathbf{P}-\Delta$ são muito próximos para qualquer valor de $\gamma_{\mathbf{z}}$. 


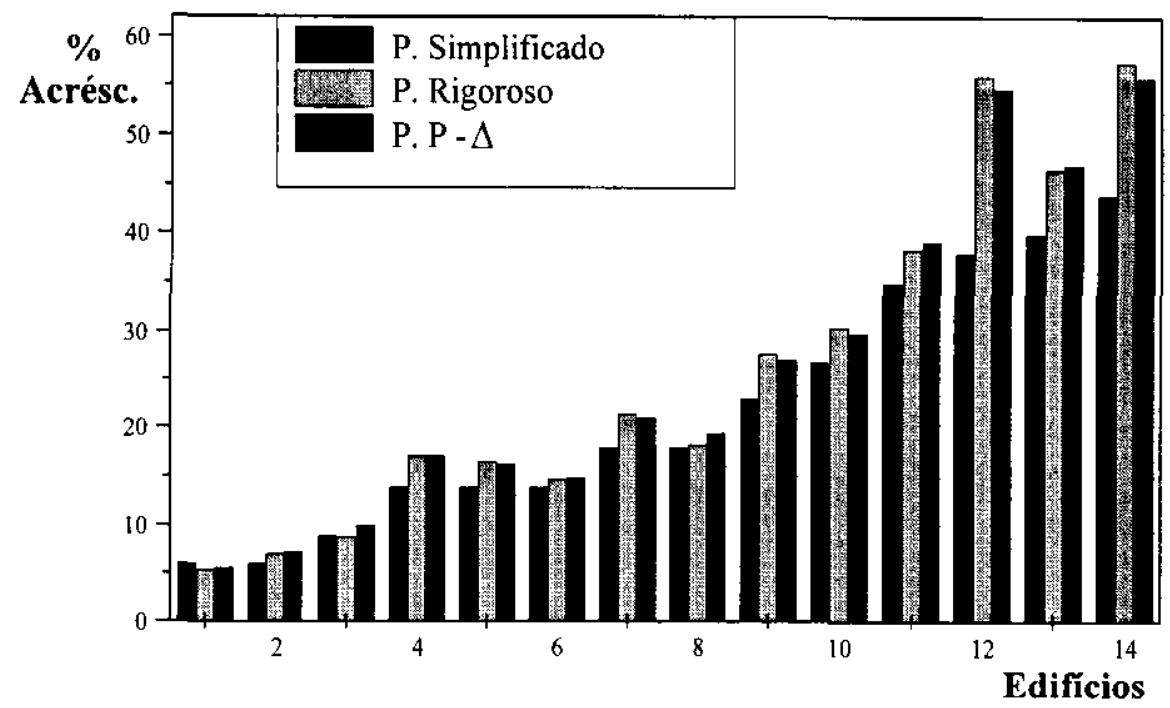

FIGURA 29 - Resultados Globais para a Primeira Faixa

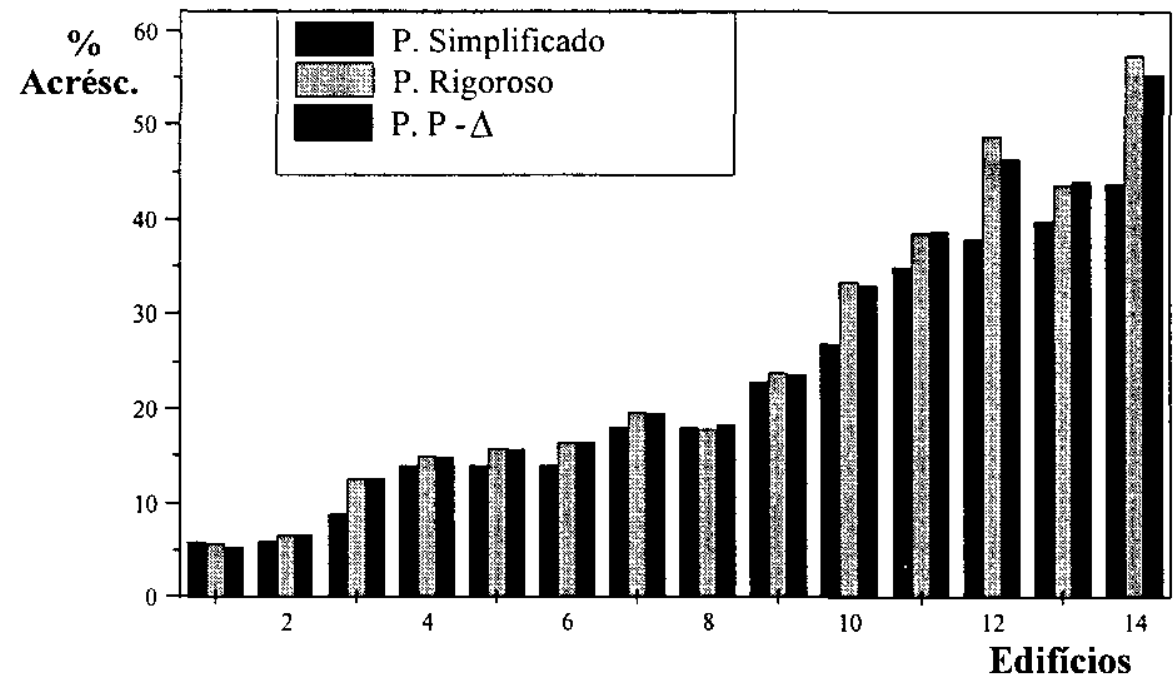

FIGURA 30 - Resultados Globais para a Segunda Faixa

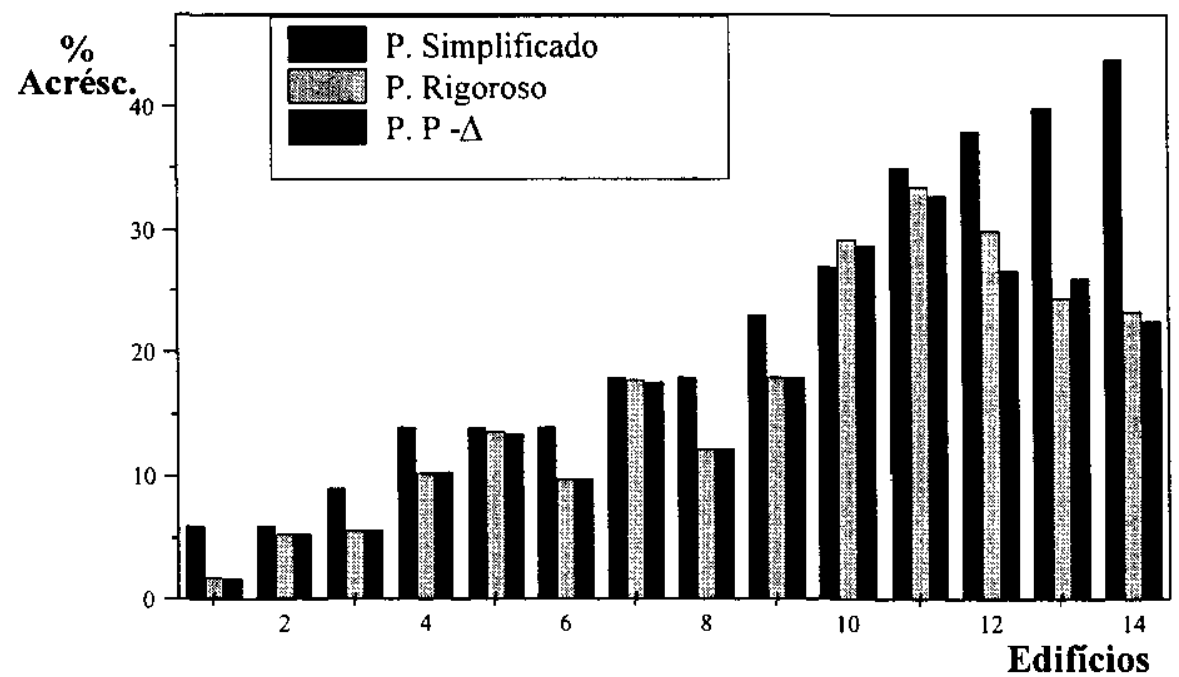

FIGURA 31 - Resultados Globais para a Terceira Faixa 


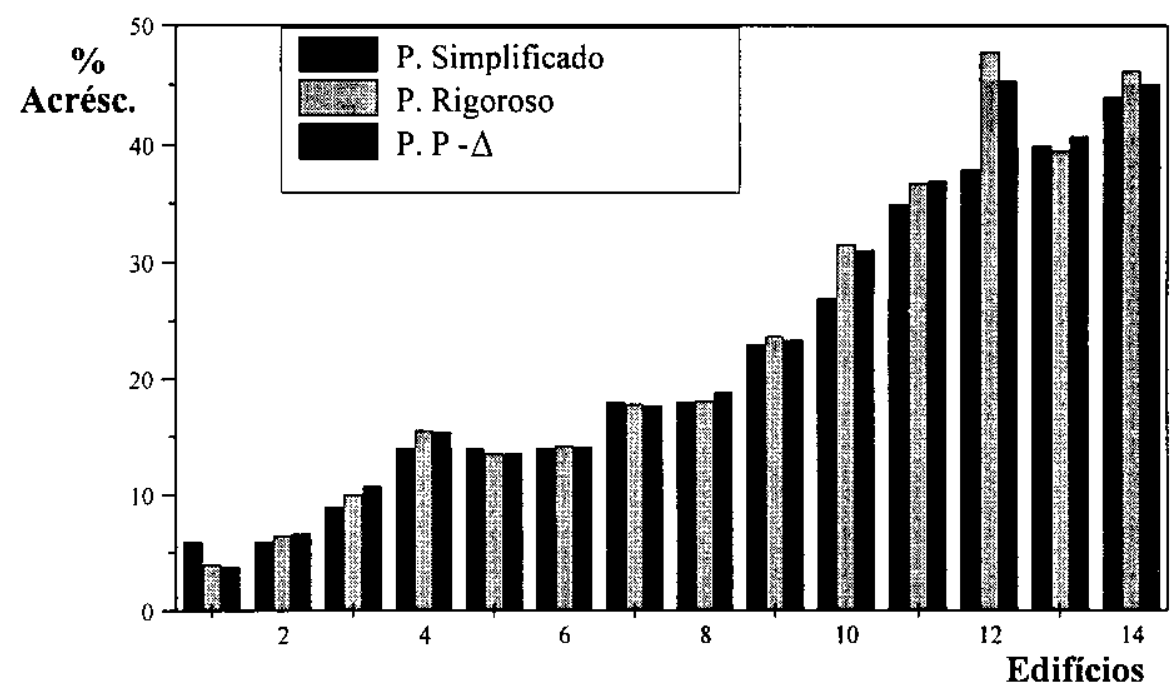

FIGURA 32 - Comparação dos Resultados Globais para os Pilares

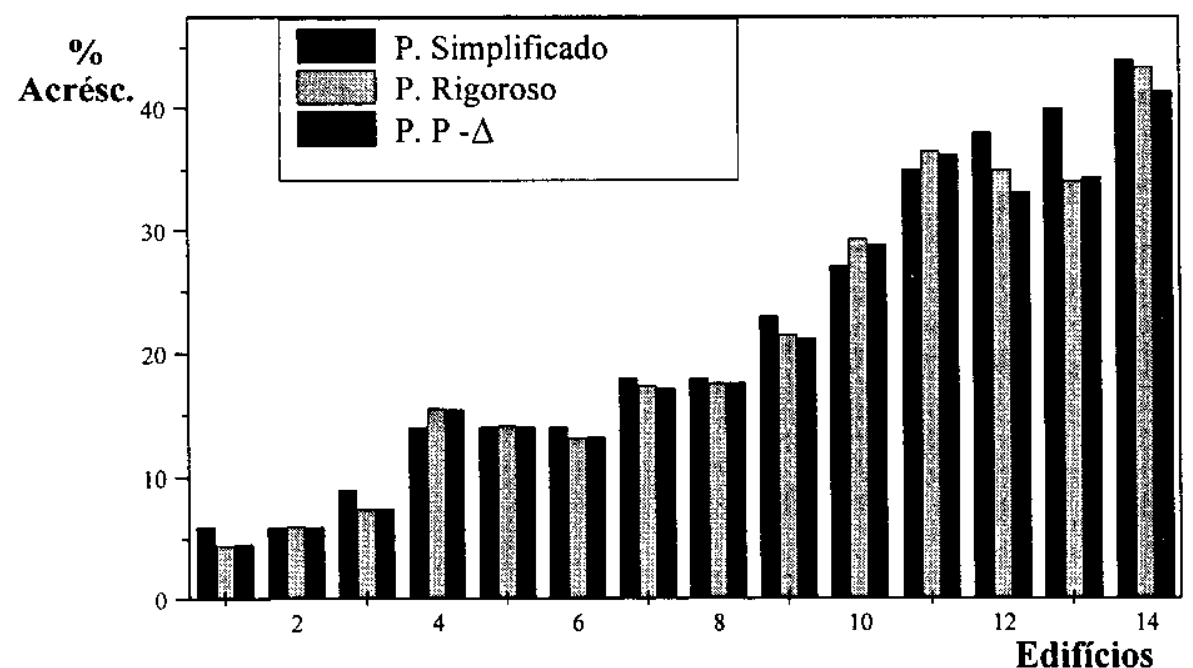

FIGURA 33 - Comparação dos Resultados Globais para as Vigas 


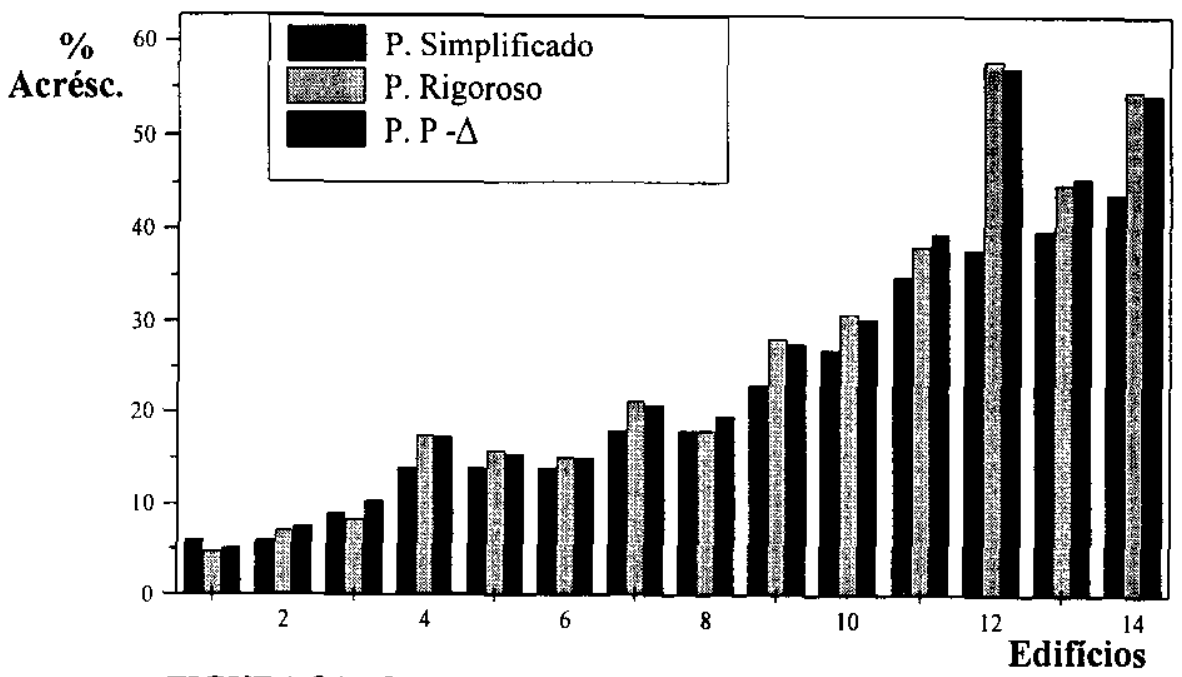

FIGURA 34 - Comparação dos Resultados para os Pilares da Primeira Faixa

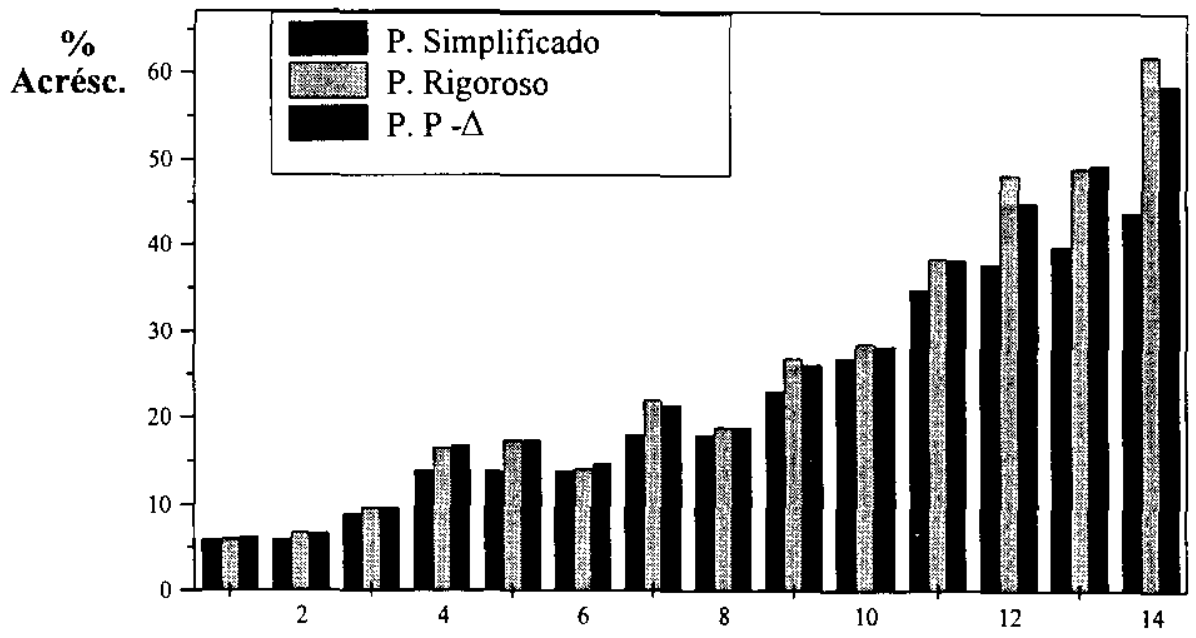

FIGURA 35 - Comparação dos Resultados para as Vigas da Primeira Faixa 


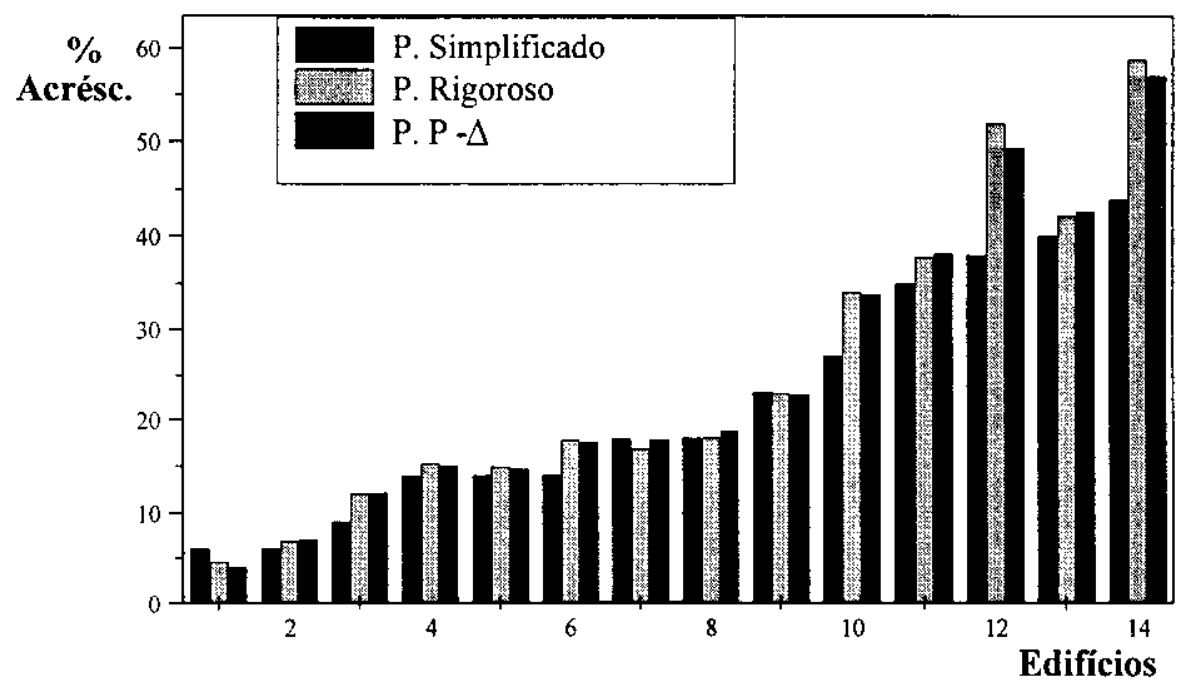

FIGURA 36 - Comparação dos Resultados para Pilares da Segunda Faixa

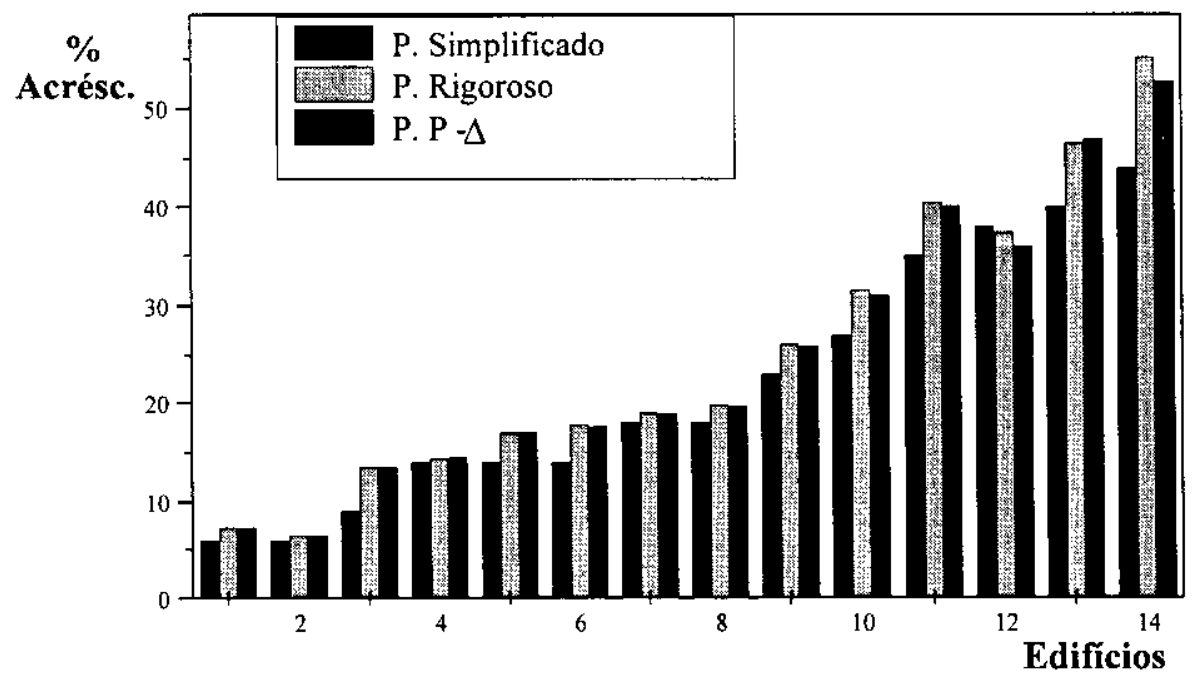

FIGURA 37 - Comparação dos Resultados para as Vigas da Segunda Faixa 


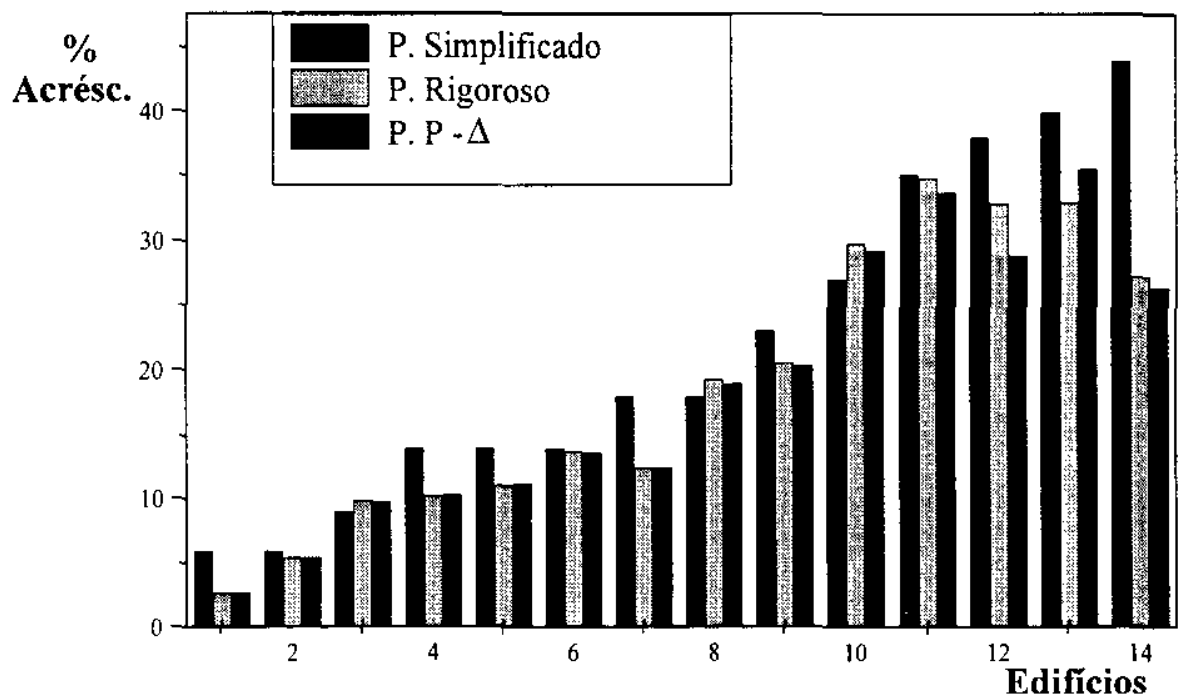

FIGURA 38 - Comparação dos Resultados para Pilares da Terceira Faixa

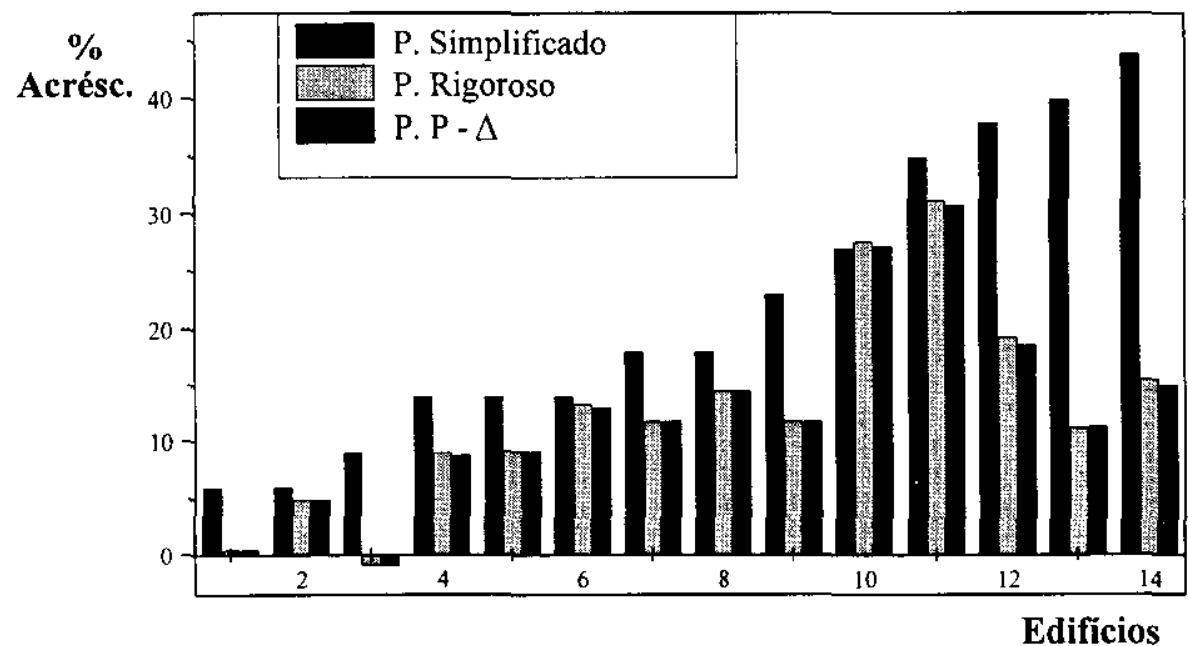

FIGURA 39 - Comparação dos Resultados para asVigas da Terceira Faixa

Em resumo, percebe-se que o processo simplificado pode ser considerado como plenamente satisfatório dentro de um certo limite. A análise dos exemplos aqui estudados, entretanto, sugere que se aumente o limite de $\gamma_{\mathbf{z}}$ em $\mathbf{1 , 2 0}$ proposto por FRANCO \& VASCONCELOS(1991), ou seja, que se permita a majoração dos esforços de primeira ordem pela simples multiplicação destes efeitos por $\gamma_{\mathbf{z}}$, toda vez que $\gamma_{\mathbf{z}}<\mathbf{1 , 3 0}$, a fim de se obter os efeitos finais que incluem os de segunda ordem com razoável aproximação. Observa-se que as maiores diferenças entre este processo 
e os demais ocorre para os exemplos com valor de $\gamma_{\mathbf{z}}$ muito elevado. Deve-se, também, estudar uma maneira de se poder variar o valor do majorador dos esforços de primeira ordem ao longo da altura da estrutura, diminuindo-o à medida que se aproxima do topo da mesma. Como existiram neste estudo poucos casos em que $\circ \gamma_{\mathbf{z}}$ foi bem próximo do valor dos majoradores calculados pelos outros processos na terceira faixa, talvez deva-se investigar alguma característica particular do edifício, como por exemplo parâmetro de forma $(\psi)$, que indique que isto possa ser feito com segurança. Depois disso, um estudo que também investigue as vantagens de se realizar esta redução deve ser feito, a fim de ser sugerida aos projetista como um procedimento seguro e compensador.

Caso o projetista prefira estimar os efeitos de segunda ordem com melhor precisão e não disponha de um programa com recursos para considerar a NLG, este estudo mostrou também que os resultados obtidos pelo processo P- $\Delta$ são bastante semelhantes aos obtidos pelo processo rigoroso. Dispondo de um programa de análises lineares de estruturas, o projetista pode perfeitamente obter excelentes resultados com as sucessivas análises lineares que o processo $P-\Delta$ requer, conforme foi visto no item 3.6.2. 


\section{CAPÍTULO 5 - CONCLUSÕES}

\section{1 - INTRODUÇÃO}

Apresentam-se neste capitulo de uma forma geral, as principais observações feitas durante a elaboração do trabalho e o manuseio de exemplos, no que se refere aos efeitos de segunda ordem em edifícios altos de concreto armado e às considerações relativas a uma análise de segunda ordem. A utilização de exemplos de estruturas de edificios possibilitou os testes de algumas dessas considerações e o estabelecimento de algumas conclusões com base nos resultados destes testes.

Conforme estudo feito no capítulo 2 (item 2.2.4), pode-se dizer que a instabilidade divergente estática das estruturas reticuladas planas se manifesta pelo surgimento de ponto de bifurcação do equilíbrio ou de ponto limite. Nas estruturas, é praticamente impossível de se evitar o surgimento de excentricidades do ponto de aplicação das ações verticais, causadas por imperfeições geométricas construtivas ou por deslocamentos laterais devidos a ações horizontais de diversas naturezas. Simular o comportamento real da estrutura mais apuradamente é considerar a existência destas excentricidades na montagem do modelo da mesma, cuja sensibilidade às imperfeições é um efeito da plasticidade. Ou seja, a consideração da não-linearidade física (NLF) e da não-linearidade geométrica (NLG) deve ser levada em conta no projeto da estrutura.

Acredita-se que o próprio desenvolvimento deste trabalho contribui para alertar aos projetistas quanto ao perigo de se abandonar a consideração das ações laterais, com base nos critérios da NB-1/1978(ABNT). Por exempio, no caso da estrutura do edificio STRADUS, de acordo com esse critério, não seria @brigatória a consideração da ação do vento (sem falar nos outros tipos de ações laterais). O edifício STRADUS possui dimensões do retângulo que circunscreve a sua forma em planta baixa iguais a $15,60 \mathrm{~m}$ por $31,10 \mathrm{~m}$, altura total de $33,34 \mathrm{~m}, 12$ pavimentos e em cada fileira de 
pilares possui mais que 3 pilares. O deslocamento de primeira ordem de cálculo no topo do edifício é de $0,083 \mathrm{~m}$. Pior que não levar em conta os efeitos de primeira ordem devidos às ações laterais é, em conseqüência, deixar de avaliar os efeitos de segunda ordem que, de acordo com o processo simplificado de análise de segunda ordem, são em torno de $38 \%$ maiores que os de primeira na direção $\mathbf{X}$ considerada para este exemplo. Ora, se os efeitos de $1^{\mathrm{a}}$ ordem provenientes das ações laterais agindo sobre esta estrutura forem significativos (o que o projetista deste edificio jamais saberia se seguisse o critério da NB-1/1978), pode-se imaginar o que poderia vir a acontecer com o seu equilíbrio.

\section{2 - CONSIDERAÇÕES FEITAS NA REALIZAÇÃO DE UMA ANÁLISE DE SEGUNDA ORDEM}

À medida que os trabalhos foram sendo desenvolvidos, deparou-se com algumas considerações a serem tomadas quando da realização de uma análise nãolinear de estruturas. Muitas atitudes admitidas com relação a algumas delas para as análises das estruturas utilizadas como exemplo neste trabalho, visavam principalmente a simplificação dos procedimentos. As atitudes mais gerais foram:

- As análises foram feitas para ações horizontais incidentes apenas nos sentidos positivos dos eixos $\mathbf{X}$ e $\mathbf{Y}$ definidos para cada estrutura;

- A NLF foi considerada de forma aproximada através da redução da rigidez de

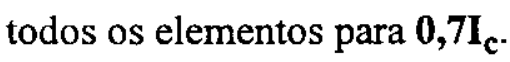

- Nas análises de $2^{\mathrm{a}}$ ordem pelo processo simplificado, não foram consideradas alterações nos coeficientes $\gamma_{z}$ devido à presença das ações verticais, por não haverem alterações significativas nos resultados no caso de estruturas regulares bem elaboradas.

O principal argumento para justificar tais atitudes mora no fato de que não existem grandes alterações nos resultados usados para as comparações necessárias e de que algumas delas serão muito provavelmente as que serão adotadas pelos escritórios de projetos estruturais.

Uma das principais destas considerações que devem ser feitas numa análise com não-linearidade é a da NLF que, como foi visto, tem sido objeto de estudos de vários pesquisadores na intenção de simplificá-la. Entretanto, como há uma grande 
variedade de valores sugeridos de redução da rigidez dos elementos estruturais para que esta consideração seja feita de forma aproximada, optou-se pelo procedimento mais simples entre todos que é a adoção de um valor único para vigas e pilares de $0,7 \mathbf{E I}_{\mathfrak{c}}$, pois este será provavelmente o procedimento mais largamente utilizado pelos projetistas, uma vez que se prevê esta possibilidade na futura NB-1 (NB1/1994(ABNT)). Utilizaram-se exemplos práticos de estruturas planas (item 3.3-b) para a verificação de variações dos seus deslocamentos horizontais máximos e um pórtico tridimensional (item 3.6.4) para avaliar a variação dos efeitos de segunda ordem para três valores de redução da rigidez $\mathbf{E I}_{\mathbf{c}}\left(\mathbf{E I}_{\mathbf{p}}\right.$ e $\mathbf{E I}_{\mathbf{v}}=0,7 \mathbf{E I} \mathbf{I}_{\mathbf{c}} ; \mathbf{E I}_{\mathbf{v}}=0, \mathbf{4} \mathbf{E I}_{\mathbf{c}} \mathbf{e}$ $\mathbf{E I}_{\mathrm{p}}=0,8 \mathbf{E I}_{\mathfrak{c}} ; \mathbf{E I}_{\mathrm{v}}=0,5 \mathbf{E I}_{\mathfrak{c}}$ e $\left.\mathbf{E I}_{\mathrm{p}}=0,8 \mathbf{E I}_{\mathfrak{c}}\right)$ sugeridos por alguns autores e pela NB1/1994(ABNT). Verificou-se que há uma variação nos resultados obtidos que não deve ser ignorada. Embora tenha-se adotado um valor único de redução da rigidez para vigas e pilares neste trabalho, mostrou-se que esta atitude não prejudicaria $o$ estudo comparativo dos resultados calculados. Como se havia dito, porém, fica-se na expectativa de que sejam realizados estudos mais especificos sobre $o$ assunto.

\section{3 - CORRELAÇÃO ENTRE OS PARÂMETROS $\alpha, \gamma_{Z}$ E A RELAÇÃO FLECHA/ALTURA}

No capitulo 3 foi apresentada a relação flecha/altura (a/H) usada na verificação do estado limite de deformações excessivas (item 3.4). Por muito tempo utilizou-se $\mathbf{a} / \mathbf{H}$ indireta e erroneamente na avaliação da estabilidade global das estruturas, uma vez que, entre os regulamentos e as pesquisas realizadas, não se sugere valor numérico limite deste fator para este fim. Mostrou-se que o valor normalmente usado pelos projetistas de $\mathbf{a} / \mathbf{H}=1 / 500$ refere-se na realidade ao valor máximo permissível para que não seja afetado o funcionamento de elementos não estruturais (esquadrias, paredes, etc.). Apresentou-se também o parâmetro de instabilidade global $\alpha$, fruto dos estudos realizados por BECK \& KöNIG(1966) sobre a estabilidade de uma estrutura simples de um pórtico rotulado contraventado por parede atuante como viga vertical em balanço. Desprezou-se, portanto, a influência da rigidez das vigas no contraventamento, como se observa também na expressão original que fornece o valor numérico de $\alpha$ (Eq. 21). Com base em estudos que mostram que esta influência existe (VASCONCELOS(1985)) é que se introduziu o conceito de rigidez equivalente $\left(\mathbf{E I}_{\mathbf{e q}}\right)$ que evita a adoção errônea da rigidez utilizada no cálculo de $\alpha$. Mostraram-se os valores limites para $\alpha$ de acordo com o CEB(1978) e a NB1/1994(ABNT) e com alguns autores, como FRANCO(1985) que os sugere 
diferenciados para cada tipo de contraventamento predominante da estrutura (Eq. 29). Esta última sugestão parece ser mais razoável, pois contempla o tipo de contraventamento adotado, tratado-os diferenciadamente. Por último mostra-se o parâmetro $\gamma_{\mathbf{z}}$, também de verificação da estabilidade global das estruturas, de prática obtenção e cuja consideração para este fim está prevista na NB-1/1994(ABNT). Utilizou-se no capitulo 3 a estrutura de um dos edifícios como exemplo para demonstrar como calcular cada um dos parâmetros acima comentados e para justificar as simplificações e os procedimentos adotados nas análises dos demais exemplos.

Através da utilização de trinta (30) estruturas correntes como exemplo no capítulo 4 , pode-se obter sessenta (60) resultados para comparação entre $\mathbf{a} / \mathbf{H}, \alpha$ e $\gamma_{\mathbf{z}}$. Desta comparação conclui-se que deve ser abandonado o cálculo do valor da relação a/H para avaliar a grandeza dos efeitos de segunda ordem, utilizando-o apenas na verificação do estado limite de deformações excessivas. Para a análise global da estabilidade das estruturas, mostrou-se que os parâmetros $\alpha$ e $\gamma_{\mathrm{z}}$ se correlacionam, sendo este último vantajoso, conforme a sua própria formulação, por permitir estimar os esforços finais que incluem os de segunda ordem com boa aproximação. Embora tenha sido sugerido um majorador de ações (k), função do parâmetro $\alpha$, para este mesmo fim, verificou-se que este procedimento pode não ser muito simples e adequado. A comparação entre os parâmetros $\alpha$ e $\gamma_{\mathbf{z}}$ gerou uma equação empírica (Eq. 43) que os relaciona, permitindo aos projetistas, que determinam o parâmetro $\alpha$ em suas rotinas de cálculo ou programas, obter o correspondente valor aproximado do coeficiente $\gamma_{\mathrm{z}}$. Enfim, uma vez calculado o coeficiente $\gamma_{\mathrm{z}}$ pela Eq. 43, aqui transcrita:

$$
\gamma_{z}=0,90+0,52 \alpha-0,62 \alpha^{2}+0,46 \alpha^{3}
$$

pode-se proceder com os cálculos dos efeitos finais que incluem os de $2 \underline{\mathrm{a}}$ ordem multiplicando-se os efeitos de $1 \underline{a}$ ordem por $\gamma_{\mathbf{z}}$. É importante lembrar que o coeficiente $\mathbf{k}$ é um majorador de ações e não de esforços, que significa que, para se obter os esforços de 2a ordem é preciso que seja realizada uma nova análise estrutural de $1 \underline{a}$ ordem para estas ações majoradas, o que já denuncia uma boa vantagem do $\gamma_{\mathrm{z}}$ sobre o $\alpha$. 


\section{4 -AVALIAÇÃO DO PROCESSO SIMPLIFICADO DE ANÁLISE DE SEGUNDA ORDEM}

Conforme o estudo desenvoivido no capitulo 4 , pode-se perceber que 0 processo simplificado de análise de segunda ordem, que utiliza o coeficiente $\gamma_{\mathbf{Z}}$ como majorador dos esforços de primeira ordem, é satisfatório dentro de certos limites, como havia sido reportado por FRANCO \& VASCONCELOS(1991). Porém, percebe-se uma tendência, dentro do universo de estruturas analisadas, a se permitir avançar além do valor limite de 1,2 para o majorador global de esforços $\gamma_{z}$, donde sugere-se que se aumente este limite para 1,3 com base nos resultados calculados, ampliando-se o universo de observações em pesquisa posterior. Além disso, foi visto que o valor médio do majorador dos esforços, conforme cálculo feito por processos tradicionais como o processo $\mathrm{P}-\Delta$ e o processo rigoroso, pode sofrer variações para faixas da altura da estrutura, diminuindo, na grande maioria das vezes, à medida que se aproxima do topo. Nos casos em que isto não ocorre, desconfia-se que exista alguma influência de características particulares dos edifícios, como por exemplo o parâmetro de forma $(\psi)$, donde sugere-se que estudos mais específicos revelem se há esta influência e quais as vantagens de se realizar esta redução.

Portanto, há que se dar melhor tratamento estatístico a este e a outros resultados de efeitos de segunda ordem relativos a um universo maior de exemplos. Sugere-se, inclusive, que sejam simuladas estruturas, dentro dos padrões das estruturas correntes, é claro, de modo a obter valores de $\gamma_{\mathrm{z}}$ em intervalos mais uniformes, para que possam ser estabelecidos valores numéricos limites mais específicos para este coeficiente. Assim, estaria confirmada a utilização do processo simplificado estudado neste trabalho como um processo seguro de análise de segunda ordem para valores de $\gamma_{\mathrm{z}}$ até um certo limite maior que 1,2 , como mostra a tendência dos resultados. Um número significativo de exemplos práticos ajudarão a dar maior credibilidade ao processo para os projetistas de estruturas. 


\section{REFERÊNCIAS BIBLIOGRÁFICAS}

AMERICAN CONCRETE INSTITUTE. Committee 318(1986). Building code requirements for reinforced concrete. Detroit. (ACI 318-83, revised 1986).

AMERICAN CONCRETE INSTITUTE. Committee 435(1984). Allowable deflections. Detroit. (ACI 435.3R-68, revised 1984).

AMERICAN CONCRETE INSTITUTE. Committee 442(1982). Response of buildings to lateral forces. Detroit. (ACI 442R-71, revised 1982).

ASSOCIAÇÃO BRASILEIRA DE NORMAS TÉCNICAS (1978). NB-1: Projeto e execução de obras de concreto armado. Rio de Janeiro, ABNT.

ASSOCIAÇÃO BRASILEIRA DE NORMAS TÉCNICAS (1978). NB-5: Cargas para o cálculo de estruturas de edificações. ABNT.

ASSOCIAÇÃO BRASILEIRA DE NORMAS TÉCNICAS (1984). NBR-8681: Ações e segurança nas estruturas. Rio de janeiro, ABNT.

ASSOCIAÇÃO BRASILEIRA DE NORMAS TÉCNICAS (1985). NBR-9062: Projeto e execução de estruturas de concreto pré-moldado. Rio de Janeiro, ABNT.

ASSOCIAÇÃO BRASILEIRA DE NORMAS TÉCNICAS (1988). NBR-6123: Forças devidas ao vento em edificações. ABNT.

ASSOCIAÇÃO BRASILEIRA DE NORMAS TÉCNICAS (1994). NB-1: Texto base para revisão.

BECK, H; KÖNIG, G. (1966). Restrining forces (Festhaltekräfte) in the analysis of tall buildings. In: SYMPOSIUM ON TALL BUILDINGS, Oxford. Proceedings. p.513-536.

COMITÉ EURO-INTERNACIONAL DO BÉTON. (1978). CEB-FIP: Manual of buckling and instability. Lancaster, England. The Construction Press. (Bulletin D'Information, n.123)

CORREAA, M.R.S. (1991). Aperfeiçoamento de modelos usualmente empregados no projeto de sistemas estruturais de edificios. São Carlos. 331p. Tese(Doutorado)Escola de Engenharia de São Carlos, Universidade de São Paulo. 
FRANÇA, R.L.S. (1985). Exemplo de cálculo do esforço de 2a. ordem em um edifício de concreto armado. In: REUNIÃO ANUAL DO IBRACON: Colóquio sobre Estabilidade Global das Estruturas de Concreto Armado, São Paulo, 22-26 jul. Anais.

FRANCO, M. (1985a). O parâmetro de instabilidade dos edifícios altos. Revista Portuguesa de Engenharia de Estruturas, Lisboa, n. 23, p.69-72.

FRANCO, M. (1985b). Problemas de estabilidade nos edifícios de concreto. In: REUNIÃO ANUAL DO IBRACON: Colóquio sobre Estabilidade Global das Estruturas de Concreto Armado, São Paulo, 22-26 jul. Anais. 26p.

FRANCO, M. (1995). Global and local instability of concrete tall buildings. In: SYMPOSIUM ON SPACE STRUCTURES, Milan, May. Proceedings.

FRANCO, M.; VASCONCELOS, A.C. (1991). Practical assessment of second order effects in tall buildings. In: COLLOQUIUM ON THE CEB-FIP MC90, Rio de Janeiro. Proceedings. p.307-324.

FUSCO, P.B. (1981). Estruturas de concreto armado: solicitações normais. Rio de Janeiro, Guanabara Dois.

GALAMBOS, T.V. et al. (1973). Structural deflections: a literature and state-ofthe-art survey. Washington, D.C., Nacional Bureau of Standards, U.S. Departament of Commerce. (Buildings Science Series 47)

KALYANARAMAN,V. (1984) P-Delta analysis of tall buildings. In: SEM. TALL STRUCT. USE PRESTR. CONC. HYDR.STRUCT., Srinagar, . Preliminary Pub.

MACGREGOR, J.G. (1993a). Design of slender concrete columns: Revisited. $A C I$ Structural Journal, v.90, n.3, p.302-309, May-Jun.

MACGREGOR, J.G. (1993b). Reinforced concrete: mechanics and design. 2.ed. Englewood Cliffs, N.J., Prentice Hall.

MACGREGOR, J.G.; HAGE, A.M. (1977). Stability analysis and design of concrete frames. Journal of the Structural Division(ASCE), v.103, n. ST10, p.1953-1970, Oct..

PPLAN4: manual (1991). São Carlos, EESC.

RAMALHO, M.A. (1990). Sistemas para análise de estruturas considerando interação com o meio elástico. São Carlos. 389p. Tese(Doutorado)- Escola de Engenharia de São Carlos, Universidade de São Paulo. 
SANTOS, L.M.; FRANCO, M. (1993). Instabilidade e efeitos de segunda ordem nas estruturas de concreto. In: SIMPÓSIO EPUSP SOBRE ESTRUTURAS DE CONCRETO ARMADO, 3., São Paulo, 1-3 dec.

SCANLON, A.; PINHEIRO, L. (1990). Allowable deflection: the other side of the equation. In: AMERICAN CONCRETE INSTITUTE FALL CONVENTION, Filadélfia, EUA, Nov.

TIMOSHENKO, S.P.; GERE, J.E (1961). Theory of elastic stability. New York, McGraw-Hill.

VASCONCELOS, A.C. (1985). Critérios para dispensa de consideração do efeito de 2a ordem. In: REUNIÃO ANUAL DO IBRACON: Colóquio sobre Estabilidade Global das Estruturas de Concreto Armado, São Paulo, 22-26 jul. Anais.

VASCONCELOS, A.C. (1986) Como enrijecer edifícios muito flexíveis. In: LA INGENIERÍA ESTRUCTURAL SUDAMERICANA EN LA DÉCADA DEL 80: Homenaje al Ingeniero Julio Ricaldoni, Montevidéo, Uruguai, 17-19 dic. p-237269.

VASCONCELOS, A.C. (1987). Como especificar a segurança quando há efesito de $2^{a}$ ordem a considerar. In: REUNIÃO ANUAL DO IBRACON: Seminário Sobre os Aspectos Conflitantes em Normas Brasileiras, São Paulo, 20-24 de jul. Anais.

ZAGOTTIS, D. (1980) Introdução à teoria das estruturas: estabilidade $e$ instabilidade do equilibrio das estruturas, Cap.10. São Paulo, EPUSP.

\section{OBRAS CONSULTADAS}

ANTUNES, H.M.C.C. (1978). Carregamento critico de instabilidade geral para estruturas tridimensionais de edificios altos. São Carlos. 160p. Tese(Doutorado)Escola de Engenharia de São Carlos, Universidade de São Paulo.

INTERNATIONAL ORGANIZATION FOR STANDARTIZATION (1977). ISO4356: Bases for the design of structures: deformations of buildings at the serviceability limit state. Geneva, Switzerland.

MOREIRA, D.F. (1977). Análise matricial de estruturas. São Paulo, EDUSP. Cap.13: Instabilidade elástica de estruturas discretizadas. p.307-375. 


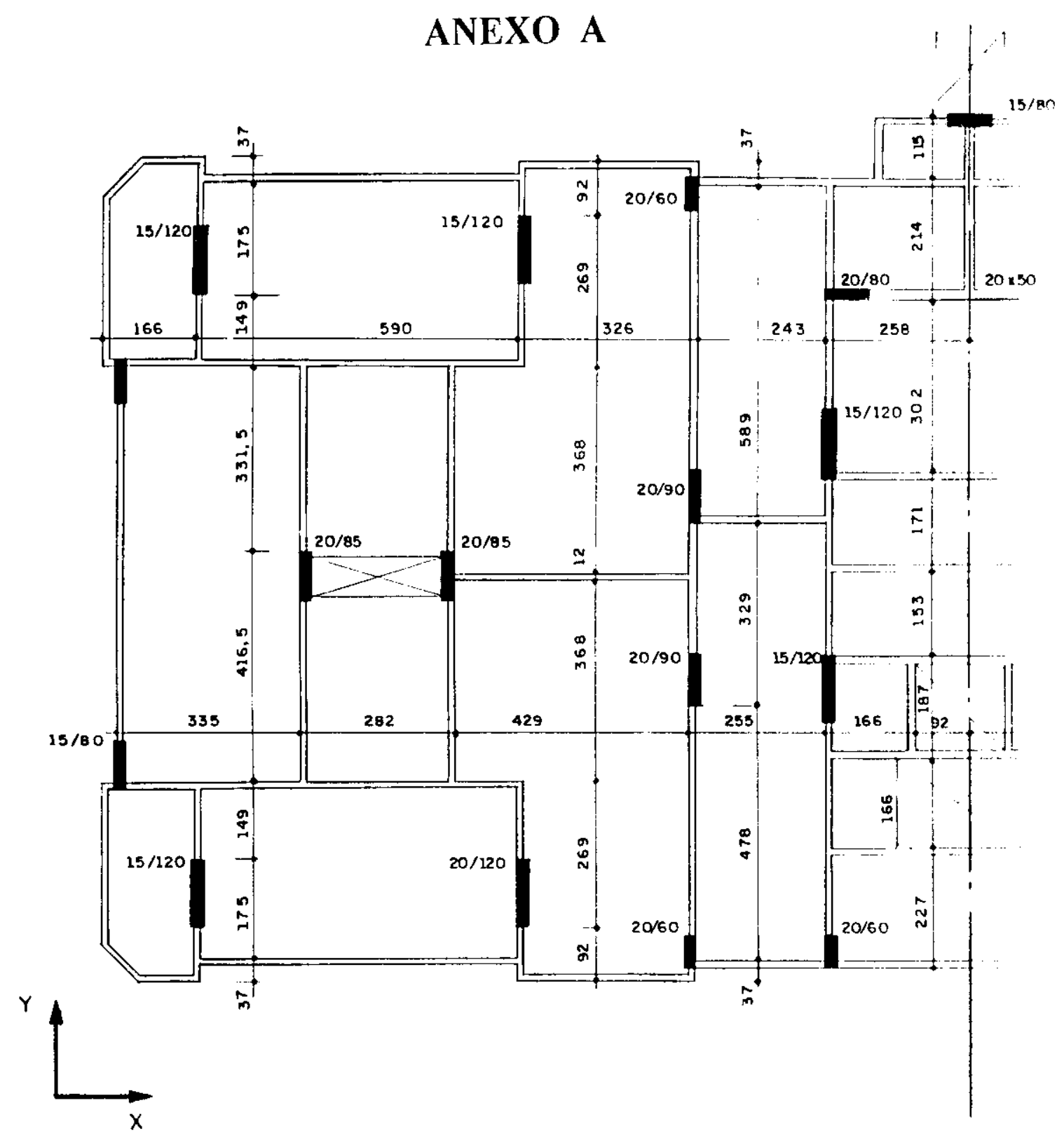

Dimensões de vigas não indicadas: $\mathbf{1 2 \times 5 0}$

Altura total da estrutura: $33,34 \mathrm{~m}$

Total de pav. subsolo : 1

Pé direito subsolo $\quad: 3,42 \mathrm{~m}$

11 pav. tipo c/ pé direito: 2,72 


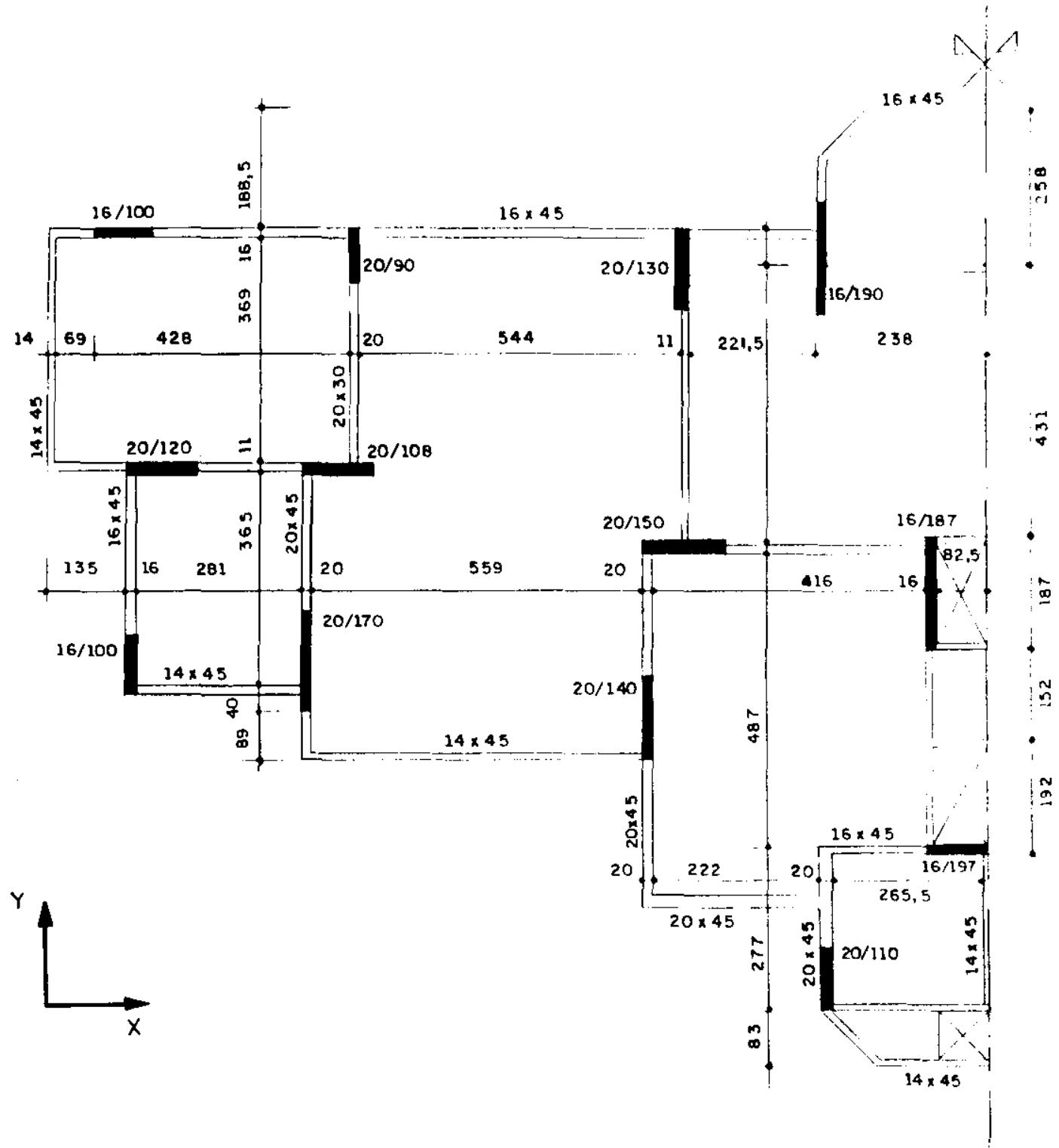

Dimensões de vigas não indicadas: $11 \times 45$

Altura total da estrutura: $67,54 \mathrm{~m}$

Total de pav. subsolo : 3

Pé direito $1_{-}^{\circ}$ subsolo $(-3,43 \mathrm{~m}) \quad: 3,43 \mathrm{~m}$

Pé direito $2_{-}^{\circ}$ subsolo $(-6.32 \mathrm{~m}) \quad: 2.89 \mathrm{~m}$

Pé direito 3 - subsolo $(-9.21 \mathrm{~m}) \quad: 2,89 \mathrm{~m}$

Pé direito pav. térreo $(0,00 \mathrm{~m}): 3,42 \mathrm{~m}$

19 pav. tipo $\mathrm{c} /$ pé direito: $2,72 \mathrm{~m}$

Pé direito cobertura : $3,23 \mathrm{~m}$ 


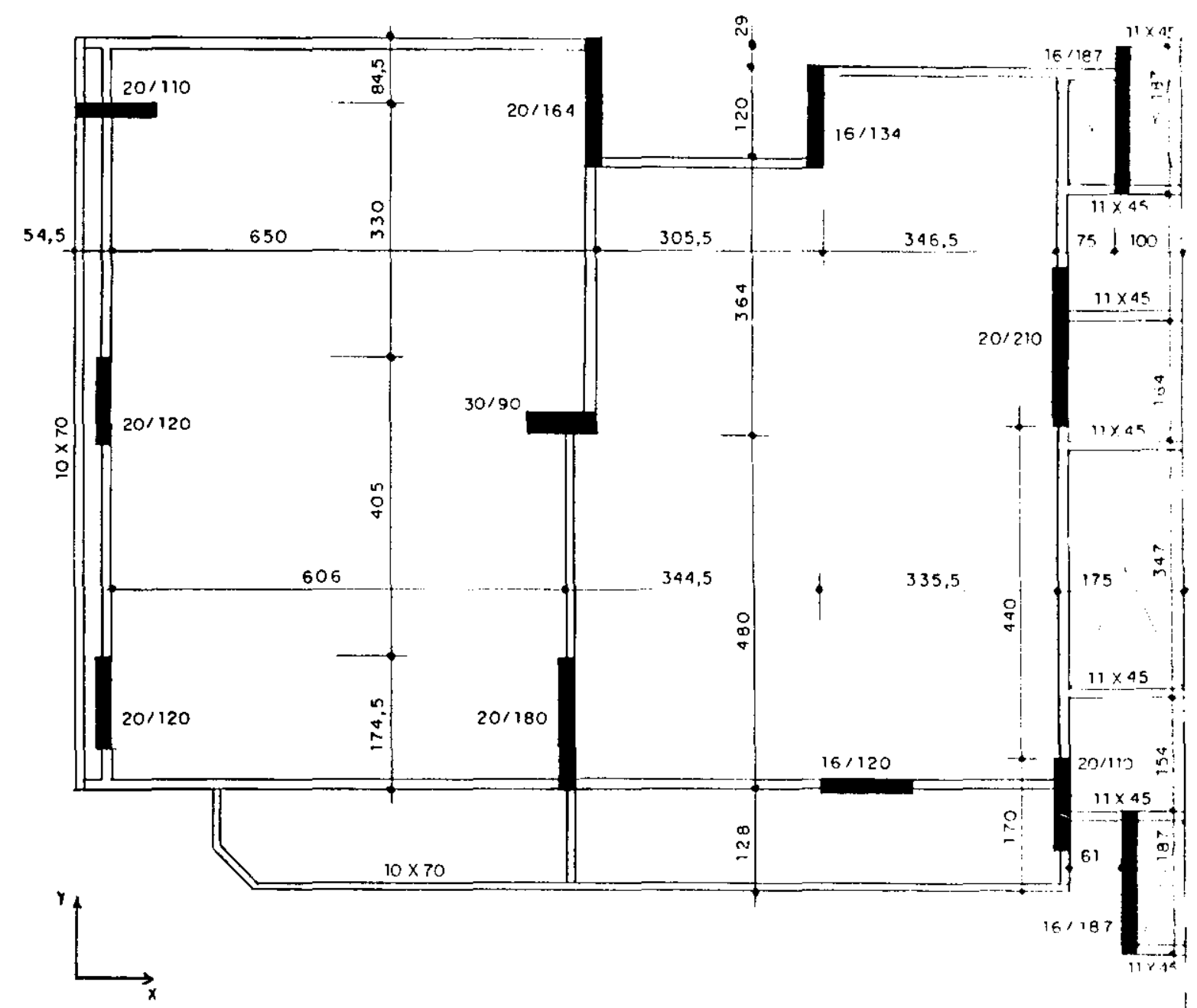

Dimensões de vigas não indicadas: $14 \times 45$

Altura total da estrutura: $73,60 \mathrm{~m}$

Total de pav. subsolo : 3

Pé direito $1_{-}^{\circ}$ subsolo $(-3,05 \mathrm{~m}) \quad: 3,05 \mathrm{~m}$

Pé direito $2_{-}^{\circ}$ subsolo $(-5,95 \mathrm{~m}) \quad: 2.90 \mathrm{~m}$

Pé direito $3_{-}^{\circ}$ subsolo $(-8,85 \mathrm{~m}$ ) : $2,90 \mathrm{~m}$

Pé direito pav. térreo $(0,00 \mathrm{~m}): 3,00 \mathrm{~m}$

20 pav, tipo c/ pé direito: $2,75 \mathrm{~m}$

Pé direito cobertura : $6,75 \mathrm{~m}$ 


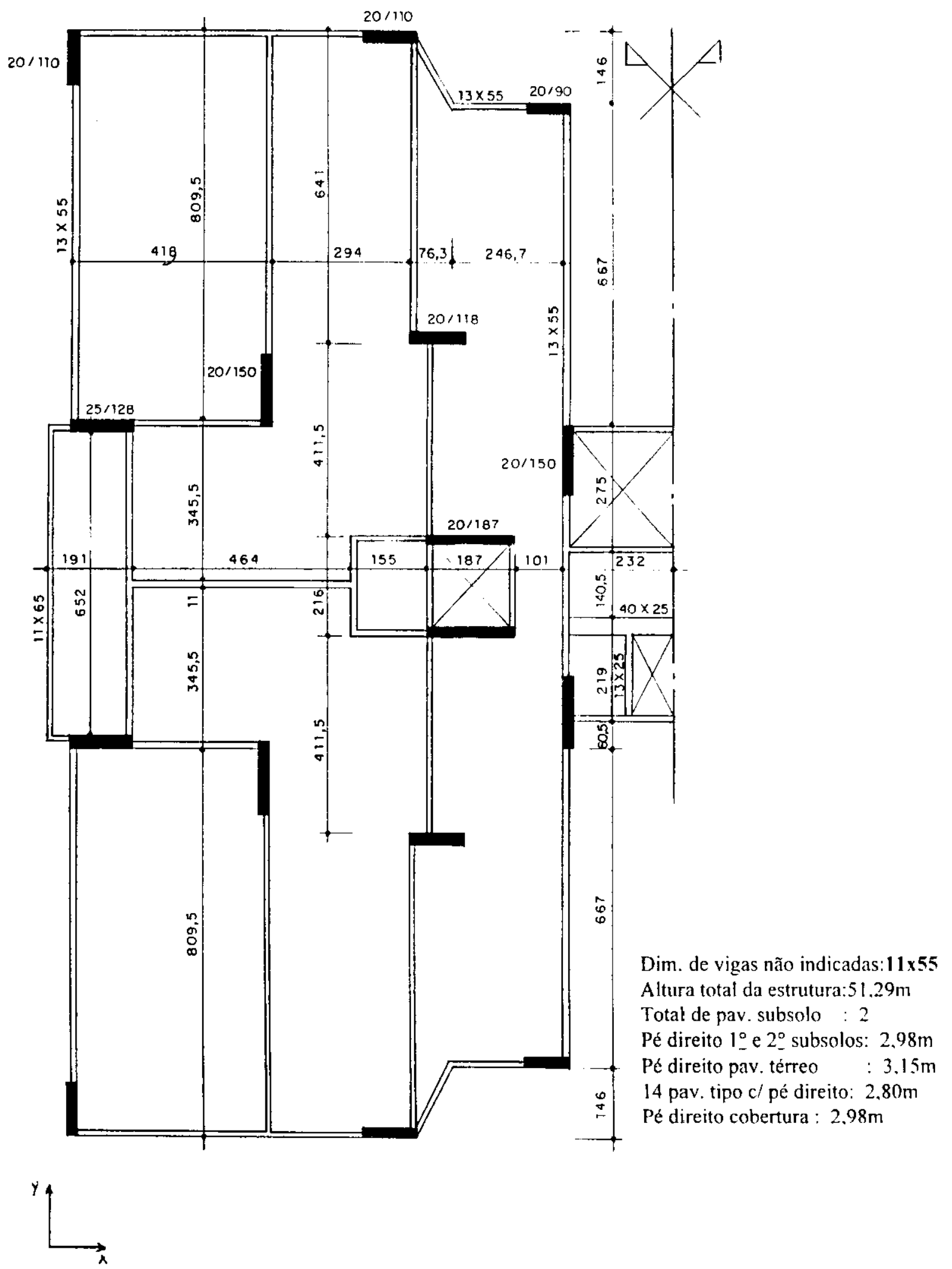

FIGURA A-4 - Estrutura Nㅡ 20 

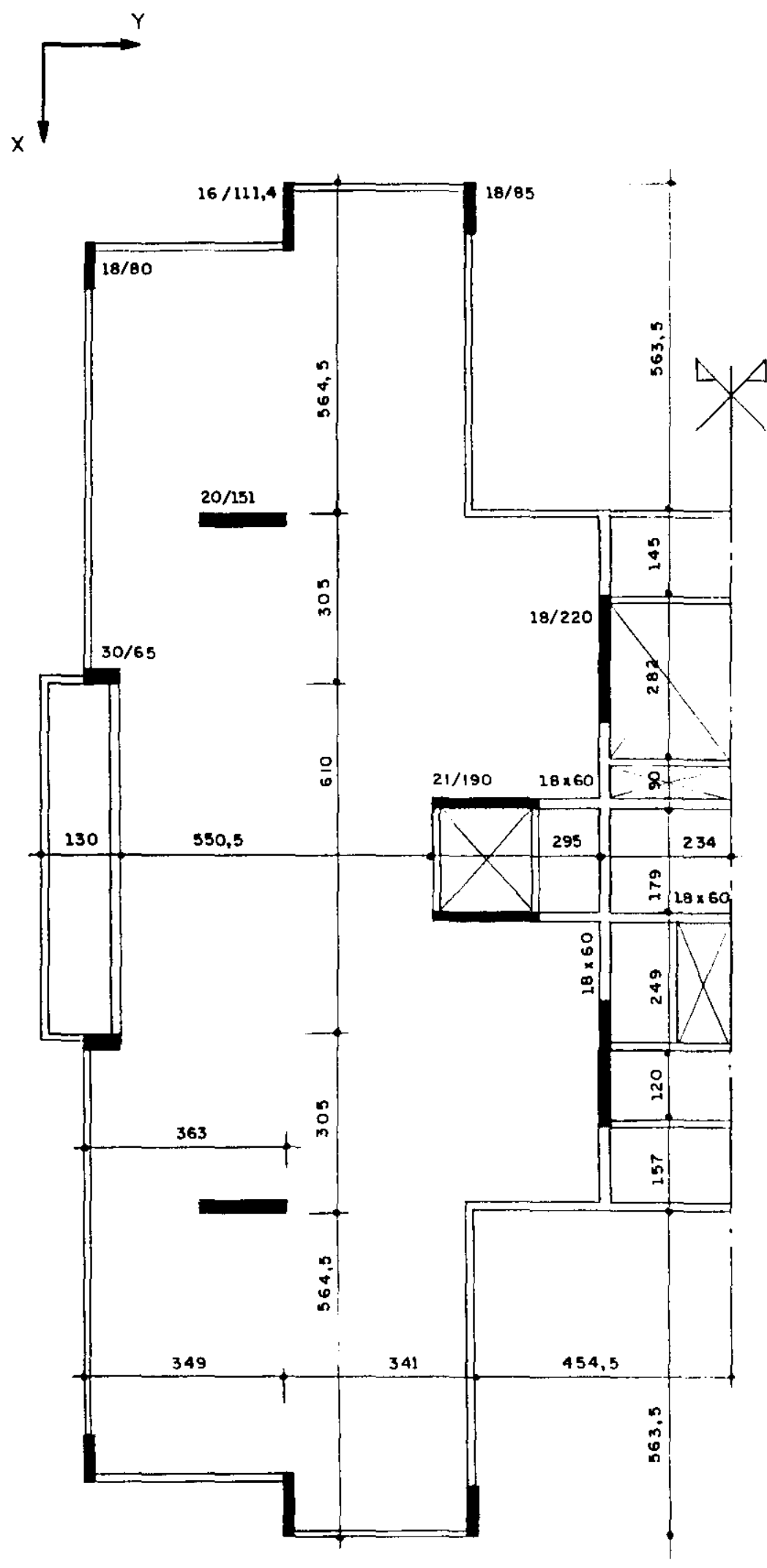

Dim. de vigas não indicadas: $12 \times 60$ Altura total da estrutura: $54.67 \mathrm{~m}$ Total de pav. subsolo : 2

Pé direito $1_{-}^{\circ}$ sub. $(\$-3.39 \mathrm{~m}): 3.39 \mathrm{~m}$ Pé direito $2_{-}^{\circ}$ sub. $(\$-7,23 \mathrm{~m}): 3.84 \mathrm{~m}$ Pé direito térreo. $(\$ 0.00 \mathrm{~m}): 3.60 \mathrm{~m}$ 14 pav. tipo $\mathrm{c} /$ pé direito: $2.80 \mathrm{~m}$ Pé direito cobertura : $4.55 \mathrm{~m}$ 